\title{
Degradation Mechanisms and Mitigation Strategies of Nickel-Rich NMC-Based Lithium-Ion Batteries
}

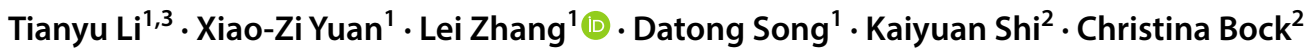

Received: 25 April 2019 / Revised: 2 July 2019 / Accepted: 13 September 2019 / Published online: 21 October 2019

(C) The Author(s) 2019

\begin{abstract}
The demand for lithium-ion batteries (LIBs) with high mass-specific capacities, high rate capabilities and long-term cyclabilities is driving the research and development of LIBs with nickel-rich NMC $\left(\operatorname{LiNi}_{x} \mathrm{Mn}_{y} \mathrm{Co}_{1-x-y} \mathrm{O}_{2}, x \geqslant 0.5\right)$ cathodes and graphite $\left(\mathrm{Li}_{x} \mathrm{C}_{6}\right)$ anodes. Based on this, this review will summarize recently reported and widely recognized studies of the degradation mechanisms of Ni-rich NMC cathodes and graphite anodes. And with a broad collection of proposed mechanisms on both atomic and micrometer scales, this review can supplement previous degradation studies of Ni-rich NMC batteries. In addition, this review will categorize advanced mitigation strategies for both electrodes based on different modifications in which Ni-rich NMC cathode improvement strategies involve dopants, gradient layers, surface coatings, carbon matrixes and advanced synthesis methods, whereas graphite anode improvement strategies involve surface coatings, charge/discharge protocols and electrolyte volume estimations. Electrolyte components that can facilitate the stabilization of anodic solid electrolyte interfaces are also reviewed, and trade-offs between modification techniques as well as controversies are discussed for a deeper understanding of the mitigation strategies of Ni-rich NMC/graphite LIBs. Furthermore, this review will present various physical and electrochemical diagnostic tools that are vital in the elucidation of degradation mechanisms during operation to supplement future degradation studies. Finally, this review will summarize current research focuses and propose future research directions.
\end{abstract}

Keywords Lithium-ion battery $\cdot$ Ni-rich NMC $\cdot$ Degradation $\cdot$ Mitigation $\cdot$ Graphite $\cdot$ Diagnostic tools

\section{Introduction}

Due to significant advantages such as high energy densities, high galvanic potentials, wide temperature ranges, no memory effects and long service lifespans, lithium-ion batteries (LIBs) have been widely employed in various applications, including in the fields of communication, aviation and transportation. Overall, the chemistries of LIBs are constantly evolving, and in terms of cathode materials,

Lei Zhang

lei.zhang@nrc.gc.ca

1 Energy, Mining and Environment Research Center, National Research Council Canada, 4250 Wesbrook Mall, Vancouver, BC V6T 1W5, Canada

2 Automotive and Surface Transportation Research Centre, National Research Council Canada, 75 Boulevard de Mortagne, Boucherville, QC J4B 6Y4, Canada

3 Department of Chemistry, University of Victoria, 3800 Finnerty Rd, Victoria, BC V8W 3V6, Canada
$\mathrm{LiNi}_{x} \mathrm{Mn}_{y} \mathrm{Co}_{1-x-y} \mathrm{O}_{2}$ (NMC) layered oxides have received increasing attention due to their enhanced specific capacity and thermal stability [1]. As compared with $\mathrm{LiMO}_{2}(\mathrm{M}=\mathrm{Ni}$, $\mathrm{Mn}$, or Co) cathodes, NMC-based cathodes also possess the combined merits of three transition metals in which nickel can offer high specific capacities, whereas Co and Mn can provide layered structures and enhanced structural integrity. In addition, NMC-based cathodes can outperform lithium iron phosphate (LFP) cathodes in many areas, particularly in terms of operational voltage in which LFP-based LIBs can only output voltages below 3.4 V [2] and suffer from high rates of self-discharge. Moreover, materials such as $\mathrm{Li}_{2} \mathrm{MnO}_{3}$ and lithium titanate do not possess great industrial potential as cathodes due to short lifespans and high costs. Here, NMC-based cathode materials are much cheaper to produce ( $\sim$ USD 23 per kg for NMC111) as suggested by researchers using a co-precipitation method [3], and the increase in NMC-based material prices from January 2017 to March 2018 ( 43\% for NMC532 and NMC622, and $27 \%$ for NMC811) [4] indicates that more research is 
being directed to the field of NMC-based cathode materials due to their commercial potential.

Following the initial commercial success of $\mathrm{LiNi}_{1 / 3} \mathrm{Mn}_{1 / 3} \mathrm{Co}_{1 / 3} \mathrm{O}_{2}$ (NMC333 or NMC111), NMC-based LIBs have become the mainstream with gradual improvements in NMC technology through the steady increase in the nickel content in each generation of cathode materials. And because $\mathrm{Ni}$ can cycle between $\mathrm{Ni}^{2+} \beta^{3+}$ and $\mathrm{Ni}^{3+} / 4+$ redox couples without large variations in voltage during the charge/discharge process, layer-structured $\mathrm{Ni}$ rich NMC ( $\left.\mathrm{LiNi}_{x} \mathrm{Mn}_{y} \mathrm{Co}_{1-x-y} \mathrm{O}_{2}, x \geqslant 0.5\right)$ cathodes [e.g., $\mathrm{LiNi}_{0.5} \mathrm{Mn}_{0.3} \mathrm{Co}_{0.2} \mathrm{O}_{2}$ (NMC532), $\mathrm{LiNi}_{0.6} \mathrm{Mn}_{0.2} \mathrm{Co}_{0.2} \mathrm{O}_{2}$ (NMC622) and the most recent $\mathrm{LiNi}_{0.8} \mathrm{Mn}_{0.1} \mathrm{Co}_{0.1} \mathrm{O}_{2}$ (NMC811)] have been developed. Here, the main advantage of Ni-rich materials is their high discharge capacity (200-220 mAh g${ }^{-1}$ ), which represents a large increase in energy density $\left(\sim 800 \mathrm{Wh} \mathrm{kg}^{-1}\right)$ as compared with conventional $\mathrm{LiCoO}_{2}\left(\sim 570 \mathrm{Wh} \mathrm{kg}^{-1}\right)$ and $\mathrm{LiMn}_{2} \mathrm{O}_{4}$ spinel $\left(\sim 440 \mathrm{Wh} \mathrm{kg}^{-1}\right)$ materials [5]. In addition, increasing the $\mathrm{Ni}$ content is the most effective method to enhance capacity in the current state-of-the-art LIBs without requiring advanced and novel battery chemistries. As a result, researchers are reviewing recent progress achieved in the development of Ni-rich cathode materials in an attempt to provide important clues for the future design of Ni-rich cathodes [6].

However, although increasing Ni percentages can allow for enhanced Ni-rich NMC-based battery performances as compared with other NMC combinations in terms of capacity, capacity fading becomes severely pronounced. To address this, significant efforts have been made to elucidate the mechanisms of capacity fading and associated growth of impedance [7, 8], as well as to find remedies [9-12]. And in recent decades, numerous studies and reviews have been published worldwide [13-15] in which various testing protocols [16], research methodologies, models [17-19] and physical characterizations $[9,20]$ have been used to interpret the behavior of NMC-based cathodes with or without modifications. Here, studies based on microscopy [21], crystallography [22], mass spectroscopy [23], gas measurements [24] and calorimetry [8] have revealed that parasitic reactions [7], cation mixing (leading to restructured surface regions) [25], active material dissolution [26] and oxygen release [23, 25] are primary factors responsible for cathode degradation at the atomic scale. In addition, scanning electron microscopy (SEM) [13] together with computational studies [27] has revealed that intergranular cracking can weaken connections between primary particles. Despite these findings, the majority of recently published studies are insufficient and only partially cover the processes through which degradation occurs. For example, Liu et al. [28] reviewed surface layers and surface chemistries during Ni-rich NMC-based LIB operations and presented cationic doping and metal oxide coating as recent research progress, whereas Myung et al. [29] in their review only provided a brief developmental history of NMC and NCA-based LIBs with a focus on the categorization of gradient layers and core-shell structures as remedies. A more recent and detailed review conducted by Hou et al. [30] covered more mitigation topics varying from ion substitution and electrolyte additives to gradient layers; however, to the best of our knowledge, no review has presented a comprehensive collection of mitigation methods or has categorized them based on characteristics. Similarly, controversies in mitigation strategies and trade-offs need to be considered, such as the selection of dopants or coating materials, all of which have yet to be discussed. Based on this, these vacancies in the literature will be covered in this review to assist in the further investigation of Ni-rich NMCbased LIBs.

Apart from the cathode, graphite-the anode material that has received the most attention in LIBs due to its high mass-specific capacity and economic advantages [26, 31, 32] — can function collaboratively with NMC-based cathodes to provide promising performances in coin cells [20, 33], pouch cells [9, 34], pouch bags [11] and T-cells [35]. Based on this, this review will also provide a complete picture of the aging of graphite anodes that can affect both electrodes in battery cells based on degradation mechanisms and effective mitigation strategies. Furthermore, the solid electrolyte interface (SEI) is a film that forms on graphite anode surfaces during initial charging [36-39] and thickens in subsequent cycles, which can protect and impede anodes and is vital in the discussion of the aging behaviors of graphite anodes. Therefore, detailed mechanisms of anode SEIs are also reviewed to supplement previously published reviews.

To further investigate the degradation mechanisms of LIBs, multiple physical methods have been used in both electrochemical tests and physical characterizations [e.g., electrochemical impedance spectroscopy (EIS) to characterize the resistance of electron transfer and surface films]. Conventional and modern physical characterization methods have also been utilized to reveal surface morphology, element compositions, crystal lattice dimensions and reaction processes, and are also important to the interpretation of the degradation of Ni-rich NMC/graphite LIBs. Based on this, these diagnostic tools will also be presented in this review.

To fully present the evolution of electrode performances in Ni-rich NMC/graphite LIBs, degradation mechanisms based on various experiments and recent mitigation strategies in which cell conditions were evaluated separately or as a whole are presented in this review. And overall, this review will provide a summary of the recent advances in Ni-rich NMC-based batteries and can supplement pioneering reviews published previously. 


\section{Degradation Mechanisms}

Ni-rich NMC-based materials are some of the most promising cathode candidates for next-generation LIBs due to high capacities and large voltage windows. Despite impressive progress in the development of advanced materials and fabrication processes, the development of high-capacity electrodes with long-term stability and prolonged cycle lifespans remains an important challenge. To address this, the understanding of underlying degradation mechanisms presented in this review can serve as a starting point to learn and improve the performance of Ni-rich NMC-based cathodes. In addition, the information included in this review can provide valuable insights into the creation of new devices with improved efficiency and productivity. And for the sake of completeness in the understanding of degradation mechanisms in LIB full cells, parasitic reactions on NMC-based cathode surfaces, the aging of graphite anodes as well as SEI formation and aging are also briefly presented in this section.

\subsection{Ni-Rich NMC-Based Cathodes}

The degradation of Ni-rich NMC LIBs involves different types of capacity loss, including initial capacity loss (ICL), sudden capacity loss (SCL) and gradual capacity loss (GCL), all of which are accompanied by impedance growth. And in the case of GCL, which is the most frequently investigated process, a major cause is the loss of $\mathrm{Li}$ and transition metals on cathode surfaces. In general, the majority of degradation mechanisms for Ni-rich NMC-based cathodes can be indexed to the same mechanism independent of $\mathrm{Ni} / \mathrm{Mn} / \mathrm{Co}$ ratios because they share similar crystal and microspherical structures. Here, adjustments (typically increases in $\mathrm{Ni}$ ) to the relative amounts of $\mathrm{Ni}, \mathrm{Mn}$ and $\mathrm{Co}$ can result in augmented performances as well as various negative features. For example, enhanced mass-specific capacity can be achieved but at the expense of rate capability and structural stability. In addition, researchers have also reported higher electronic conductivity and reduced polarization [40] in which the varied polarization as compared with the portion of $\mathrm{Ni}$ is caused by the higher $\mathrm{e}_{\mathrm{g}}$ orbital of $\mathrm{Ni}$ over the $t_{2 \mathrm{~g}}$ orbital of Co [41]. Researchers have also shown that the reduced $\mathrm{Mn}$ content can result in faster degradation through surface reconstruction [42] and that the increased $\mathrm{Ni}$ content can result in increased cation mixing due to the bulk diffusion of $\mathrm{Ni}^{2+}$ into the Li-layer and increased parasitic reactions as the valence of surface $\mathrm{Ni}$ increases toward highly reactive $\mathrm{Ni}^{4+}$. Overall, cathode performances can be impacted by various factors that interact with each other, and therefore, this section will discuss degradation mechanisms in detail.

\subsubsection{Surface Degradation During Cell Operation}

Lattice Expansion/Contraction NMC oxide possesses an $R \overline{3} m$ structure (rhombohedral symmetry) with a Li-layer on the $3 \mathrm{a}$ site, an NMC layer on the $3 \mathrm{~b}$ site and an oxygen layer on the $6 \mathrm{c}$ site [7] and can usually be indicated in the splitting of (110) and (108) peaks and of (006) and (102) peaks. For example, the expansion and contraction of the $c$-axis $(14.21 \AA)$ of NMC811 lattices can be observed by using in situ XRD measurements in the cell voltage windows of $3.0-4.0 \mathrm{~V}$ and $4.0-4.4 \mathrm{~V}$, in which (003) peaks can decrease from $18.96^{\circ}(3.0 \mathrm{~V})$ and subsequently rise to $19.09^{\circ}(4.4 \mathrm{~V})$ $[7,10,43]$. This can also be observed for the movement of (104), (015) and (108) peaks. Here, researchers suggest that the expansion of the $c$-axis is due to the repulsive force generated from $\mathrm{MO}_{6}$ slabs, which are positively charged in a highly delithiated state, whereas the loss of electrons can shrink the radius of transition metal ions to reduce the $a$-axis [44]. In addition, the (110) peak can shift to higher angles in experiments, suggesting that the $a$-axis can contract during charging due to the smaller radius of transition metal ions at elevated valences [45]. Researchers have also reported that the $a$-axis of NMC811 lattices remains constant at potentials exceeding $4.3 \mathrm{~V}$ [10] and that a steep drop of the $c$-axis occurs at potentials exceeding $4.2 \mathrm{~V}$ in which the drop becomes steeper as the Ni content increases [7, 20,43]. Here, researchers proposed that this drop is due to the fact that the repulsion between $\mathrm{O}^{2-}$ layers decreases with more covalent $\mathrm{M}-\mathrm{O}$ bonding at higher delithiated states [46, 47] (Fig. 1a, b). Furthermore, studies have also confirmed two pathways (Fig. 1c2, c3) involved in the delithiation of Nirich NMC-based cathodes $[40,48]$, including oxygen dumbbell hopping and tetrahedral site hopping, in which at the beginning of charging, $\mathrm{Li}$ can exit through oxygen dumbbell hopping until a certain degree of delithiation is reached and continue through tetrahedral site hopping due to increased energy barriers as caused by $\mathrm{Li}-\mathrm{O}$ bonds during delithiation.

Surface Reconstruction to Fm $3 m$ Rocksalt Surface reconstruction of the particles of NMC-based cathodes can initiate if delithiation exceeds $70 \%$ as shown in NMC111 [49]. In addition, increasing the $\mathrm{Ni}$ content can lead to increased portions of $\mathrm{Ni}^{3+}$ (usually $\mathrm{Ni}$ ions with higher valences) in the total amount of Ni. Furthermore, elemental Ni partially located in the transition metal layer as $\mathrm{Ni}^{2+}(0.69 \AA)$ possesses a similar radius to $\mathrm{Li}^{+}\left(0.76 \AA\right.$ ) [50], and $\mathrm{Li}^{+}$and $\mathrm{Ni}^{2+}$ can exchange positions in a delithiated state through $\mathrm{Ni}^{2+}$ diffusion to the octahedral sites of $\mathrm{Li}^{+}$(energetically favorable) through a neighboring tetrahedral site (Fig. 1c) $[42,51]$. Here, the degree of $\mathrm{Ni}^{2+}$ migration can be evaluated by calculating the $c / a$ ratio of the NMC lattice because this migration reduces the $c / a$ ratio. And based on XRD 
measurements, ratios of $I_{003}$ to $I_{104}$ can decrease to less than 1.2 after significant cation mixing and can therefore serve as an indicator of the degree of cation mixing [52]. Moreover, researchers reported that cation disorder can lower spacing between atomic layers in the lattice of the NMC-based cathodes, hinder $\mathrm{Li}^{+}$movement and reduce the amount of active $\mathrm{Ni}$ and $\mathrm{Li}$ [53]. In the case of higher $\mathrm{Ni}$ percentage cathodes, $\mathrm{Mn}^{4+}$ can partially be replaced by $\mathrm{Ni}$, which increases the valence of $\mathrm{Ni}$ and therefore lowers the possibility of Ni atoms migrating to $3 \mathrm{a}$ sites [8]. However, because the total amount of $\mathrm{Ni}$ also increases, $\mathrm{Ni}^{2+}$ migration still occurs to a larger extent. To minimize $\mathrm{Ni}^{2+}$ migration, researchers reported that mitigation methods can be used to modify cathodes [54]. Furthermore, a disordered spinel structure $(F d 3 m)$ due to non-ideal cation mixing [55] can form if LIBs are charged to high voltages (e.g., 4.8 V) [21, 56-60] and consists of a $\mathrm{LiM}_{2} \mathrm{O}_{4}$ spinel structure and a $\mathrm{M}_{3} \mathrm{O}_{4}$ spinel structure if Co migration into tetrahedral sites occurs [42] (Fig. 2a). Xiong et al. [61] and Eom et al. [62] also reported that spinel phases can be formed on charged cathodes stored at $90{ }^{\circ} \mathrm{C}$ for a week. Moreover, researchers found that migrated $\mathrm{Mn}$ and Co possess high valences and smaller radii for movement and more vacancies in the Li-layer in a highly delithiated state [63]. Researchers also reported that long-term cycling to 4.2 V (NMC 622) [64] can result in phase changes to an $F m 3 m$ structure consisting of $\mathrm{Ni}^{2+}, \mathrm{Mn}^{2+}$ and $\mathrm{Co}^{2+}$ with lowered valence states as compared with a spinel structure $[63,65]$ and ion-insulating $[56$, 63, 66] (a cubic rocksalt phase) (Fig. 2b). Here, the conversion from a layered structure to a cubic rocksalt phase (usually confirmed by HRTEM/EELS [9]) can release $\mathrm{O}_{2}$ into the cell, which can react with electrolytes to generate $\mathrm{CO}_{2}$ and result in increased electrode interfacial resistances due to kinetic barriers in the $\mathrm{Li}^{+}$insertion/desertion process [50]. To address this, researchers reported that NMC811 cathodes pretreated with ramping to $4.5 \mathrm{~V}$ limited the growth of the rocksalt layer in subsequent cycles and can serve as a pillar structure to stabilize the lattice and isolate the surface of NMC particles [67]. Furthermore, researchers reported that the oxidation states of $\mathrm{Mn}$ and Co decrease in the surface layer/region of NMC811 and NMC442 after cycling [9, 63].

Phase Transformations Two hexagonal phases of NMC811 can coexist on the surface of particles if freshly prepared in which the evolution of one phase is irreversible and vanishes after initial charging (with lattice constants remaining at the initial value), whereas the second phase is reversible (except for a small difference between charging and discharging above $4.2 \mathrm{~V}$ ). Here, the fading of the (110) peak at $65.12^{\circ}$ can track the conversion of the region in which the two hexagonal phases coexist and are converted to a single phase [7]. In addition, the broadening of the (003) peak during cycling as recorded by using in situ XRD measurements is of great interest in which researchers [25] suggested that this phenomenon was due to the creation of a second phase in the potential range of 3.8-4.0 $\mathrm{V}(\mathrm{H} 2$, evolved from the monoclinic phase in contrast to the phase $\mathrm{H} 1$ following the stoichiometric composition) that possesses less Li. Researchers also reported that this process occurred earlier with higher Ni portions (Fig. 2c) and that at higher voltages, the conversion from $\mathrm{H} 2$ to $\mathrm{H} 3$ occurs with impedance growth (volume contraction) only for NMC811 (or NMCs
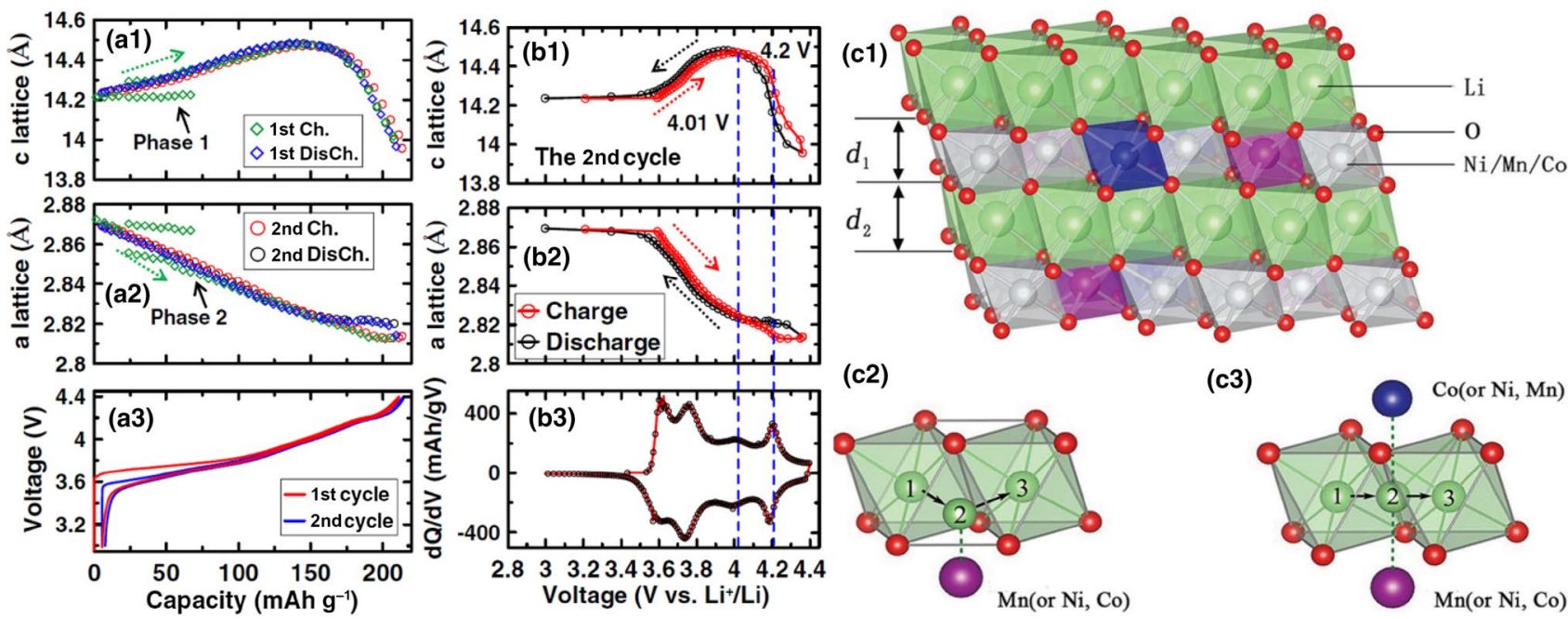

(c2)

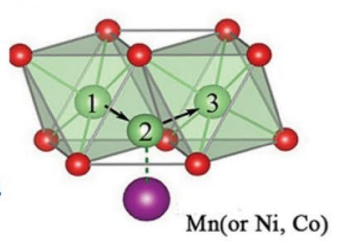

(c3)

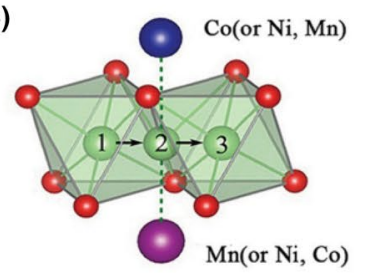

Fig. 1 The $c$-axis (a1), the $a$-axis (a2) and potential (a3) of an NMC 811 cell as a function of specific capacity. The $c$-axis (b1) and the $a$-axis (b2) as a function of cell potential during the second cycle and $\mathrm{d} Q / \mathrm{d} V$ of the second cycle as a function of cell potential (b3) (Reprinted with permission from Ref. [7]. Copyright (C) The
Author(s) 2015. Published by ECS). c1 Lattice of an NMC layered structure. c2 Tetrahedral site pathway and c3 oxygen dumbbell pathway for Li-ion diffusion in an NMC layered structure (Reprinted with permission from Ref. [48]. Copyright (C) 2015 WILEY-VCH Verlag GmbH \& Co. KGaA, Weinheim) 
with Ni portions larger than 80\%) [25]. Researchers have also found that the phase transition from $\mathrm{H} 2$ to $\mathrm{H} 3$ can lead to (003) peaks shifting to higher degrees [68] and that Lireordering (Li diffusing into $\mathrm{Ni}^{4+}$-rich sites) can further convert H3 to H3-2 [69] in which the fast shrinkage of the $c$-axis at potentials above $4.15 \mathrm{~V}$ is a clear indication of this phase transition. Moreover, the generated microregion of $\mathrm{NiO}_{2}$ in the intralayer of the NMC811 lattice as a result of the phase transition from $\mathrm{H} 2$ to $\mathrm{H} 3$ can lead to the irreversible transformation of the NMC811 structure [45] and this phase transition becomes severer as Ni portions further increase to extreme numbers as indicated by rising peaks of the differential capacity curve centered at $4.15 \mathrm{~V}$ [68]. Here, the fading of this peak leads to capacity fade and is referred to as the "deleterious effect." Furthermore, phase changes to a second hexagonal phase for other NMC-based cathodes have yet to be clarified. (Fig. 2d illustrates crystal lattice evolution during delithiation.)

Surface Stabilizer In general, NMC-based cathodes with more Mn content tend to possess better cycling stability [13, 70], whereas NMC-based cathodes with more Ni content are believed to be incapable of reaching high cutoff voltages due to the lack of $\mathrm{Mn}^{4+}$ as a structure stabilizer [65]. Apart from $\mathrm{Ni}^{2+}$, structural instability also applies to $\mathrm{Mn}^{3+}$, although with the high $\mathrm{Ni}$ content, Mn migration is not considered to be significant. Here, due to low octahedral site stability energy, NMC-based cathodes possess a tendency to form spinel-structured $\mathrm{LiMn}_{2} \mathrm{O}_{4}$ on surfaces [71] and $\mathrm{Mn}^{4+}$ possesses a similar tendency to migrate to the Li-layer [33, 71] and decrease capacity. Nevertheless, diffused $\mathrm{Mn}^{4+}$ on particle surfaces can stabilize structures during long-term cycling [50].

\subsubsection{Impurities and Parasitic Reactions}

Surface Impurities To maintain a layered structure, excessive $\mathrm{Li}$ is used for Ni-rich NMC-based cathodes. However, side reactions of $\mathrm{Li}$ with water vapor and $\mathrm{CO}_{2}$ in air can lead to $\mathrm{LiOH}$ and $\mathrm{Li}_{2} \mathrm{CO}_{3}$ in which exposure to air can result in a reconstructed surface layer $3 \mathrm{~nm}$ thick (evidenced by STEM) that thickens if cycled [9]. A surface layer with similar impacts can also form as cathodes come into contact with electrolytes [65]. Here, researchers suggest that this reconstructed layer can be tuned through different synthesis methods of the cathode powder [63] and that in the case of NMC111, surface impurities can also grow on top of cathode particles as resistive films over the same time period for uncycled Ni-rich NMC-based LIBs [35] that contain mainly insulating hydroxides and carbonates as revealed through Raman spectroscopy (Fig. 3a). Here, the circumstances in which $\mathrm{Li}_{2} \mathrm{CO}_{3}$ (Eq. 1) or $\mathrm{NiCO}_{3}$ is favored remain unclear $[35,72,73]$. Researchers also reported that high humidity can lead to more hydroxide (e.g., LiOH) on NMC622 [72] and that surface impurities can affect cell impedances in subsequent cycles through reactions with electrolytes to form a $\mathrm{Li}^{+}$diffusion inhibiting layer.

$$
\begin{aligned}
& \mathrm{Li}(\mathrm{Ni}, \mathrm{Mn}, \mathrm{Co}) \mathrm{O}_{2}+\frac{x}{2} \mathrm{CO}_{2}+\frac{x}{4} \mathrm{O}_{2} \\
& \rightarrow \mathrm{Li}_{1-x}(\mathrm{Ni}, \mathrm{Mn}, \mathrm{Co}) \mathrm{O}_{2}+\frac{x}{2} \mathrm{Li}_{2} \mathrm{CO}_{3}
\end{aligned}
$$

NMC Dissolution The dissolution of NMC materials can also result in capacity attenuation $[26,74]$ because it can decrease $\mathrm{Li}^{+}$insertion sites and is triggered by the products of electrolyte decomposition such as HF from the reaction of $\mathrm{PF}_{5}$ with $\mathrm{H}_{2} \mathrm{O}$ (Eqs. 2, 3) [31]. In addition, higher voltages can accelerate the dissolution of NMC111 due to the release of more acidic components as a result of rapid electrolyte decomposition [75]. Despite these findings, effects on $\mathrm{Ni}$ rich NMC have yet to be reported. The dissolution of NMC materials can also cause a concurrent issue involving the production of resistive $\mathrm{MF}_{x}$ as a side product on the surface of NMC particles. Moreover, the dissolution of transition metals can pose a threat to anodes through electrodeposition $[32,76]$, catalysis of solvent reduction [77] and formation of inorganic layers in SEIs [78], all of which can impede $\mathrm{Li}^{+}$intercalation and reduce capacity [79]. Here, $\mathrm{Mn}^{3+}$ disproportion into $\mathrm{Mn}^{2+}$ and $\mathrm{Mn}^{4+}$ was proposed to explain Mn dissolution [26, 75] as previously reported in $\mathrm{Li}-\mathrm{Mn}-\mathrm{O}$ spinel structures $[80,81]$ and various electrolytes have been utilized to form protective surface films containing carbon on electrodes to isolate surfaces from electrolytes [33].

$\mathrm{LiPF}_{6} \rightarrow \mathrm{LiF}+\mathrm{PF}_{5}$

$\mathrm{LiPF}_{6}+2 \mathrm{e}^{-}+2 \mathrm{Li}^{+} \rightarrow \mathrm{LiF}+\mathrm{Li}_{x} \mathrm{PF}_{y}$

Self-redox Reaction At highly delithiated states, the valence of transition metals increases, and because the low-spin $\mathrm{Co}^{3+/ 4+}: \mathrm{t}_{2 \mathrm{~g}}$ band overlaps with the $2 \mathrm{p}$ band of $\mathrm{O}^{2-}$ (Fig. $3 \mathrm{~b}$ ), electron transfer from $\mathrm{O}^{2-}$ to $\mathrm{Co}^{3+/ 4+}$ can occur and reduce oxidized transition metal ions, thus releasing $\mathrm{O}_{2}$ into battery cells [82]. Oxygen release based on this also occurs at the first charging period in which $\mathrm{O}^{2-}$ reduces transition metals oxidized to 4+ (similar effects on $\mathrm{Ni}^{4+}$ also exist and dominate oxygen release in Ni-rich NMC-based cathodes) $[14,42]$.

Parasitic Reaction: Effects of $\mathrm{Ni}^{4+}$ Highly delithiated (highly charged) states tend to generate large amounts of $\mathrm{Ni}^{4+}$ that can react with electrolytes. (No reaction schemes have been proposed.) This side reaction can significantly thicken cathode-electrolyte interfaces (CEIs) and reduce the number 


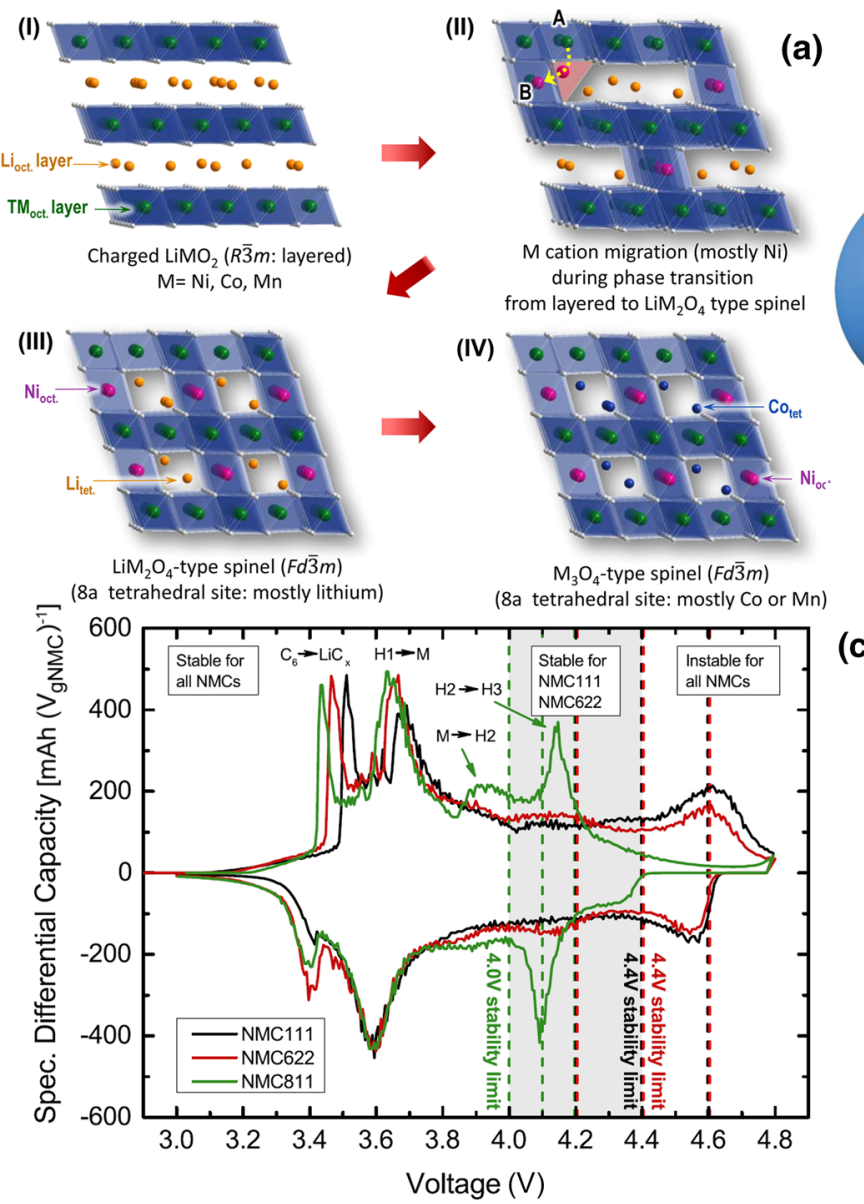

Fig. 2 a Schematic of phase transition and possible TM cation migration pathways in charged NMC cathode materials during thermal decomposition (Reprinted with permission from Ref. [42]. Copyright (C) 2014, American Chemical Society). b Degradation mechanisms of $\mathrm{LiNi}_{0.5} \mathrm{Co}_{0.2} \mathrm{Mn}_{0.3} \mathrm{O}_{2}$ after cycle tests under two upper cutoff voltage conditions (4.5 V and $4.8 \mathrm{~V}$ ) (Reprinted with permission from Ref. [56]. Copyright () 2013 WILEY-VCH Verlag GmbH \& Co. KGaA, Weinheim). c Differential capacity plot of three different $\mathrm{NMC} /$

of available $\mathrm{Li}^{+}[14,83]$, thus increasing impedance [13]. Researchers have also investigated gas evolution $\left(\mathrm{CO}_{2}\right)$ from NMC532 cathodes using DEMS [84], and isothermal calorimetry (IMC) results have shown that at highly delithiated states above $4.2 \mathrm{~V}$, the further removal of $\mathrm{Li}$ from NMC811 cathodes can result in decreased entropy and endothermic heat flow [7] in which rapidly increasing heat flow indicates that the highly delithiated cathode is very reactive with the electrolyte and can therefore cause capacity fading. In addition, researchers also found that remaining at a highly delithiated state can cause significant electrolyte oxidation as well as other side reactions [9].

Parasitic Reaction: $\mathrm{CO}_{2}$ generation Large $\mathrm{Ni}^{4+}$ portions at higher voltages can cause increased $\mathrm{CO}_{2}$ evolution at increased upper cutoff voltages [85] in which cathodes with

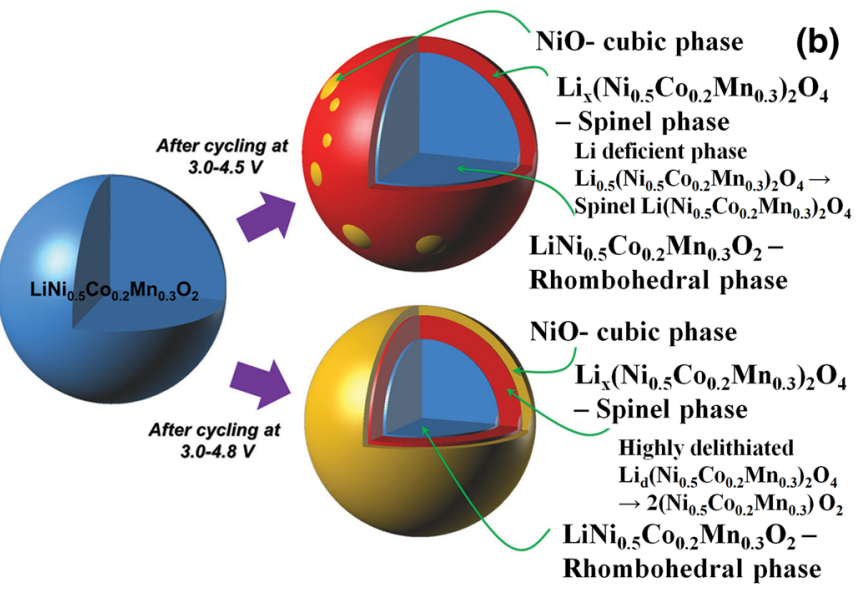

(c)

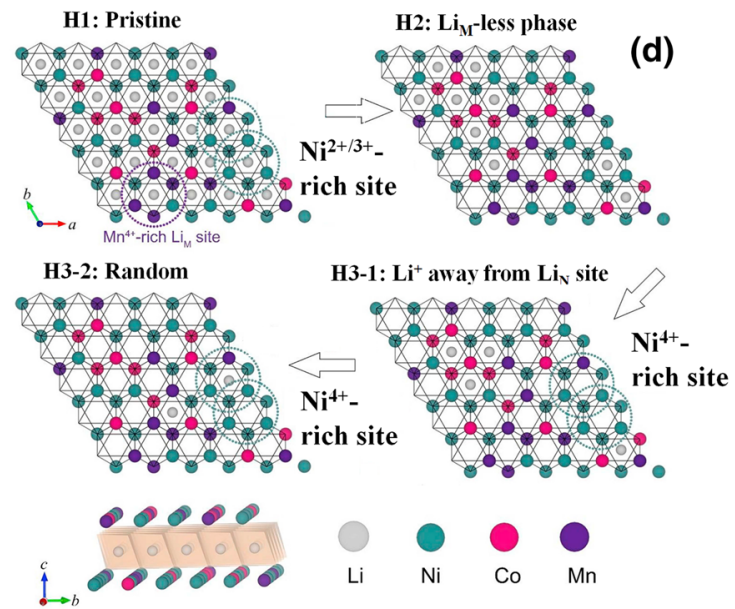

graphite cells recorded at $0.1 \mathrm{C}$-rate (3rd cycle) with marked phase transformations (Reprinted with permission from Ref. [25]. Copyright (C) The Author(s) 2017. Published by ECS). d Schematic of H1$\mathrm{H} 2-\mathrm{H} 3$ phase transformation from the perspective of local environments in different views along the $c$-axis (up) and the $a$-axis (bottom) (Reprinted with permission from Ref. [69]. Copyright @ (c) 2018, Elsevier B.V. All rights reserved.)

higher Ni content suffer more from parasitic reactions with $\mathrm{Ni}^{4+}$ that are a source of emitted $\mathrm{CO}_{2}$. In addition, because highly reactive oxygen can be produced through $\mathrm{O}^{2-}$ from self-redox reactions, surface reconstructions and highly delithiated cathodes (ca.> 80\%) [86], $\mathrm{CO}$ and $\mathrm{CO}_{2}$ can also be traced back to the reaction between $\mathrm{O}_{2}$ and alkyl carbonate electrolytes (Eq. 4) [24, 25]. Alternatively, sweeping to higher voltages can also cause the electrochemical decomposition of electrolytes to produce $\mathrm{CO}_{2}$ (Eq. 5, Fig. 3c) [23, 24, 87]. Furthermore, Gasteiger et al. [88] have experimentally shown three other mechanisms that may contribute to $\mathrm{CO}_{2}$ emission, including solvent hydrolysis (if trace amounts of $\mathrm{OH}^{-}$exist), electrolyte impurity oxidation and HF reacting with lithium carbonate as a surface impurity. Moreover, the decomposition of lithium carbonate has also proven to be a source of $\mathrm{CO}_{2}[89,90]$. Researchers have also suggested that 
(a)

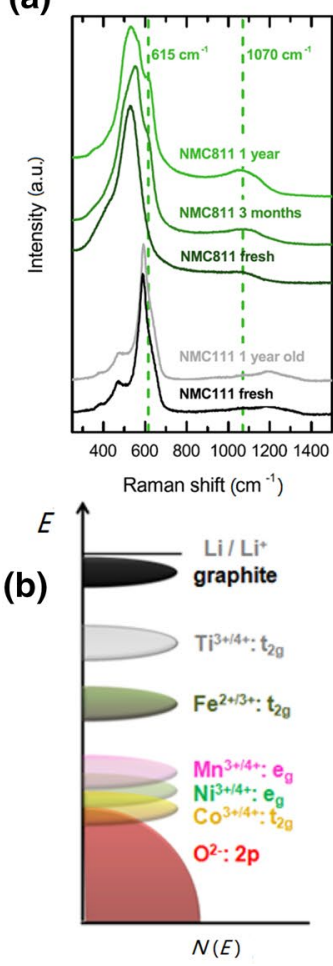

(c)

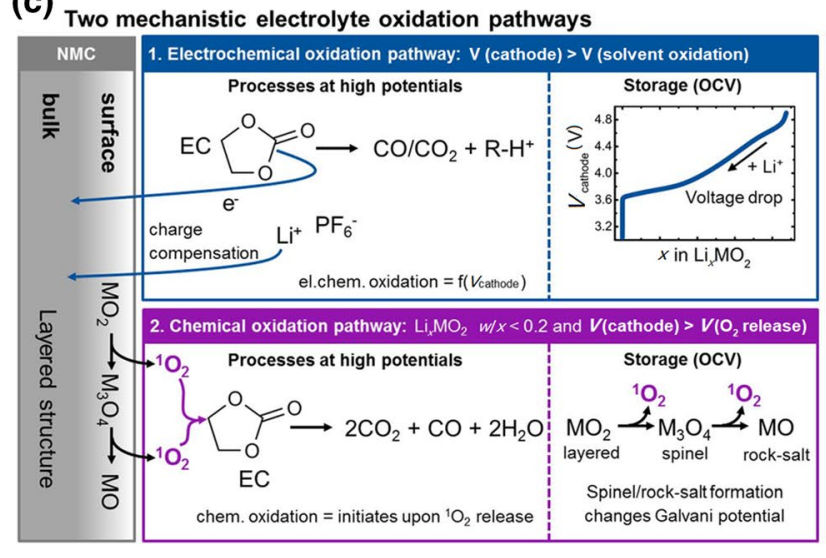

(d)

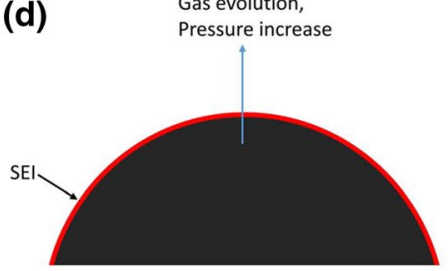

1. Reaction of $\mathrm{Ni}^{4+}$ with electrolyte solution to form cSEl and continuous side reactions (gas evolution, lithium consumption, capacity loss)

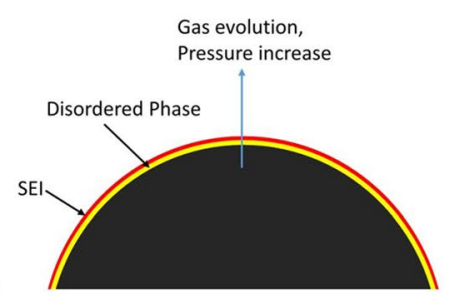

2. Formation of disordered spinel and rock salt phase at the surface (gas evolution, capacity fade)
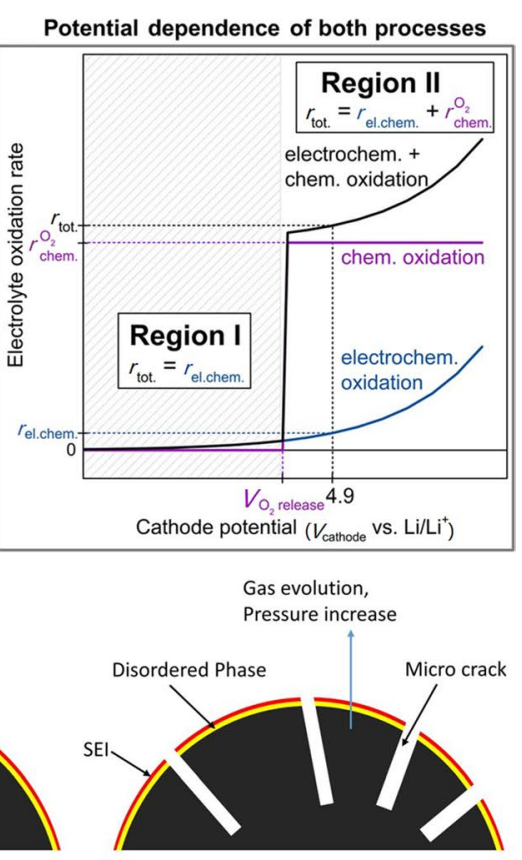

3. Formation of micro cracks $\rightarrow$ continuous fresh surface area for 1 . and 2.

(gas evolution, lithium consumption, capacity loss, contact loss to current collector)
Fig. 3 a Raman spectra of fresh and stored NMC111 and NMC811 electrodes before cycling, measured in air within $\sim 1 \mathrm{~h}$ with the samples not treated prior to measurements (Reprinted with permission from Ref. [35]. Copyright (C) The Author(s) 2018. Published by ECS). b Positions of various redox couples relative to the top of the oxygen $2 p$ band (Reprinted with permission from Ref. [14], https://pubs. acs.org/doi/10.1021/acscentsci.7b00288. Copyright (C) 2017, American Chemical Society. Further permissions related to this figure should be directed to ACS). c Proposed electrooxidation and chemi-

NMC-based cathodes with Ni-rich surfaces behave differently than other cathodes with different portions of Ni [7]. For example, the degradation of NMC811 cells was studied by using different electrolyte additives including $\mathrm{VC}$ and PES211 to suppress side reactions and it was revealed that NMC442/graphite cells and NMC111/graphite cells showed better performances with PES211, whereas NMC811/graphite cells aged slower with VC (with slower capacity fading and impedance growth) [79]. Here, PES was also reported to be a viable additive for the suppression of gas evolution [91] and impedance growth during cycling to higher voltages (above $4.3 \mathrm{~V}$ ), and rocksalt surface layers formed with the use of VC but not with PES211, concluding that electrolyte additives can significantly affect the rate of parasitic reactions and that parasitic reactions were the main reason for capacity fading [7, 92].

$$
\begin{aligned}
& \mathrm{EC}+2 \mathrm{O}_{2} \rightarrow 2 \mathrm{CO}_{2}+\mathrm{CO}+2 \mathrm{H}_{2} \mathrm{O} \\
& \mathrm{EC} \rightarrow \mathrm{CO} / \mathrm{CO}_{2}+\mathrm{R}-\mathrm{H}^{+}+\mathrm{e}^{-}
\end{aligned}
$$

cal oxidation pathways for ethylene carbonate (EC) and their potential dependence (Reprinted with permission from Ref. [25]. Copyright (C) The Author(s) 2017. Published by ECS). d Schematic of the different issues facing Ni-rich NMC materials: (1) SEI formation and reactivity of $\mathrm{Ni}^{4+}$; (2) $\mathrm{Li} / \mathrm{Ni}$ displacement and formation of disordered phases; (3) microcracks in secondary particles (Reprinted with permission from Ref. [13]. Copyright (C) The Author(s) 2016. Published by ECS)

\subsubsection{Other Issues}

Initial Capacity Loss Initial capacity loss is strongly linked to the loss of available $\mathrm{Li}$ and the growth of impedance in anodes due to SEI formation. Here, researchers have reported that NMC-based cathodes cannot return to their fully lithiated states after initial cycling [26] in which separate mechanisms have been proposed, including parasitic reactions consuming $\mathrm{Li}^{+}[93]$ and the sluggishness of $\mathrm{Li}^{+}$ diffusion into the few vacancies of the Li-layer [94] (circumstantially proved by Gasteiger et al. [26]). In addition, researchers have also suggested that initial capacity loss is related to the C-rate because it is kinetically influenced. Furthermore, partial losses of available cathodic Li occur to compensate for losses of anodic $\mathrm{Li}^{+}$to SEIs [26], and other losses of $\mathrm{Li}$ in the cycling period can be attributed to parasitic reactions including the immobilization of $\mathrm{Li}$ in the SEI and enlarged polarization, which become significant at higher cutoff potentials [26, 95]. 
Cracking of Secondary Particles Reduced performances due to the cracking of spherical secondary particles have been extensively reported and are of significant concern [96]. Here, the expansion and contraction of the $c$-axis during repeated cycling at above $4.2 \mathrm{~V}$ can lead to microstrains on particles in cathodes, leading to the generation of microcracks in the core of primary particles with some initially generated cracks being able to close in subsequent cycles [68]. These cracks can cause poor connection between particles and micropores and even the cracking of secondary particles [13], all of which contribute to degradation at the microscale. To address this, Lim et al. [27] have used firstprinciple calculations to study these cracks generated by gaps between primary particles and found that they were a result of anisotropic and average contractions. In addition, researchers reported that these cracked particles possessed enlarged surface areas and therefore increased the possibility of parasitic reactions [13]. Moreover, these microcracks were also found to partially originate from the gas evolution of NMC particles [13] (Fig. 3d), and recent studies on coated NMC (76 14 10) suggested that the infiltration of liquid electrolytes into the gap between primary particles can also cause cracking [97]. Alternatively, various NMCs have also been found with no cracking by using SEM [7, 20]. Here, Dahn et al. [20] suggested that the shell of core-shell structured NMC cathodes (a Mn-rich shell and a Ni-rich core) was resistant to cracking due to the absence of compressive stress on the core and tensile stress on the shell. Based on all of this, numerous mitigation methods including carbon matrixes and gradient layers have been proposed to resolve cracking at the microscale (further details in Sect. 4.1).

The Effects of Temperature Studies have shown that cell degradation can accelerate at elevated temperatures above $30{ }^{\circ} \mathrm{C}$ and that at low $\mathrm{C}$-rate cycling, cell degradation is mainly affected by the time in which cells are placed under high temperatures and not by cycling [98]. Long-term operation of LIB cells can produce large amounts of heat. And although this released heat may even be useful in cold weather conditions, heat emissions are a major issue of $\mathrm{Ni}$ rich NMC-based LIBs due to thermal instability [33] in which thermal runaways can occur if NMC-based cathodes react with $\mathrm{LiPF}_{6}$ from the electrolyte and limit the commercial and practical use of these battery packs. To improve thermal stability, coatings such as $\mathrm{SiO}_{2}$ [62], $\mathrm{TiO}_{2}$ [99] and $\mathrm{Li}_{2} \mathrm{ZrO}_{3}[100]$ have been chosen to prevent contact between cathodes and electrolytes, and an ALD-coated NMC532 with $\mathrm{Al}_{2} \mathrm{O}_{3}$ has even been reported [101] to resolve the issue of uneven coatings and prevent the failure of cathode separation from electrolytes.

\subsection{Graphite Anode}

Similar to the cracking of NMC secondary particles, cracking can also occur in graphite anodes due to $\mathrm{Li}$ intercalation/ deintercalation, which can expand and contract the distance between graphite layers [102]. In addition, recent research indicated that unit cell expansion (13.2\% in total) during $\mathrm{Li}$ intercalation is neither continuous nor linear, but staged (Fig. 4a-e) [103]. Here, $\mathrm{Li}$ intercalation from $\mathrm{C}_{6}$ ( $\mathrm{Li}$-free graphite) to $\mathrm{LiC}_{24}$ (Stage $2 \mathrm{~L}$ ) showed no in-plane ordering of intercalated $\mathrm{Li}$, whereas from $2 \mathrm{~L}$ to $\mathrm{LiC}_{12}$ (Stage 2), the ordering of $\mathrm{Li}$ appeared and the lattice can be assigned to the space group $P 6 / \mathrm{mmm}$. Furthermore, in the transition from Stage 2 to $\mathrm{LiC}_{6}$ (Stage 1), total volume change suddenly increases as the amount of $x$ exceeds 0.6 in $\mathrm{Li}_{x} \mathrm{C}_{6}$ (where Stage 1 appears as Li presents in every interlayer). These results showed that optimal composition was between 20 and $80 \%$ charged in which Stage 2 stably exists or extends into.

Furthermore, "dead lithium," which is Li-ions electrochemically plated onto the surface of graphite anodes, is the principal reason for capacity fading, especially at final stages [104]. This phenomenon occurs on graphite surfaces that possess limited mass transport, slow diffusion within the graphite or low charge transfer speeds [105] and is strongly promoted by low temperatures/large polarizations (including high electrolyte resistances induced by high temperatures) during lithiation as well as the properties of the graphite electrode (e.g., morphology [102], loading). And as $\mathrm{Li}^{+}$intercalation is replaced by $\mathrm{Li}$ plating, issues such as dendrite growth become more pronounced, leading to increased impedance and more importantly, potential safety hazards due to internal short circuiting. To avoid this, the limits of charging currents and the state of charge need to be established to maintain polarization in optimal ranges [106]. However, large polarizations also need to be adopted to minimize charging durations to meet industrial application demands. Here, researchers reported that the reduction of graphite thicknesses and improvements in porosity can decrease charge transfer impedances [105, 107].

\subsection{SEI}

Electrolytes used in LIBs contain two main components including Li salt and organic solvents. Here, the use of additives as film-forming agents can allow for stable SEIs and, in general, the concentration of Li salt is maintained at $0.8-1.3 \mathrm{M}$ to optimize electrolyte viscosity and ion conductivity. As compared with cathodes, the potential of LIB anodes is low and can trigger electrolyte reduction (SEI formation), which can cause Li loss during initial charging (Fig. 4f) [31]. However, because SEIs are electronically insulating, further reductions of electrolytes do not occur 
in which formed SEIs are usually $10-50 \mathrm{~nm}$ thick and are conductive to $\mathrm{Li}^{+}$ions. Researchers have extensively studied the constituents of passivating SEIs on graphite anodes and have reported that lithium ethylene dicarbonate (LEDC, Eq. 6, Fig. 5a-d) [108] was the main component of SEIs formed with ethylene carbonate (EC) solvent [109] apart from electronically insulating $\mathrm{LiF}$ and gaseous products $\left(\mathrm{H}_{2}\right.$ and $\left.\mathrm{C}_{2} \mathrm{H}_{4}\right)$. Propylene carbonate (PC) as a solvent has also been well investigated due to its thermal stability and wide voltage windows. Furthermore, DFT calculations have shown that stable SEI films can be produced by oligomers of SEI film components (SFCs) [108], which are first created through solvent decomposition. $\mathrm{LiF}$ is also a product of almost all common $\mathrm{Li}$ salts such as $\mathrm{LiPF}_{6}$ (the only commercially available salt), $\mathrm{LiBF}_{4}, \mathrm{LiTFSi}$, LiTSi, etc., in which researchers reported that the amount of LiF produced from $\mathrm{LiBF}_{4}$ was large and would result in the formation of a grainy film instead of a smooth film.

$2 \mathrm{EC}+2 \mathrm{Li}^{+}+2 \mathrm{e}^{-} \rightarrow \mathrm{Li}_{2} \mathrm{EDC}+\mathrm{C}_{2} \mathrm{H}_{4}$

As aging continues during cycling, researchers believe that the inorganic portions of SEIs also increase as LiF (can be used as an indicator of SEI maturation) is produced through $\mathrm{LiPF}_{6}$ reacting with lithium carbonates (Eqs. 7, 8) [37].

$$
\begin{aligned}
& 2 \mathrm{RCO}_{3} \mathrm{Li}+\mathrm{LiPF}_{6} \rightarrow 2 \mathrm{LiF}+2 \mathrm{RF}+\mathrm{LiPO}_{2} \mathrm{~F}_{2}+2 \mathrm{CO}_{2} \\
& \mathrm{RCO}_{3} \mathrm{Li}+\mathrm{LiPF}_{6} \rightarrow 2 \mathrm{LiF}+\mathrm{RF}+\mathrm{POF}_{3}+\mathrm{CO}_{2}
\end{aligned}
$$

After SEI formation, the resistance of anodes/SEIs toward divalent transition metal ions such as $\mathrm{Ni}^{2+}, \mathrm{Co}^{2+}, \mathrm{Cu}^{2+}$ and $\mathrm{Mn}^{2+}$ (relatively more impactive) is significantly enhanced, preventing the reduction of EC solvent by these ions. However, formed SEIs remain targets to many reductive substances in which reductive decomposition can degrade SEIs $\left(\mathrm{Li}_{2} \mathrm{CO}_{3}\right.$ and $\mathrm{C}_{2} \mathrm{H}_{4}$ are produced as a result $)$ and expose thermodynamically unstable graphite anodes to reactive environments [38]. Here, if the exposure of graphite anodes occurs, a series of damage can occur on the graphite anode, including the intercalation of solvated $\mathrm{Li}^{+}$, which leads to larger sizes and the potential risk of the breaking of the graphite layer. In addition, $\mathrm{Mn}^{2+}$ has been reported to be able to penetrate SEIs and reside in the inner area between the SEI and the anode through the exchange of positions with $\mathrm{Li}^{+}$ions located in the SEI [110]. Furthermore, the recurrent generation of $\mathrm{C}_{2} \mathrm{H}_{4}$ suggests that $\mathrm{Mn}^{2+}$ is a destructive substance to both solvents and graphite anodes in which accumulated $\mathrm{Mn}^{2+}$ near graphite can function as a catalyst, suggesting that it is reduced at the surface of the anode but can reduce EC afterward, leading to thickened SEI films and the immobilization of active Li (Fig. 5e) [110]. In addition, the reduction of $\mathrm{Mn}^{2+}$ can cause the gradual transfer of active $\mathrm{Li}^{+}$to SEIs or the conversion of active $\mathrm{Li}^{+}$into compounds deposited onto graphite anodes, both of which lower storage capacity [38]. Researchers have also proposed another mechanism of $\mathrm{Li}^{+}$that suggests that even monolayer $\mathrm{Mn}^{2+}$ can impede the movement of $\mathrm{Li}^{+}$through the graphite and the SEI [111]. As for $\mathrm{PF}_{5}$, it is produced from the decomposition of various electrolytes and can trigger the open-ring polymerization of EC, which further increases SEI decomposition along with the production of HF [112]. Moreover, the damage/repair process caused by gaseous $\mathrm{PF}_{5}$ consumes active $\mathrm{Li}$-ions until $\mathrm{Li}$-ions are depleted in the system [113]. Researchers have reported, however, that this degradation can be mitigated through the addition of Lewis-basic additives. The presence of $\mathrm{H}_{2} \mathrm{O}$ in electrolytes can also reduce the production of $\mathrm{C}_{2} \mathrm{H}_{4}$ (usually used as an indicator of $\mathrm{EC}$ reduction) and promote $\mathrm{H}_{2}$ production. Here, the existence of SEIs can reduce the reduction of trace amounts of water that usually generate $\mathrm{H}_{2}$ and $\mathrm{CO}_{2}$ [114].

An automotive scale NMC pouch cell was also analyzed by Dahn group using ultra-high precision cycling technologies, and it was revealed that the performance of graphite anodes was decisive and that corresponding capacity fading (proportional to $t^{1 / 2}$ ) was related to SEI thickness and was inversely proportional to the rate of SEI growth, suggesting that the gradual lowering of SEI thickening rates can lead to stable SEIs $[115,116]$. Here, alternative relationships proposed for SEI growth need to take stability as a factor into consideration [117].

\subsection{Summary}

Overall, the degradation of Ni-rich NMC-based cathodes originates from the insertion/desertion of $\mathrm{Li}^{+}$during charge/ discharge in which the expansion and contraction of crystal lattices (primary particles) gradually generates tension, leading to the cracking of secondary particles (Fig. 6). Electrolyte infiltration as well as oxygen release can further deteriorate this issue. On an atomic scale, $\mathrm{Ni}^{4+}$ can accumulate during charging because delithiation can elevate the valence state of Ni together with high-valence $\mathrm{Mn}$ and Co ions. And due to smaller radii, easier diffusion can lead to surface reconstruction (from rhombohedral to rocksalt), which can further inhibit $\mathrm{Li}^{+}$insertion/desertion. Moreover, increased voltage levels of high-valence ions can trigger side reactions such as the oxidization/decomposition of electrolytes and the further dissolution of NMC materials. Electrochemical potentials of electron-depleted $\mathrm{Co}$ and $\mathrm{Ni}$ can also fall below the fermi level of $\mathrm{O}^{2-}$, leading to the transfer of electrons from $\mathrm{O}^{2-}$ to transition metal ions and the release of $\mathrm{O}_{2}$ into systems, which can also cause electrolyte decomposition. Throughout the operation of Ni-rich NMC-based LIBs, four types of unwanted substances exist on the surface of cathodic particles, including other phases, surface impurities (carbonates and hydroxide), rocksalt structures and surface films. To 
Fig. 4 Crystal structures of a graphite (space group P63/mmc) and two major $\mathrm{Li}$ intercalation compounds, $\mathbf{b} \mathrm{LiC}_{12}$ and $\mathbf{c} \mathrm{LiC}_{6}$ (space group $P 6 / \mathrm{mmm}$ ). Different stacking of graphene layers with $\mathbf{d}$ the $\mathrm{AB}$ sequence in graphite and $\mathbf{e}$ the $\mathrm{AA}$ sequence in $\mathrm{LiC}_{12}$ and $\mathrm{LiC}_{6}$ (Reprinted with permission from Ref. [103]. Copyright @ $\odot 2018$, American Chemical Society). f Schematic of SEI formation and degradation on graphite anodes (Reprinted with permission from Ref. [31]. Copyright (C) 2005, Elsevier B.V. All rights reserved.)
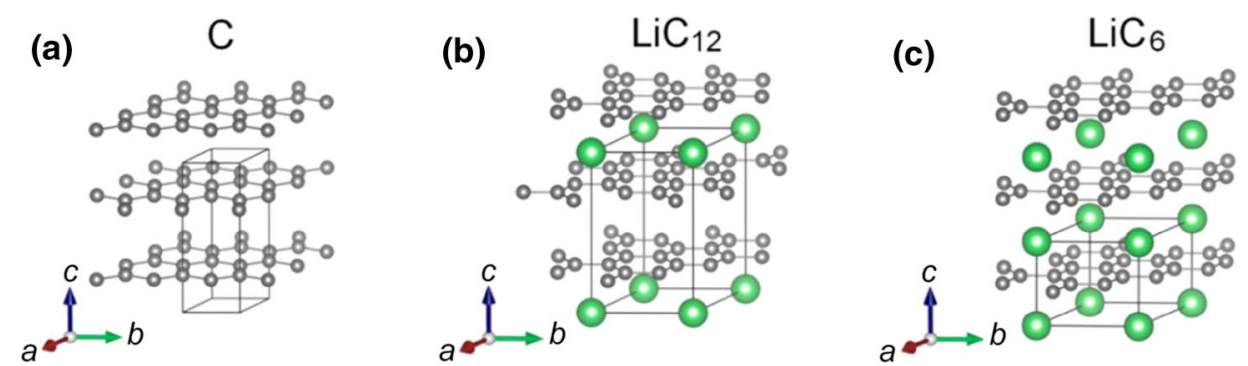

(e)

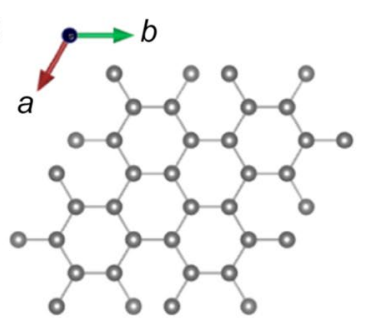

(f)
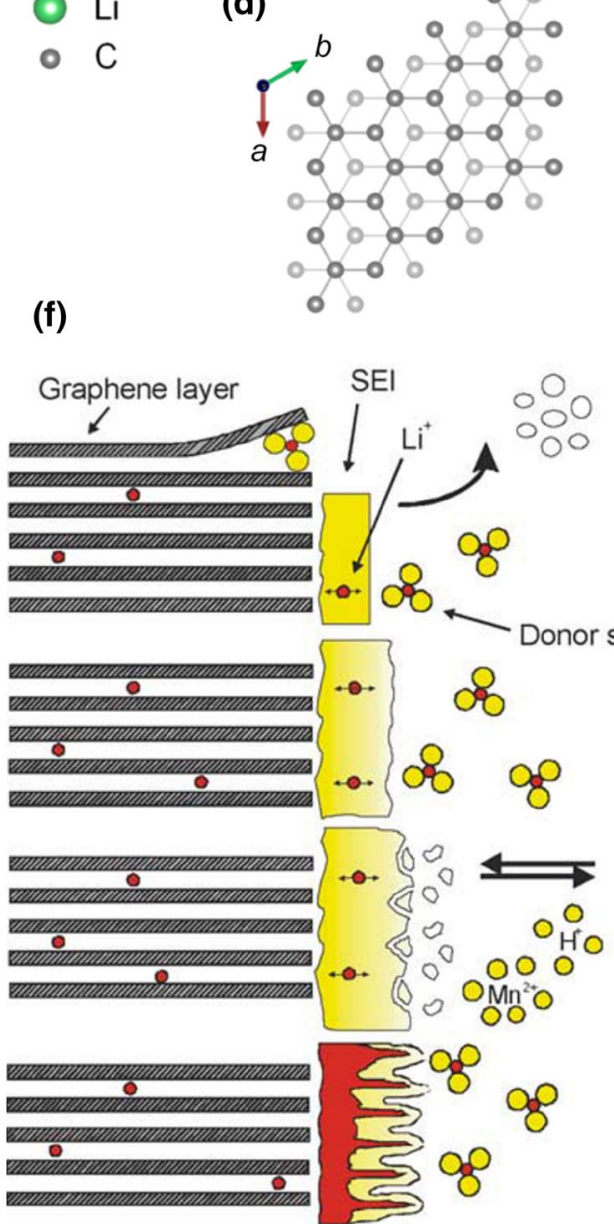

Graphite exfoliation, cracking (gas formation, solvent co-intercalation)

Electrolyte decomposition and SEI formation
SEI conversion, stabilization and growth

SEI dissolution, precipitation

Positive / Negative interactions

Lithium plating and subsequent corrosion sum up, aging effects on both micrometer and atomic scales can result in two common outcomes in which the first is the chemical (through chemical reactions) and mechanical (through the breakage of crystallites) damage/loss of active materials and the second is the production of detrimental substances on electrode particle surfaces, including surface films (both SEIs and CEIs), surface impurities and surface layers. And although many differences in the performance of various Ni-rich NMC-based cathodes have been discovered, these remain unexplained. Therefore, future studies should focus on the interpretation of different aging behaviors in NMCs with or without mitigation methods.
As for graphite anodes, degradation primarily occurs due to the plating of Li dendrites and the cracking of layered graphitic structures. In addition, SEIs tend to thicken during cell operation as EC solvent is reduced electrochemically. Furthermore, transition metals, especially $\mathrm{Mn}^{2+}$ from dissolved NMC, can cause significant capacity loss due to massive damage to SEIs. A comprehensive list of identified degradation mechanisms for Ni-rich NMC-based cathodes, graphite anodes, SEIs and CEIs is presented in Table 1. Here, the degradation mechanisms of SEIs are categorized based on anodes and the degradation mechanisms of CEIs 
(a)

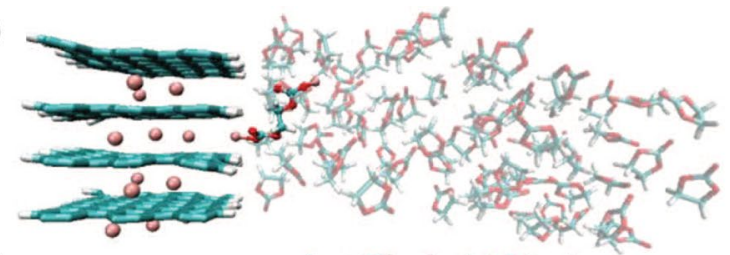

(b)

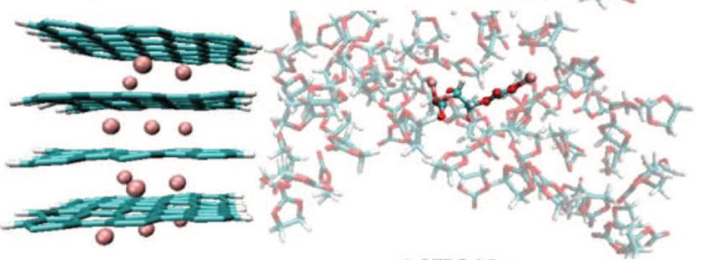

(c)

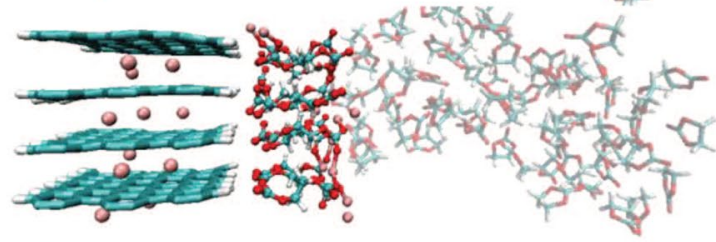

(d)

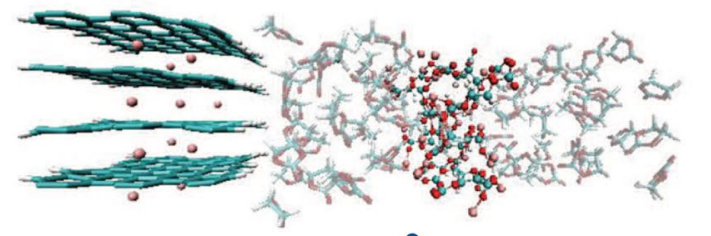

(e)

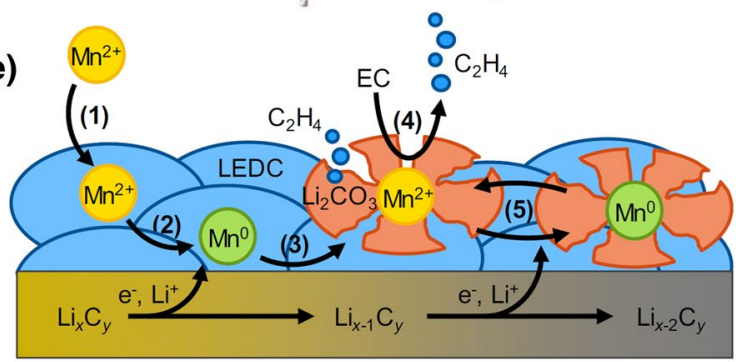

Fig. 5 DFT-MD snapshots of electrode/electrolyte interphases with $\mathrm{Li}_{2} \mathrm{EDC}$ : $\mathbf{a}$ adhesion structure of one $\mathrm{Li}_{2} \mathrm{EDC}$ monomer on a graphite electrode, $\mathbf{b}$ dissolution structure of one $\mathrm{Li}_{2} \mathrm{EDC}$ molecule in $\mathrm{EC}$ solvent, $\mathbf{c}$ adhesion structure of $12 \mathrm{Li}_{2} \mathrm{EDC}$ molecule aggregates on a graphite anode, $\mathbf{d}$ dissolution structure of $12 \mathrm{Li}_{2} \mathrm{EDC}$ molecule aggregates in EC solvent (Reprinted with permission from Ref. [108]. Copyright (C) The Author(s) 2015. Published by ECS). e Proposed mechanism for the continuous decomposition of SEI and electrolytes as monitored by $\mathrm{C}_{2} \mathrm{H}_{4}$ evolution for a preformed electrode with a $\mathrm{Mn}^{2+}$-containing electrolyte: (1) absorption of $\mathrm{Mn}^{2+}$ ions into the SEI; (2) reduction of $\mathrm{Mn}^{2+}$ ions in the SEI and deintercalation of $\mathrm{Li}^{+}$ from graphite; (3) re-oxidation of $\mathrm{Mn}^{0}$ to $\mathrm{Mn}^{2+}$; (4) recurrent electrolyte reduction; (5) the catalytic cycle of electrolyte decomposition (Reprinted with permission from Ref. [38]. Copyright (C) The Author(s) 2018. Published by ECS)

are categorized based on cathodes because certain degradation mechanisms may involve both electrode materials and interfaces.

\section{Diagnostic Tools}

\subsection{Electrochemical Techniques}

Throughout the development of LIBs, a variety of electrochemical methods have been employed to test, analyze and diagnose LIBs. To provide a comprehensive overview, these methods are categorized into three groups, including charge/ discharge tests, cyclic voltammetry (CV) and electrochemical impedance spectroscopy (EIS).

\subsubsection{Charge/Discharge Tests}

Charge/discharge tests include basic electrochemical characterizations that can be used to determine the voltage at which a certain reaction (including $\mathrm{Li}^{+}$insertion/desertion reactions that generate current in external circuits and side reactions that negatively impact cell performance) occurs and that can be used to evaluate the reversibility of cycling performances. Data from these charge/discharge tests can be analyzed by using many methods and can provide useful information on cell performance, reaction and reversibility, degradation and associated mechanisms.

Voltage versus capacity Charge/discharge curves are common and useful plots contained in almost every published study in the field of batteries. These plots are usually displayed in the format of voltage versus capacity (normalized by the mass of the active material) for a clear understanding of total capacity within a voltage range and capacity loss for certain cycles, including initial capacity loss (ICL), sudden capacity loss (SCL), gradual capacity loss (GCL) and voltage versus time. In some studies, the horizontal axis is changed to the content of $\mathrm{Li}$ in NMC compounds for easier comparison with physical characterization results in terms of lattice parameters/structures. Furthermore, the reversibility of cycling can be interpreted through these curves in which the presence of a reaction that can reconstruct the cathode at a certain voltage can be clearly predicted if the curve does not repeat itself in the next cycle after reaching that point [35]. Moreover, a small but important feature (a small peak) often found in the charge/discharge curve at the beginning of the initial charging can indicate the existence of impurities (most probably nickel hydroxide and nickel carbonate) during storage (a typical example showing the reaction of surface impurities of NMC811 after long-term storage during cycling is illustrated in Fig. 7a) [35]. Finally, the polarization of battery cells can be estimated by comparing the voltage levels of different cycles at fixed capacities.

Differential Capacity Curve Differential capacity curves are another kind of plots derived from charge/discharge curves [7, 
Fig. 6 Summary of degradation mechanisms of Ni-rich NMCbased cathodes on the micrometer and atomic scale

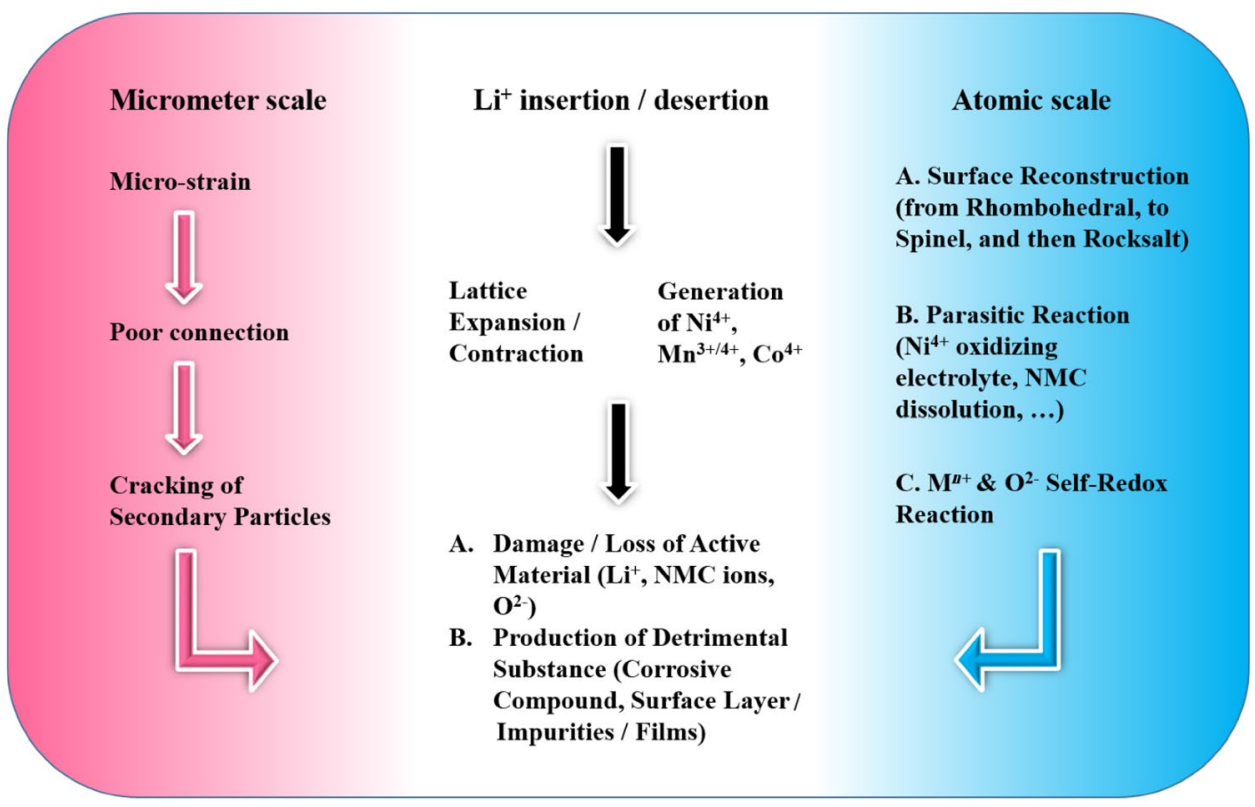

$20,118]$. These curves are also referred to as the incremental capacity and can be obtained by plotting $\frac{\mathrm{d} Q}{\mathrm{~d} V}$ versus voltage. (For similar reasons mentioned above, the vertical axis is converted to $\frac{\mathrm{d} x}{\mathrm{~d} V}$ in some cases, as shown in Fig. 7b.) The main use of these curves is to cross-check features already shown in charge/discharge curves at certain voltages but can also provide other information. Here, the most important feature revealed based on differential capacity curves for Ni-rich NMC-based cathodes is the phase transition in which three peaks can be identified in both charging and discharging processes, indicating phase transition from $\mathrm{H} 1$ (hexagonal) to $\mathrm{M}$ (monoclinic), and subsequently to $\mathrm{H} 2$ and $\mathrm{H} 3$ (see Sect. 2.1.1) as $\mathrm{Li}$ is extracted from the cathode [45]. In addition, differential capacity curves can be plotted with in situ X-ray diffraction results to correlate phases to corresponding lattice parameters [119]. Moreover, the loss of available Li between graphite layers or in the Li-rich layers of cathodes can be revealed through the fading of these peaks. And by integrating peak areas and calculating the ratio of these peak areas to the total charge/discharge capacities for each cycle, trends in the pathways/steps of Li transfer can be implied (e.g., more dominating, remaining the same or fading). Furthermore, the position of peak potential is indicative of cell impedance in which positive shifting during cycling implies an increasing cell impedance. Similarly, a differential voltage plot $\left(\frac{\mathrm{d} V}{\mathrm{~d} Q}\right.$ vs. $\left.Q\right)$ can be used to show the fluctuation of voltage during charge/discharge and is also linked to phase transitions [98].

Maximum Capacity To determine maximum capacity and associated fading, electromotive force (EMF) data [120] can be derived from the discharge curve of the same cell at different C-rates. Here, comparisons of EMF curves with charge/ discharge curves can reveal the impact of C-rates on cell degradation. In addition, discharge capacities at each time slot during discharge can be plotted versus corresponding C-rates and a trendline fitting of all data points taken at the same voltage can be drawn and extrapolate to the $Q$-axis, thus revealing the relationship between maximum capacity $Q_{\max }$ and voltage. Moreover, maximum capacity fading plots based on EMF curves can be used to determine capacity loss (irreversible capacity loss $\Delta Q_{\text {ir }}$ ) at different C-rates. Differential voltage curves can also be applied to EMF, and $\frac{\mathrm{d} V_{\mathrm{EMF}}}{\mathrm{d} Q}$ can be regarded as a nondestructive method in which peak shifting is indicative of cell degradation and can reveal anode material decay and voltage slippage effects [121].

Capacity Fading Capacity fading curves can provide more macroscopic views of capacity loss during long-term cycling and can be derived from capacity fading plots in which cell capacity at different conditions is displayed. And because electrode materials and aging conditions vary significantly in difference battery systems, the speed of capacity fading can also vary significantly. Therefore, the degree of cell aging needs to be normalized in which the vertical axis of capacity fading curves is sometimes converted to represent normalized capacity. A modified version has also been recently presented [16] to investigate the effects of the amount of $\mathrm{Li}^{+}$ions entering/exiting Li-layers in cathodes rather than focusing on the number of alterations. Here, an accumulative discharge capacity fading plot can be drawn and used to compare capacity fading in different currents, which can provide insights into the possible relationships between the amount of $\mathrm{Li}^{+}$transferred and structure deformations. 
Table 1 List of identified degradation mechanisms of Ni-rich NMC/graphite LIBs

\begin{tabular}{|c|c|c|c|c|}
\hline No. & Condition & Degradation mechanism & Electrode & References \\
\hline 1 & N/A & Initial SEI formation consuming active $\mathrm{Li}$ & Anode & {$[108]$} \\
\hline 2 & N/A & $\mathrm{Li}$ diffusion into the NMC layer & Cathode & [26] \\
\hline 3 & N/A & Sluggish Li diffusion back into the cathode & Cathode & [94] \\
\hline 4 & High voltage, high temperature & $\begin{array}{l}\text { Sudden capacity loss caused by surface film formation and thickening under } \\
\text { harsh conditions }\end{array}$ & Anode/cathode & {$[31]$} \\
\hline 5 & High SOC & $\begin{array}{l}\mathrm{Ni}^{2+} \text { migrating to vacant } \mathrm{Li}^{+} \text {sites (cation mixing), reducing the number of } \\
\mathrm{Li} \text { sites and blocking } \mathrm{Li} \text { diffusion pathways }\end{array}$ & Cathode & {$[51]$} \\
\hline 6 & N/A & $\begin{array}{l}\text { Structural changes from rhombohedral (layered) to spinel and later to rock- } \\
\text { salt (NiO, nickel carbonate and minor quantities of hydroxides) as a result } \\
\text { of massive cation mixing }\end{array}$ & Cathode & {$[64]$} \\
\hline 7 & Long cycling & $\begin{array}{l}\mathrm{Mn}^{3+} \text { forms a spinel structure from a layered (rhombohedral) structure } \\
\text { because of low octahedral site stability energy (based on studies of Mn- } \\
\text { rich NMC cathodes) }\end{array}$ & Cathode & [71] \\
\hline 8 & High SOC & $\mathrm{Ni}^{4+}$ oxidizing electrolytes and thickening CEI (self-discharge) & Cathode & [83] \\
\hline 9 & Storage in air & $\begin{array}{l}\text { Surface impurities formed on particle surfaces due to long-term storage in } \\
\text { air }\end{array}$ & Cathode & {$[35]$} \\
\hline 10 & N/A & $\begin{array}{l}\text { NMC dissolution in HF (less active sites and higher charge transfer resist- } \\
\text { ances) }\end{array}$ & Cathode & [74] \\
\hline 11 & Extreme high temperature & $\begin{array}{l}\text { Thermally unstable NMC reacting with } \mathrm{LiPF}_{6} \text { and causing thermal runa- } \\
\text { ways (fire and explosion) }\end{array}$ & Cathode & {$[33]$} \\
\hline 12 & N/A & $\begin{array}{l}\text { Release of reactive oxygen due to surface reconstruction causing chemical } \\
\text { oxidation of electrolytes to produce } \mathrm{CO} \text { and } \mathrm{CO}_{2}\end{array}$ & Cathode & {$[25]$} \\
\hline 13 & High voltage & $\mathrm{CO}_{2}$ produced from the electrochemical oxidation of electrolytes & Cathode & {$[87]$} \\
\hline 14 & High voltage (above $4.6 \mathrm{~V}$ ) & $\begin{array}{l}\text { Oxygen reducing metal ions due to the hybridization of electrons and orbit- } \\
\text { als (self-redox reaction) }\end{array}$ & Cathode & {$[82]$} \\
\hline 15 & Low voltage & Disproportion of $\mathrm{Mn}^{3+}$ (based on studies of Mn-rich NMC cathodes) & Cathode & [75] \\
\hline 16 & N/A & Carbonate layers reacting with electrolyte & Cathode & {$[35]$} \\
\hline 17 & Long cycling, high DOD & $\begin{array}{l}\text { Secondary particles cracking along grain boundaries and enlarging surface } \\
\text { areas for more side reactions to occur }\end{array}$ & Cathode & [13] \\
\hline 18 & N/A & Loss of active Li metal to SEI as immobilized during cell operation & Anode & {$[110]$} \\
\hline 19 & High voltage & $\begin{array}{l}\text { SEI layer decomposition facilitated by the precipitation of transition metals } \\
\text { into the SEI (huge capacity loss) }\end{array}$ & Anode & [38] \\
\hline 20 & N/A & $\begin{array}{l}\text { Volume expansion and contraction of graphite during operation cracking the } \\
\text { graphitic layer }\end{array}$ & Anode & {$[102]$} \\
\hline 21 & N/A & $\begin{array}{l}\text { Metal ions from the cathode inserting into the anode and blocking active } \\
\text { sites }\end{array}$ & Anode & [111] \\
\hline 22 & N/A & $\begin{array}{l}\mathrm{Mn}^{2+} \text { reacting at the surface of the anode to generate } \mathrm{Li}_{2} \mathrm{CO}_{3} \text {, which can } \\
\text { crack graphite surfaces }\end{array}$ & Anode & {$[38]$} \\
\hline 23 & N/A & Solvents getting into the holes of graphite & Anode & {$[31]$} \\
\hline 24 & N/A & Solvated $\mathrm{Li}^{+}$cracking graphite during $\mathrm{Li}$ intercalation & Anode & {$[110]$} \\
\hline 25 & N/A & $\begin{array}{l}\mathrm{Li} \text { dendrite plating (may trigger short circuiting if growth becomes too } \\
\text { large) }\end{array}$ & Anode/cathode & [104] \\
\hline 26 & N/A & Continuous thickening of surface films during cell operation & Anode/cathode & [37] \\
\hline
\end{tabular}

Note: N/A in the condition column indicates a common degradation mechanism occurring in many conditions; Only one representative reference is provided for each degradation mechanism because many of them have been reported extensively in many studies

Based on capacity fading plots, the number of electrons consumed by side reactions (both at the cathode and at the anode) can be measured by subtracting the discharge capacity by the corresponding charge capacity. Here, a charge efficiency (CE) plot focusing on the degree of side reactions is commonly used in which the charge efficiency of an anode can be calculated by $\frac{Q_{\text {discharge, },}}{Q_{\text {charge, } n}}$, because it describes the percentage of electrons charged to the anode that can be used to release $\mathrm{Li}^{+}$(remaining electrons consumed by side reactions during charging), whereas the number of electrons that can be discharged from the cathode can be calculated by $\frac{Q_{\text {charge }, n+1}}{Q_{\text {discharge, }}}$. And in general, the two percentages should be around $100 \%\left(\mathrm{CE}_{\text {anode }}\right.$ is a bit less, 


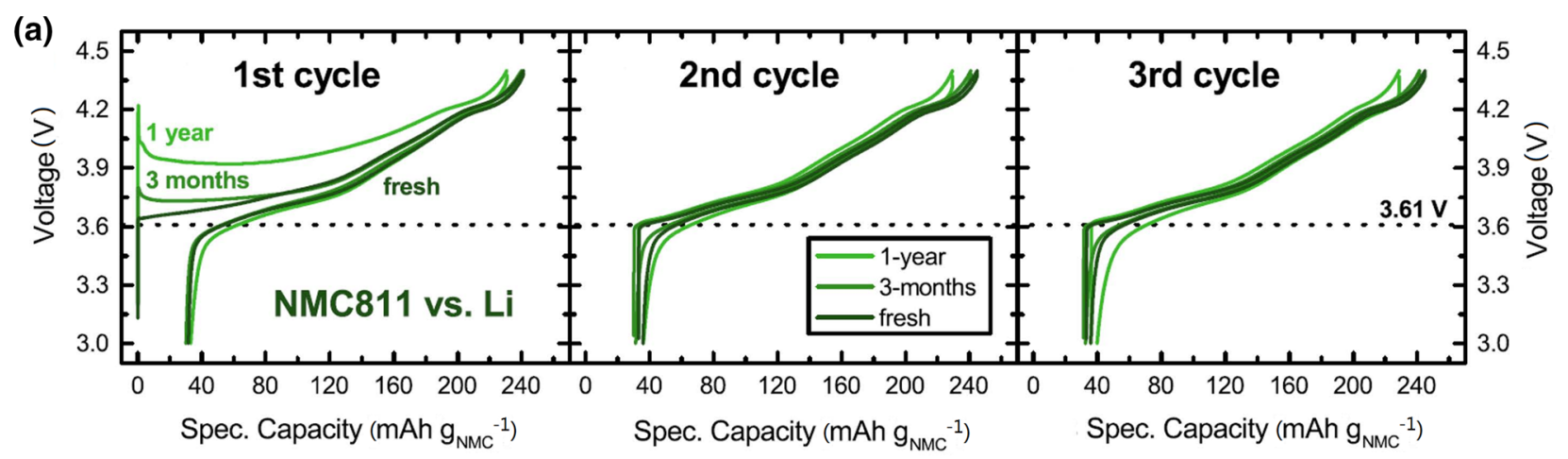

(b)

(d)

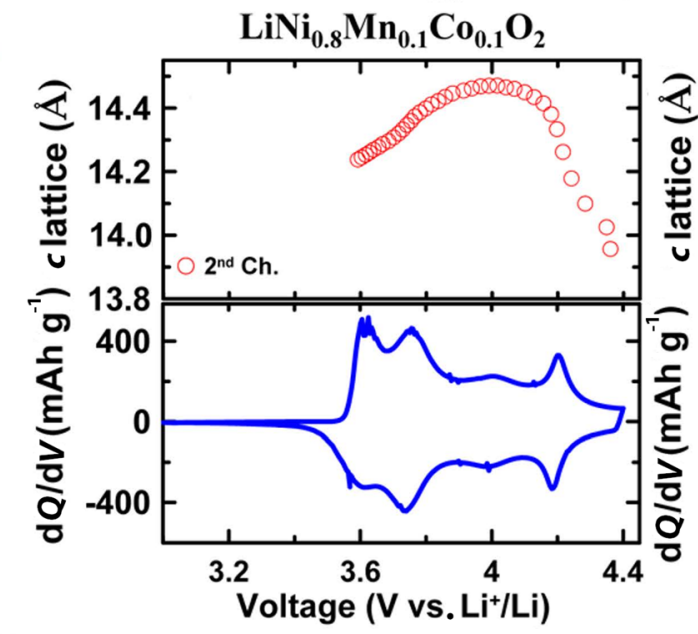

(c)
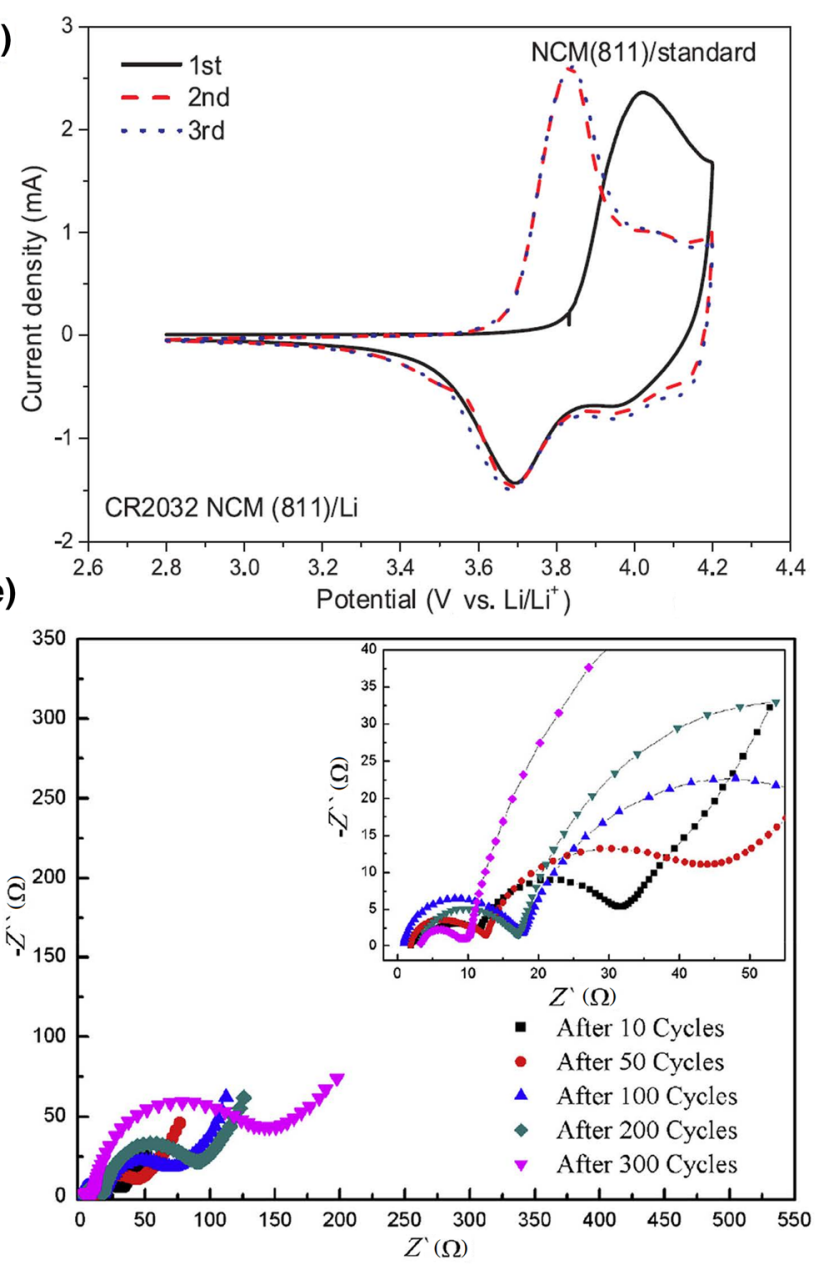

Fig. 7 a Charge/discharge curves of the 1st, the 2nd and the 3rd cycles of NMC811-Li (Reprinted with permission from Ref. [35]. Copyright (C) The Author(s) 2018. Published by ECS). b The $c$-lattice constant and differential capacity as a function of cell voltage for NMC811 ( $\mathrm{LiNi}_{0.8} \mathrm{Mn}_{0.1} \mathrm{Co}_{0.1} \mathrm{O}_{2}$ ) (3-4.4 V) (Reprinted with permission from Ref. [20]. Copyright (C) 2016, American Chemical Society). c Cyclic voltammetry of the first three cycles of an NMC 811/
Li coin cell (Reprinted with permission from Ref. [33]. Copyright (C) 2018, Elsevier B.V. All rights reserved.). d The Nyquist plot of NMC 811 (The inset: the equivalent circuit model used for data fitting). $\mathrm{e}$ The Nyquist plot of $\mathrm{SiO}_{2}$-coated NMC 811 (Reprinted with permission from Ref. [123]. Copyright (C) 2015, Elsevier B.V. All rights reserved.) 
but $\mathrm{CE}_{\text {cathode }}$ is a bit more); however, the existence of kinetic barriers may cause enlarged differences.

To study impedance growth during cycling, average polarization plots combined with discharge voltage decay plots can be obtained and can reveal capacity retention behaviors by measuring $\Delta V_{\text {ave }}$ increases, which can indicate impedance growth through cell degradation as well as potential kinetic barriers of $\mathrm{Li}^{+}$insertion/desertion [9].

\subsubsection{Cyclic Voltammetry}

As a supplementary method, cyclic voltammetry (CV) can be used to determine the reversibility of charge/discharge in electrodes by measuring the difference in charge/discharge peak potentials, which is related to major delithiation/lithiation processes (Fig. 7c) [33]. As such, CV can assist in the investigation of transition metal oxidation and reduction in which the plot of the initial $\mathrm{CV}$ can differ from subsequent cycles due to the formation of SEIs during the first delithiation. In addition, upper cutoff voltages can also be determined by using CV [122].

\subsubsection{Electrochemical Impedance Spectroscopy}

Electrochemical impedance spectroscopy (EIS) is another common method to investigate cell impedance evolution and degradation mechanisms and involves the application of $\mathrm{AC}$ sinusoidal waves (voltage or current) to target cells. Here, AC sinusoidal waves are applied at an amplitude with different frequencies because semicircles in resulting Nyquist plots can overlap with each other if represented processes occur in the same frequency range. In addition, half-cell EIS can be carried out with either 2-electrode symmetric cells (e.g., Swagelok 2-electrode symmetric configuration cells) or 3-electrode cells by installing a reference electrode in which the resulting EIS curve often involves a vertical short tail, two depressed semicircles (only if a half cell is tested) and a long tail at a certain degree to the horizontal axis from high to low frequencies. Here, the short tail usually appears at extremely high frequencies, indicating the inductance of cables, which is rarely seen in test results. Solution resistances can also be measured at the intercept of the short tail with the real $(Z)$ axis and therefore can be represented by a resistor. As for the first semicircle at high frequencies (usually a small one), this is indicative of the resistance of the CEI, and as the CEI continuously reacts (thickening and decomposing), the impedance cannot be taken as merely resistive. The second semicircle can be attributed to charge transfer at the cathode. (Double-layer capacitance is generated because of voltage decay across the interface.) In typical EIS curves, these semicircles can appear as depressed due to surface roughness (unevenness), which can cause varied capacitance from point to point. To address this, a resistor in parallel with a constant phase element (CPE) can be used to model each process. As for the long tail attached to the two semicircles in the EIS curve, this is related to mass-transfer resistance and therefore can be represented by using a Warburg element. During aging, both semicircles commonly increase (Fig. 7d, e), indicating large cell polarizations and thickened CEIs; however, with remedial efforts, the increase in both resistances (linked to both semicircles) can usually be reduced. For example, researchers have reported that impedance growth of surface films and charge transfer can be significantly reduced through a $\mathrm{SiO}_{2}$-layer coating of NMC811 (Fig. 7e) [123].

\subsection{Physical Techniques}

\subsubsection{Crystal Lattice and Particle Morphology}

$X$-ray Diffraction In situ and ex situ XRD methods are the most frequently used physical characterization methods to determine lattice parameters and crystal structures. Here, in situ XRD can be used to measure the evolution of lattice parameters (both $a$-axis and $c$-axis) of NMC-based cathodes during cycling [43]. For example, the use of in situ XRD can evidence the shrinking of the $a$-axis to a constant value and the expansion and rapid shrinking of the $c$-axis during delithiation in Ni-rich NMC cathodes through the shifting of (003) and (006) peaks to a lower angle together with the shifting of the (101) peak to a higher angle (Fig. 8a). In addition, in situ XRD can allow for the comparison of the lattice shrinkage percentage of the $a$-axis to that of the $c$-axis, leading to the conclusion that lattice shrinkage is anisotropic and that lattice parameters are linked to corresponding phases (H1, M, H2, H3). In situ XRD can also be used to test the thermal stability of NMC cathodes and show temperature-resolved (TR) results [42] similar to voltageresolved results. For example, TR-XRD results of heated NMC-based cathodes can be used to examine thermal stability in which researchers found that the structures of all NMC cathodes tested experienced surface reconstruction from rhombohedral to spinel (first the $\mathrm{LiMn}_{2} \mathrm{O}_{4}$ type and later the $\mathrm{Mn}_{3} \mathrm{O}_{4}$ type) and subsequently to rocksalt structure (Fig. 8b). In another study, in situ XRD plots were combined with gas chromatography-mass spectroscopy (GC-MS) data to reveal the relationship between the Li content and evolved gas from NMC-based cathodes [90].

Ex situ XRD with Rietveld refinement is easier to conduct than in situ XRD but conveys less information because it can only illustrate the crystal structure of NMC-based cathodes. For ex situ XRD data, more peaks can be seen if a bulk phase of impurities or coating materials is formed on the 
surface of cathode materials. Here, the ratio of $I_{003}-I_{104}$ in the ex situ XRD data indicates the degree of cation mixing and can be used to determine the ameliorative performance of a mitigation method in which ratios lower than 1.2 represent significant cation mixing. Moreover, the peak splitting of $(110) /(108)$ and $(006) /(102)$ represents a well-layered hexagonal structure (Fig. 8c) [45] and the evolution of the full width at half maximum (FWHM) of peaks represents change in crystallinity. Surface species can also cause peak shifting [e.g., (003) of NMC622] if stored [72], or generate new peaks, and therefore, ex situ XRD can also be used to cross-check the existence of impurities.

Microscopy and Electron Diffraction Scanning electron microscopy (SEM) and transmission electron microscopy (TEM) can be used to reveal microscopic structures of NMC-based cathodes and assess structural damage [124]. In addition, diameters of primary and secondary particles can be measured from obtained images together with the thickness of any surface coating layers [100]. Here, aggregates of primary particles, i.e., secondary particles, are usually observed in electron microscopy images possessing elongated or even needle-like shapes before degradation, whereas microcracks on secondary particles can usually be seen after repeated cycling, which can cause the breakage of particles. As a result, the spherical shape of secondary particles is usually distorted, and subfigures of SEM images obtained from samples aged under different conditions are usually displayed together for comparison. Another indispensable microscopic method is high-resolution transmission electron microscopy (HRTEM), which can reveal microregions of $F m 3 m \mathrm{NiO}$ and spinel structures and allow for the distance between atomic layers to be clearly marked (Fig. 9a shows a surface reconstruction region on a NMCbased cathode and an electron diffraction pattern of selected spots) [56, 70]. A drawback of HRTEM, however, is that it is unable to distinguish between phases with similar structures and lattice parameters [50].

Electron diffraction is a useful tool to characterize phases and microregions in NMC lattice crystals and includes selected area electron diffraction (SAED) and nano-beam electron diffraction (NBED, in which a condenser lens and an upper objective lens are used to achieve nano-beams of electrons). Here, Kang et al. [56] have used electron diffraction to measure the space group of NMC-based cathodes with the zone axis at the bulk and surface regions of a NMC particle. In addition, electron diffraction is usually conducted separately on different regions of particles such as surface regions, transitional regions and bulk regions. Here, the existence of secondary phases can be confirmed based on obtained patterns in which spinel structures can lead to an additional spot (Fig. 9a2-a5), whereas Fm3m space groups will show two strong diffraction spots that indicate the formation of rocksalt phases with high symmetry. Phase conversion can also be tracked and compared by using HAADFSTEM results [9].

High-angle annular dark-field scanning transmission electron microscopy (HAADF-STEM) measurements can provide array images of transition metal atoms located from the bulk to the surface of NMC particles and spectra of electron energy loss spectroscopy (EELS). Here, orderly arrays of atoms can clearly display layered structures of the crystal lattices of NMC (Fig. 9b) [63, 124, 125]. Here, the degree of surface reconstruction can be determined based on changes in atom patterns and a clear boundary between reconstructed and unreconstructed phases can be traced. In addition, region thicknesses can also be measured based on HAADF-STEM images.

\subsubsection{Chemical Analysis}

Elemental Analysis Elemental analysis is necessary for the physical characterization of NMC-based LIBs and the composition of NMC-based cathodes as well as the investigation of impurities and remedial coatings/dopants. In addition, the semiquantitative properties of various elemental analyses are useful in the quantification of relative increases/decreases of certain elements during operation or storage. Here, energydispersive spectroscopy (EDS) mapping analysis can illustrate elemental distributions ( $\mathrm{Li}$, transition metals, $\mathrm{C}$, etc.) semiquantitatively on cathode particle surfaces. For example, the dissolution of these surfaces through attack with HF can be evidenced by the increase in $\mathrm{F}$ element signals and the loss of transition metals.

Alternatively, electron-probe X-ray microanalysis (EPMA) accompanied with SEM can allow for the examination of transition metal element concentrations within different regions of NMC particles with a spatial resolution of $\sim 0.3 \mu \mathrm{m}$ and can often be used to determine the concentration gradient layer of modified-NMC particles [126]. Researchers have also reported that the average composition of $\mathrm{Ni}, \mathrm{Mn}$ and $\mathrm{Co}$ can be measured using atomic absorption spectroscopy (AAS) [126].

$\mathrm{X}$-ray photoelectron spectroscopy (XPS) is another elemental analysis method that can detect the chemical and electronic states of transition metals and oxygen in NMC cathodes as well as elemental carbon from current collectors and binders [73]. Here, the $2 p$ orbitals of $\mathrm{Ni}, \mathrm{Mn}$ and $\mathrm{Co}$ and the 1s orbital of $\mathrm{O}$ can be captured to reveal oxidation states by checking the peak positions of $2 p_{1 / 2}$ and $2 p_{3 / 2}$ (Fig. 9c) [127]. For example, the binding energies of $\mathrm{Ni} 2 \mathrm{p}_{3 / 2}$ in $\mathrm{NiO}$ and in $\mathrm{Ni}_{2} \mathrm{O}_{3}$ were found to be located at 854.0 and $856.0 \mathrm{eV}$, respectively [50]. In addition, the shift in oxidation states can be clearly shown by changes in peak positions, 

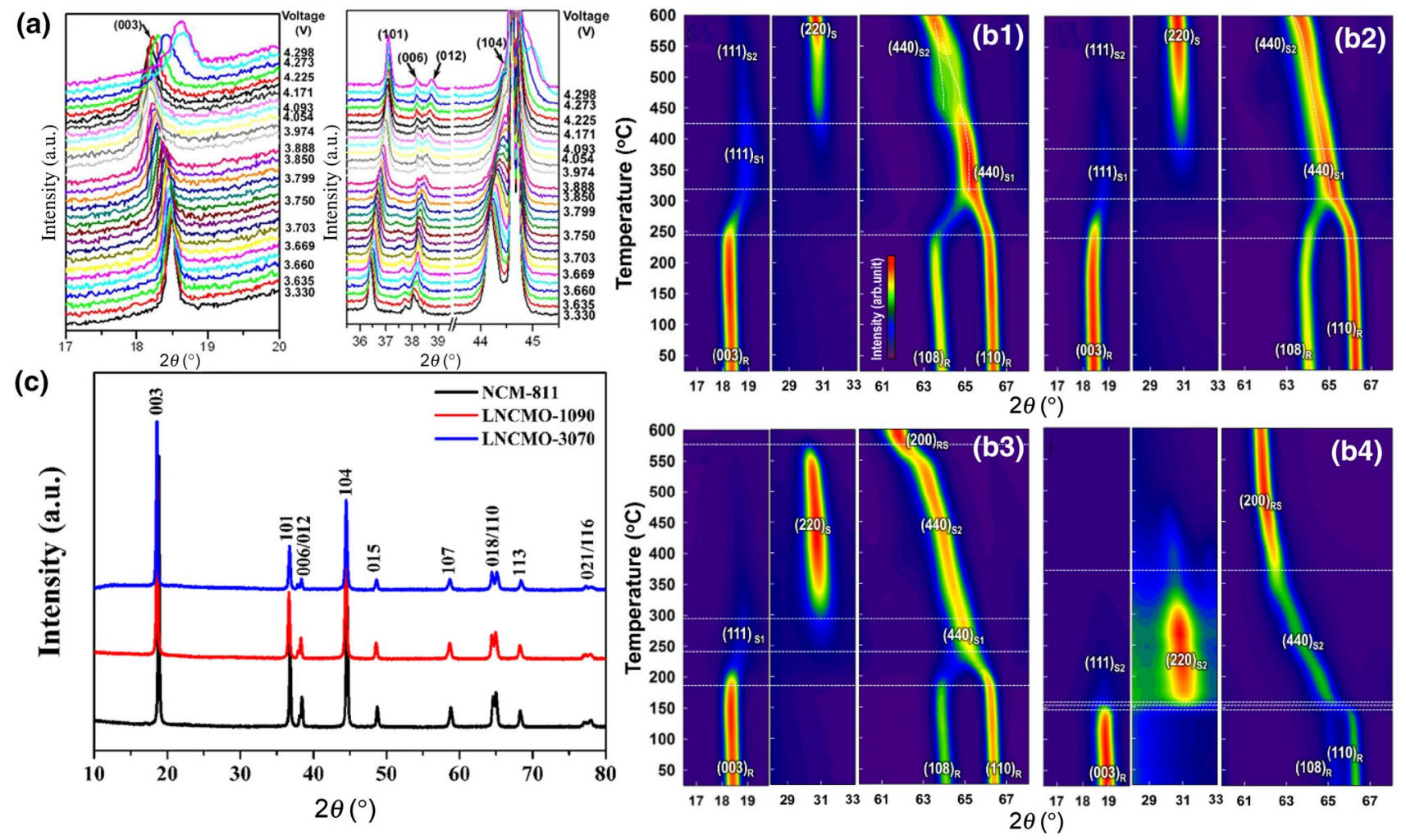

Fig. 8 a In situ XRD patterns of an NMC 811 cathode over a voltage range from 3.330 to $4.298 \mathrm{~V}$ during the first charge (Reprinted with permission from Ref. [43]. Copyright (C) 2015 WILEY-VCH Verlag $\mathrm{GmbH} \& \mathrm{Co}$. KGaA, Weinheim). b Contour plots of TR-XRD patterns at the selected $2 \theta$ range for charged b1 NMC433, b2 NMC532,

and changes in the amount of Ni can be deduced from the increase in peak area and intensity. Moreover, the use of cycle-dependent XPS can allow for the change of valence states to be attributed to a certain range of cycles, whereas a decrease in XPS peaks can indicate the loss of elements or the coverage of elements with surface impurities. Furthermore, XPS can enable the identification of new substances on cathode surfaces that evolve during storage or operation [35]. As for organic elements including C (1s), O (1s), F (1s), N (1s) and S (2p) that are contained in the components of SEI layers, XPS can also be used to track the existence of these elements in different molecules versus voltage [128].

To validate XPS data, X-ray absorption spectroscopy (XAS) can be used as a supplementary technique to monitor transition metal valence changes during charge/discharge and include extended X-ray absorption fine structure (EXAFS) and X-ray absorption near edge structure (XANES) [129]. For example, stronger $\mathrm{Ni}^{2+}$ signals over $\mathrm{Ni}^{4+}$ in NMC532 at $4.5 \mathrm{~V}$ reveal that the redox reaction of $\mathrm{Ni}^{4+}$ with electrolytes can occur, which reduces $\mathrm{Ni}^{4+}$ to $\mathrm{Ni}^{2+}$ [130]. And due to the viability of XAS in the examination of transition metal concentrations and oxidation states, XAS b3 NMC622 and b4 NMC811 (Reprinted with permission from Ref. [42]. Copyright (C) 2014, American Chemical Society). c Ex situ XRD patterns of NMC-811 and $\mathrm{Li}_{2} \mathrm{MnO}_{3}$-coated (10\% and 30\%) NMC-811 (Reprinted with permission from Ref. [45]. Copyright () 2016, American Chemical Society)

has also been widely utilized for anodic elemental analysis (e.g., transition metals deposited on graphite anodes) under various cycling conditions [113], leading to the discovery that the massive dissolution of Mn can occur if NMC111/ graphite cells are charged above $4.6 \mathrm{~V}$ [76].

Electron energy loss spectroscopy (EELS) is another elemental analysis method that can investigate elemental energy loss and possesses three modes, including auger electron yield (AEY), total electron yield (TEY) and total fluorescence yield (TFY), each of which provides information from different depths $(1-2 \mathrm{~nm}, 2-5 \mathrm{~nm}$ and $50 \mathrm{~nm}$, respectively). Due to smaller probing depths, EELS signals reflect information on the top layer of cathodes [63], and the shift in energy loss peaks from time to time or from the bulk to the surface can indicate shifts in oxidation states of elements, in which lower energy losses translate to lower oxidation states of transition metals [9]. In general, each EELS curve consists of two peaks, including a pre-edge peak and a primary peak. Here, the pre-edge peak of oxygen is thought to be caused by the transition of electrons from the $1 \mathrm{~s}$ to the unoccupied $2 p$ state, which can hybridize with the $3 \mathrm{~d}$ orbitals of transitional metals [66]. Alternatively, the primary 

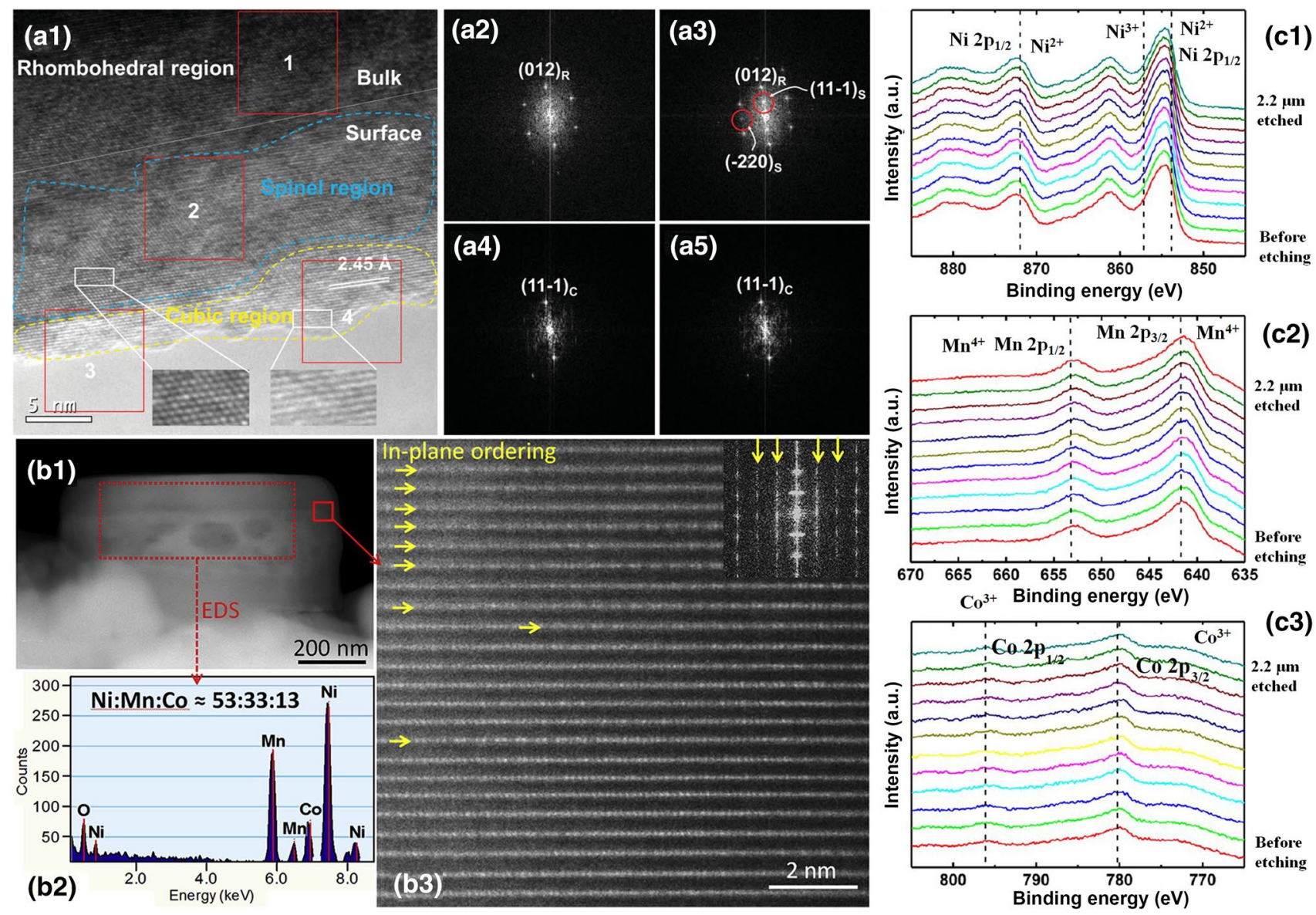

Fig. 9 HRTEM images and FFTs after 50 cycles under $3.0-4.8 \mathrm{~V}$ conditions. a1 Lattice image of the surface region where a2-a5 correspond to the FFTs of regions $1-4$, respectively. $(11-1)_{C}$ is the diffraction spot of the rocksalt phase of the metal monoxide (Reprinted with permission from Ref. [56]. Copyright (C) 2013 WILEY-VCH Verlag GmbH \& Co. KGaA, Weinheim). b1 Low-magnification STEM-HAADF image of one surface primary particle of the $x=0.10$ sample. b2 Corresponding X-ray spectrum from the highlighted area in (a). b3 High-resolution STEM-HAADF image showing the lattice structure from the highlighted area in (b1) (Reprinted with permission from Ref. [124]. Copyright (C) 2016, Elsevier B.V. All rights reserved.). c XPS data for lithiated FCG-Mn-F Li( $\left.\mathrm{Ni}_{0.60} \mathrm{Co}_{0.15} \mathrm{Mn}_{0.25}\right)$ $\mathrm{O}_{2}$ : c1 Ni 2p, c2 Co 2p and c3 Mn 2p (Reprinted with permission from Ref. [127]. Copyright (c) 2013, American Chemical Society) peak originates from the transition of electrons from the $1 s$ to the $2 \mathrm{p}$ state of $\mathrm{O}$ or to the $4 \mathrm{sp}$ state of transition metals. Moreover, area-integrated EELS data can be compared to check the homogeneity of NMC particles [63].

Electron paramagnetic resonance (EPR) spectroscopy can also be applied to NMC materials such as NMC622 to investigate the effects of doping with $\mathrm{Al}$ and $\mathrm{Fe}$ on cation mixing in which the change of the $\mathrm{Ni}^{2+}$ line indicates the redistribution of Ni within the structure. Hubert Gasteiger's group have also demonstrated Li plating onto graphite anodes quantitatively and in real time by using operando EPR [106] quantified the amount of Li-ions not available for future cycling. Despite these uses, EPR cannot provide more detailed structural information, which requires other physical characterization methods [131].

Inductively coupled plasma-atomic emission spectroscopy (ICP-AES or ICP) is a cutting-edge technique that can provide relatively precise information on the amounts of $\mathrm{Li}$ [132], transition metals [133-135] and impurities in examined samples in which concentrations can be indicated by the intensity of characteristic waves emitted from excited atoms or ions. In addition, changes in the elemental composition of electrodes or powder samples due to operation or modification can be reflected in ICP-AES data and the results (in ppm) are often compared with theoretical values or results obtained by using other elemental analysis tools to observe differences. Researchers have also combined ICP with mass spectroscopy in studies. For example, ICP-MS was used to reveal significant increases in the $\mathrm{Ni}$ content on graphite anodes related to the dissolution of Ni from NMC 811 cathodes [136] and was also used to conduct a series of Li content measurements in sampled electrolytes, including sample preparation procedures [137], in which the 
results were pre-calibrated with known Li concentrations and proved the credibility of the ICP-MS method.

Gas Measurement Ex situ gas measurements have been adopted by many researchers in the study of LIBs in which the volume of evolved gas is measured as the cell is charged to certain voltage levels $[9,85]$. Gas evolution under other conditions can also be measured, including the addition of electrolyte additives or under different compositions of $\mathrm{Ni}$, $\mathrm{Mn}$ and Co. And if combined with mass spectroscopy, the content of emitted gas can be identified (usually including $\mathrm{H}_{2}$, $\mathrm{C}_{2} \mathrm{H}_{4}, \mathrm{CO}$ and $\mathrm{CO}_{2}$ ) and allows for volume or moles versus voltage to be plotted with various curves related to different gases [24]. Furthermore, online electrochemical mass spectroscopy (OEMS) is a tool that can facilitate the detection of gas in real time and can quantify the amount of $\mathrm{H}_{2}, \mathrm{CO}_{2}$ and $\mathrm{O}_{2}$ from different mass to charge ratios $[23,90]$ in which gas evolution (e.g., $\mathrm{O}_{2}$ ) is related to cathode surface reconstruction (if aimed at cathodic processes) through comparisons of voltage profiles (or SOC) (Fig. 10a). Similarly, anodic processes with gas evolution can also be tracked by using OEMS. Researchers have also combined differential electrochemical mass spectrometry (DEMS) with differential electrochemical infrared spectroscopy (DEIRS) to identify and quantify gases emitted from NMC 532/graphite cells [84] and found that potential-resolved gas evolution partially originates from SEI formation. And if combined with thermogravimetry (TG), the mass loss of cells can be correlated to oxygen evolution from NMC-based cathodes heated to a certain temperature, showing that the majority of weight loss can be attributed to oxygen release as they both rapidly rise to around $175^{\circ} \mathrm{C}$ [85].

Impurities and Organics Raman spectroscopy can be used to determine the existence of surface impurities that can cause capacity fading such as nickel carbonate, lithium carbonate and nickel hydroxide [35]. Because of this, Raman spectroscopy is a useful tool in the identification of impurities produced during long-term storage (Fig. 3a). Similarly, Fourier transformed infrared spectroscopy (FT-IR) can be used to identify impurities on cathode surfaces [72] or organic coatings [138]. For example, the $\mathrm{O}-\mathrm{H}$ stretching mode from $\mathrm{LiOH}$ possesses a characteristic band between 3650 and $3200 \mathrm{~cm}^{-1}$ in corresponding FT-IR spectra, whereas 1450 and $870 \mathrm{~cm}^{-1}$ are regarded as characteristic peaks of the $\mathrm{C}=\mathrm{O}$ mode originating from $\mathrm{Li}_{2} \mathrm{CO}_{3}$ [61]. Raman spectra of NMC-based cathodes can also be voltage dependent to monitor band shifts of $\mathrm{A}_{\mathrm{lg}}$ and $\mathrm{E}_{\mathrm{g}}$ of Ni, Mn and Co. Moreover, FT-IR and Raman spectroscopy are widely used in the characterization of anodic graphite and SEIs because they can identify substances forming SEI layers such as lithium alkyl carbonates and therefore can reveal reaction mechanisms involved in the SEI formation process and present differences in mechanisms if multiple electrolyte additives are used [139].

\subsubsection{Thermal Stability}

Differential scanning calorimetry (DSC) is a method that utilizes microcalorimeters to measure heat flow from cells $\left(\mathrm{W} \mathrm{g}^{-1}\right)$ in which the thermal stability of NMC-based cathodes with/without electrolyte contact is recorded to reveal heat flow from the NMC-based cathode as it is heated to a certain temperature $[33,140]$. For example, in two NMCbased cathodes and $\mathrm{LiNi}_{0.7} \mathrm{Mn}_{0.3} \mathrm{O}_{2}$ with a concentration gradient layer, one major peak can be found for each DSC curve centering at a certain temperature in which a higher onset temperature of the DSC peak indicates better thermal stability (Fig. 10b) [126]. In addition, exothermic peaks can be integrated to calculate the amount of heat released, which can translate into the degree to which corresponding reactions occur [99]. Here, the application of common mitigation methods usually results in smaller exothermic peak areas and higher onset temperatures [100]. However, small endothermic peaks can also be seen for some cases, indicating the decomposition of Li salt in the electrolyte [101]. In addition, TG is often combined with DSC to record mass loss during the heating of NMC-based cathodes (Fig. 10c), including processes such as the addition of carbon matrixes to remedy cathode degradation [141] or the release of oxygen due to surface reconstruction [140], or through the loss of surface impurities and adsorbed species [72].

Accelerating rate calorimetry (ARC) is another method adopted by researchers to measure self-heating rates (SHRs) versus temperature $[8,142]$. For example, in the comparison of the SHR of 4 types of Ni-rich NMC-based cathodes (Fig. 10d), the onset temperature of a rapidly increasing SHR marks the upper limit of the temperature range for the safe operation of a cell [7] in which cathodes with higher SHR onset temperatures are considered to be better LIB cathodes for industrial applications. Isothermal microcalorimetry (IMC) has also been used to examine heat flow induced by polarization, entropy and parasitic reactions versus the state of charge of NMC811 and has revealed that heat flow originating from parasitic reactions can increase sharply if the relative SOC rises from 0 to 1 at certain voltages (Fig. 10e) [7].

\subsubsection{Advanced Physical Characterization}

Many advanced physical characterization methods have also been used by researchers to study LIBs. For example, 3D transmission X-ray tomography mapping [92] can be used to determine the distribution of transition metals in NMC particles in which 3D mappings can allow for elemental analysis within cross-sections at different depths. Surface potential mappings of NMC-based cathodes can also be conducted by using Kelvin probe atomic force microscopy (AFM) [143] in which smaller surface potentials can allow for easier electron 
Fig. 10 a Specific charge and $\mathrm{CO}_{2}$ and $\mathrm{O}_{2}$ evolution rate profiles versus cathode potential during the first and the second charges of four NMC-based cathodes (Reprinted with permission from Ref. [90]. Copyright (C) 2017, American Chemical Society). b DSC traces and $\mathbf{c}$ TGA curves of electrochemically delithiated FCG Li $\mathrm{L}_{0.25}\left(\mathrm{Ni}_{0.54} \mathrm{Co}_{0.16} \mathrm{Mn}_{0.30}\right)$ $\mathrm{O}_{2}, \mathrm{Li}_{0.25}\left(\mathrm{Ni}_{0.5} \mathrm{Co}_{0.2} \mathrm{Mn}_{0.3}\right) \mathrm{O}_{2}$ and $\mathrm{Li}_{0.27}\left(\mathrm{Ni}_{1 / 3} \mathrm{Co}_{1 / 3} \mathrm{Mn}_{1 / 3}\right) \mathrm{O}_{2}$ charged to $4.3 \mathrm{~V}$ (Reprinted with permission from Ref. [140]. Copyright @ 2014 WILEY-VCH Verlag GmbH \& Co. KGaA, Weinheim). d Self-heating rate as a function of temperature for delithiated NMC electrode samples reacting with electrolytes in accelerating rate calorimeter experiments (Reprinted with permission from Ref. [8].

Copyright (C) 2018, American Chemical Society). e Isothermal calorimetry measurements of heat flow of extracted polarization, entropy and parasitic reactions (Reprinted with permission from Ref. [7]. Copyright (C) The Author(s) 2015. Published by ECS)
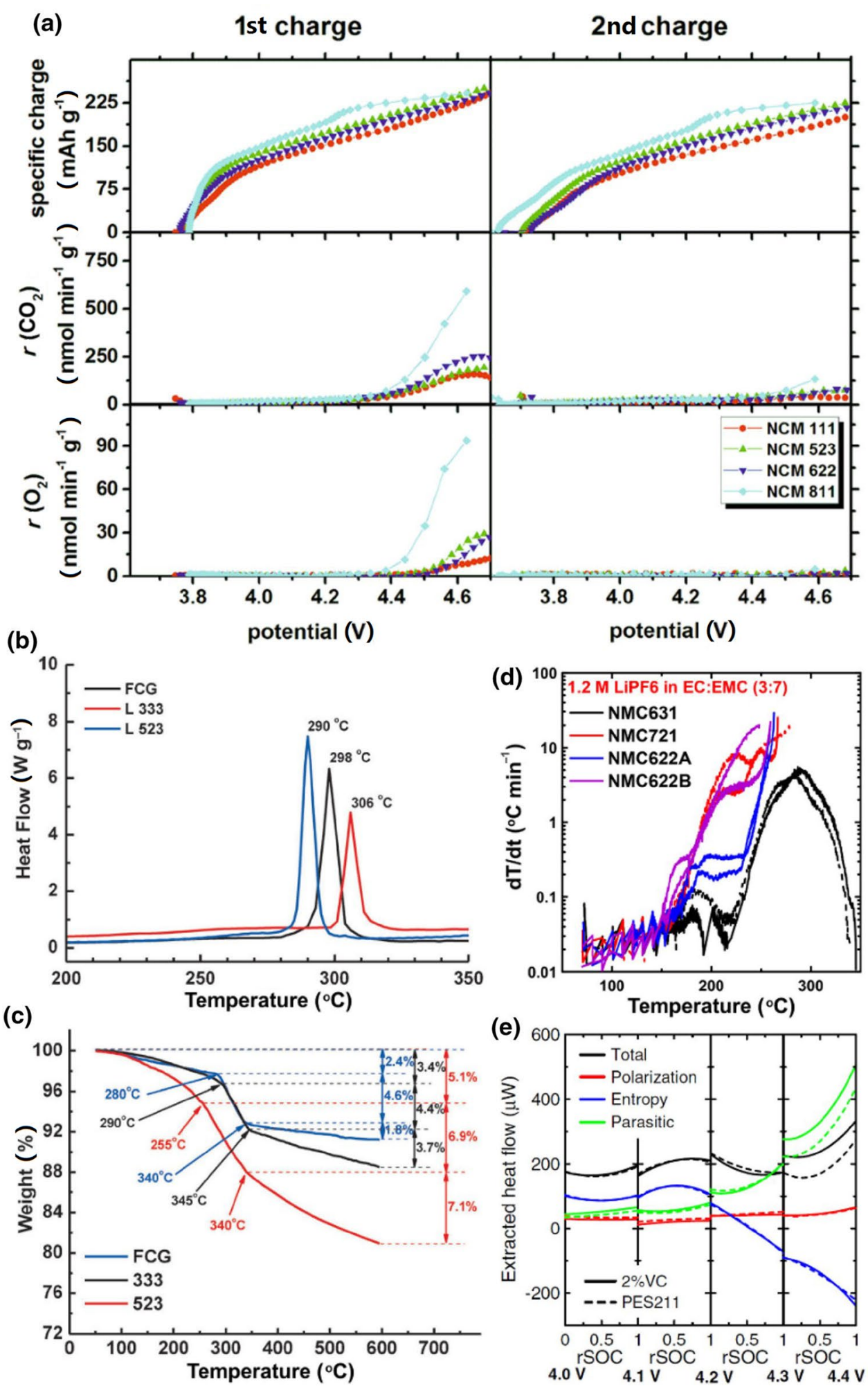

transfer from cathodes and therefore smaller polarizations. The use of nano-secondary-ion mass spectrometry (nanoSIMS) analysis can provide good spatial resolution (less than $50 \mathrm{~nm}$ ) for elemental mapping [144]. And with higher resolution, different phases can be identified by comparing the ratios of $\mathrm{Mn}$ to $\mathrm{Ni}$ along a direction across the particle. In situ neutron powder diffraction (NPD) can also be used to obtain more accurate results of lattice parameters as compared with in situ XRD [145], in which although the energy of neutrons is lower than X-rays, the penetration 
depth is higher. In situ NPD can also be used to determine the $d$-spacing of anodic graphite during $\mathrm{Li}$ intercalation and therefore the amounts of $\mathrm{LiC}_{6}, \mathrm{LiC}_{12}$ and $\mathrm{LiC}_{24}$ [44]. Despite these advantages, researchers have reported that hydrogencontaining species can attenuate neutrons. As for prompt gamma activation analysis (PGAA), this method can be used to quantify the amount of transition metals deposited onto graphite anodes by placing the sample in a neutron beam and collecting signals [26]. The use of PGAA allowed researchers to discover that cycling and high cutoff voltages can promote transition metal deposition onto graphite anodes.

\section{Mitigation Strategies for Ni-Rich NMC-Based Cathodes and Graphite Anodes}

\subsection{Ni-Rich NMC-Based Cathodes}

Ni-rich NMC-based cathodes suffer significantly more from capacity loss and impedance growth as compared with low $\mathrm{Ni}$ content NMC-based cathodes such as NMC111. This is because large amounts of $\mathrm{Ni}^{4+}$ on cathode surface regions can trigger side reactions and $\mathrm{Ni}^{2+}$ can cause cation mixing. In addition, excessive $\mathrm{Li}$ is usually added in the preparation of NMC-based cathodes and tends to accumulate on the surface of particles and react with electrolytes to convert to lithium carbonate and hydroxide. Furthermore, the continuous charging and discharging of these cathodes can cause the cracking of secondary particles.

To address these issues, researchers have proposed many strategies. One common method is the mixing of LMO with NMC [45, 118, 124], which can enhance capacity retention (not reviewed in this review because this method does not directly modify cathode particles) and another method involves the addition of electrolyte additives. Here, organic additives can be sacrificed at high voltages (4.3-4.5 V) because their HOMOs are higher than the HOMOs of organic solvents to preferentially lose electrons and be oxidized to prevent the oxidative decomposition of solvents [146]. In addition, the electropolymerization of electrolyte additives can also provide electrons to counteract the decomposition of solvents [147]. Moreover, the use of electrolyte additives can allow for the formation of more even CEIs on cathode surfaces [148, 149], which can reduce contact between electrode surfaces and electrolytes to prevent side reactions and lower impedance. One representative electrolyte additive is fluoroethylene carbonate (FEC) $[150,151]$ in which vinyl fluoride and $\mathrm{Li}_{2} \mathrm{CO}_{3}$ are produced as oxidation products during cell operation. Wang et al. [146] have also reported that 3-IPTS as an electrolyte additive can consume trace amounts of water in electrolytes to minimize the amount of HF produced from reactions between $\mathrm{LiPF}_{6}$ and water. Furthermore, Li salts can also be used to improve NMC-based cell performances. For example, $\mathrm{LiPF}_{6}$ can react with excessive alkaline $\mathrm{Li}$ on the surfaces of cathode particles to produce chemically stable $\mathrm{Li}_{3} \mathrm{PO}_{4}$ and $\mathrm{LiF}$, and significantly suppress parasitic reactions caused by excessive Li [152]. Surface coating is another commonly used strategy to separate NMC cathode surfaces from electrolytes [15], and atom substitution has also been reported to be effective in enhancing the performance of mitigated Ni-rich NMC-based LIBs. Based on these strategies, this review section will present techniques applied to improve the cycling performance of NMC cathodes in the most recent decade, in which cited studies are divided into categories based on the type of modification, including inner surfaces (doping/ gradient layers) and outer surfaces (coating/matrixes) of Ni-rich NMC-based particles. New synthesis methods of Ni-rich NMC cathodes that enhance performance without introducing new substances are also presented.

\subsubsection{Inner Surface}

Doping Doping can minimize side reactions on cathode particle surfaces and enhance the rate of Li diffusion and charge transfer. In addition, active material costs can be reduced if Co is substituted with other elements. To achieve doping/ atom substitution, researchers often use co-precipitation, solid-state reaction, self-combustion and co-calcination, in which the two types of doping include cationic doping and anionic doping. And in general, few dopants can affect the layered structure of electrodes, but some can form new phases (e.g., the presence of a $\mathrm{Li}_{2} \mathrm{SnO}_{3}$ phase in $\mathrm{Sn}$-doped NMC622 [153] and the presence of $\mathrm{Li}_{2} \mathrm{ZrO}_{3}$ in $\mathrm{Zr}$-doped NMC532 ${ }^{154}$ ).

Cation-doped surfaces of Ni-rich NMC particles can benefit from the lowered $\mathrm{Ni}$ content and therefore suppressed cation mixing [155]. Here, the selection of dopants is based on the bond energy of $\mathrm{M}-\mathrm{O}$ and the radius of dopant ions in which trade-offs between structural stability and $\mathrm{Li}^{+}$movement need to be considered. For example, strongly bonded dopants to oxygen can improve structural stability and reduce the amount of oxygen released [156, 157], but in most cases tend to withdraw more electron density from the $\mathrm{M}-\mathrm{O}$ bond, leading to the reduction in oxygen repulsion and the vertical contraction of the crystal lattice (Fig. 11a) [153], which negatively affects $\mathrm{Li}^{+}$movement due to increased kinetic barriers [158]. For easier lithiation/delithiation, increased distances between atomic layers in the lattice structure are desired and can be achieved by using dopants with larger radii. For example, dopants such as $\mathrm{Fe}^{3+}$ and $\mathrm{Sn}^{4+}$ (with radii larger than substituted $\mathrm{Co}^{3+}$ ) can expand Ni-rich NMC crystal lattices horizontally [145] and $\mathrm{Ca}^{2+}$ (with a radius larger than $\mathrm{Ni}^{2+}$ ) can expand lattices horizontally by substituting 
$\mathrm{Ni}$ at 3a sites [53]. Researchers have also reported that doping with $\mathrm{Al}$ can contract cathode lattices slightly due to the smaller radius of $\mathrm{Al}^{3+}$ [159]. Here, reported results of different cationic dopants can sometimes be contradictory in which enlarged lattices due to cationic dopants with larger radii can either promote (mostly reported) or hinder (blocking effect, rarely reported) $\mathrm{Li}^{+}$diffusion in different studies. Because of this, these results need to be comprehensively reviewed in the future $[154,160]$.

To achieve better cycling stability, capacity is sometimes sacrificed because some dopants such as $\mathrm{Al}^{3+}$ are chemically inactive [28]. Cr doping can improve cycling stability without capacity decrease [161], and $\mathrm{Zr}$ doping can enhance cycling performance $[154,162]$ but will reportedly produce a $\mathrm{Li}_{2} \mathrm{ZrO}_{3}$ phase. In addition, different dopants possess different valences and stabilize crystal structures at different sites. For example, $\mathrm{Mg}^{2+}$ possesses a similar radius to $\mathrm{Li}^{+}$ and will enter the Li-layer rather than the transition metal layer on the surface region of Li-rich NMC particles [125, 163], allowing for the suppression of cation mixing due to the repulsion of $\mathrm{Mg}^{2+}$ to transition metal ions and the delaying of the surface transformation to a spinel structure (Fig. 11b, c). Alternatively, $\mathrm{Na}^{+}$can substitute for $\mathrm{Li}^{+}$at 3 a sites $[52,164]$ to enlarge the distance between layers, and benefitting from the larger radius of $\mathrm{Na}^{+}$, cation mixing can be suppressed [165] and weakened $\mathrm{Li}-\mathrm{O}$ bonds can enhance potential capacity. However, because $\mathrm{Na}^{+}$doping can enlarge primary particles, optimal amounts are limited to ensure a connection between primary particles. Chen et al. have also suggested that the standard of choosing appropriate cationic dopants for NMC cathode improvements had not been established [53], whereas others have reported that ions with low valences were favored for $\mathrm{Li}^{+}$diffusion [166]. New methods of cation doping have also been proposed in which Mn doping into NMC71515 can provide an outer region with $F m 3 m \mathrm{Ni}^{2+}$ (reduced from $\mathrm{Ni}^{3+}$ ) residing in Li slabs (pillar structure) and can be used to consolidate the layered structure of cathodic crystal lattices and avoid particle degradation [167]. As for anionic doping, fluorine is usually used [168] and can expand both lattice parameters by reducing transition metal ions (mainly $\mathrm{Ni}$ and $\mathrm{Mn}$ ) [169] and increase mean charging voltages due to increased bond energy of $\mathrm{Li}-\mathrm{F}$ as compared with $\mathrm{Li}-\mathrm{O}$ [170]. In addition, fluorine substitution can protect cathode materials from HF. Furthermore, although bromine and sulfur atoms can be used to enhance NMC cathode performances, few studies have shown their effect on Ni-rich NMC-based cathodes. And currently, studies into the surface modification of $\mathrm{Ni}$ rich NMC-based cathodes have been insufficient and the effects of dopants such as $\mathrm{Ti}$ [171], $\mathrm{Zn}$ [160], $\mathrm{Cl}$ and $\mathrm{Br}$ [172] and their influences on Ni-rich NMC-based cathode cycling stability need to be further explored.
Gradient Layer Modifications of Ni-rich NMC-based cathode particles have been investigated by many studies in which a typical modification is a concentration gradient layer that can cover a Ni-rich NMC core [126, 173-175]. This concentration gradient layer design originates from a simple core-shell structure in which the shell (single or multiple) is composed of other NMC compositions (lower Ni content and higher Mn content) to stabilize the layered structure. And to overcome drawbacks of voids generated between the shell and the core during long-term cycling and mismatches of different lattice parameters, gradient layers were invented to replace core-shell structures. Here, the composition of the gradient layer is different from the core material, in which $\mathrm{Ni}$ atoms are gradually replaced by $\mathrm{Mn}$ atoms from the interface to the outer edge, resulting in a surface with higher structural integrity (Fig. 12a). Furthermore, concentration gradient layers can reshape primary particles into a rod-like structure, which can promote $\mathrm{Li}^{+}$movement by minimizing diffusion pathways [140]. This feature can be further magnified in needle-shaped structures for some cases and turned into plates if calcined [175, 176]. Modifications with concentration gradient layers can also prevent the separation of cores and shells caused by continuous expansion and contraction. Moreover, gradient layers can be extended into full concentration gradient (FCG) layers [175, 177, 178] and multiple gradient layers with different slopes can also be obtained to maximize the $\mathrm{Ni}$ content at the core as compared with single-sloped gradient layers [179]. For example, Noh et al. [127] reported a NMC (60 25 15) particle with a constant Mn concentration from the center to the surface and a gradually decreasing $\mathrm{Ni}$ and increasing Co concentration and found that the composition of the surface layer did not change significantly after long-term cycling.

\subsubsection{Outer Surface}

$L i_{x} M_{y} O_{z}$ coating $\mathrm{Li}_{x} \mathrm{M}_{y} \mathrm{O}_{z}$ coatings can be applied to the surface of primary particles to enhance performance and are composed of two subgroups. One group involves layered NMCs with different compositions/structures as compared with core Ni-rich NMCs and usually possesses higher Co or Mn content. Here, a Mn-rich NMC shell can significantly enhance the chemical and structural stability of $\mathrm{Ni}$ rich NMC cores $[180,181]$ in which studies have shown that the coating of Mn-rich spinel oxide onto Ni-rich NMC can significantly improve chemical stability in both operation and storage [144, 182]. The second group includes all other types of $\mathrm{Li}_{x} \mathrm{M}_{y} \mathrm{O}_{z}$ coatings (different transition metals or structures) and also includes pioneering works with disparate coating materials and methods in which $\mathrm{Si}, \mathrm{Zr}$, $\mathrm{Ti}$ and $\mathrm{Al}$ are usually used. For example, $\mathrm{Li}_{2} \mathrm{TiO}_{2}$ with a rocksalt structure can be coated onto NMC532 due to its superior structural integrity and strong adhesion to the core 
(a)

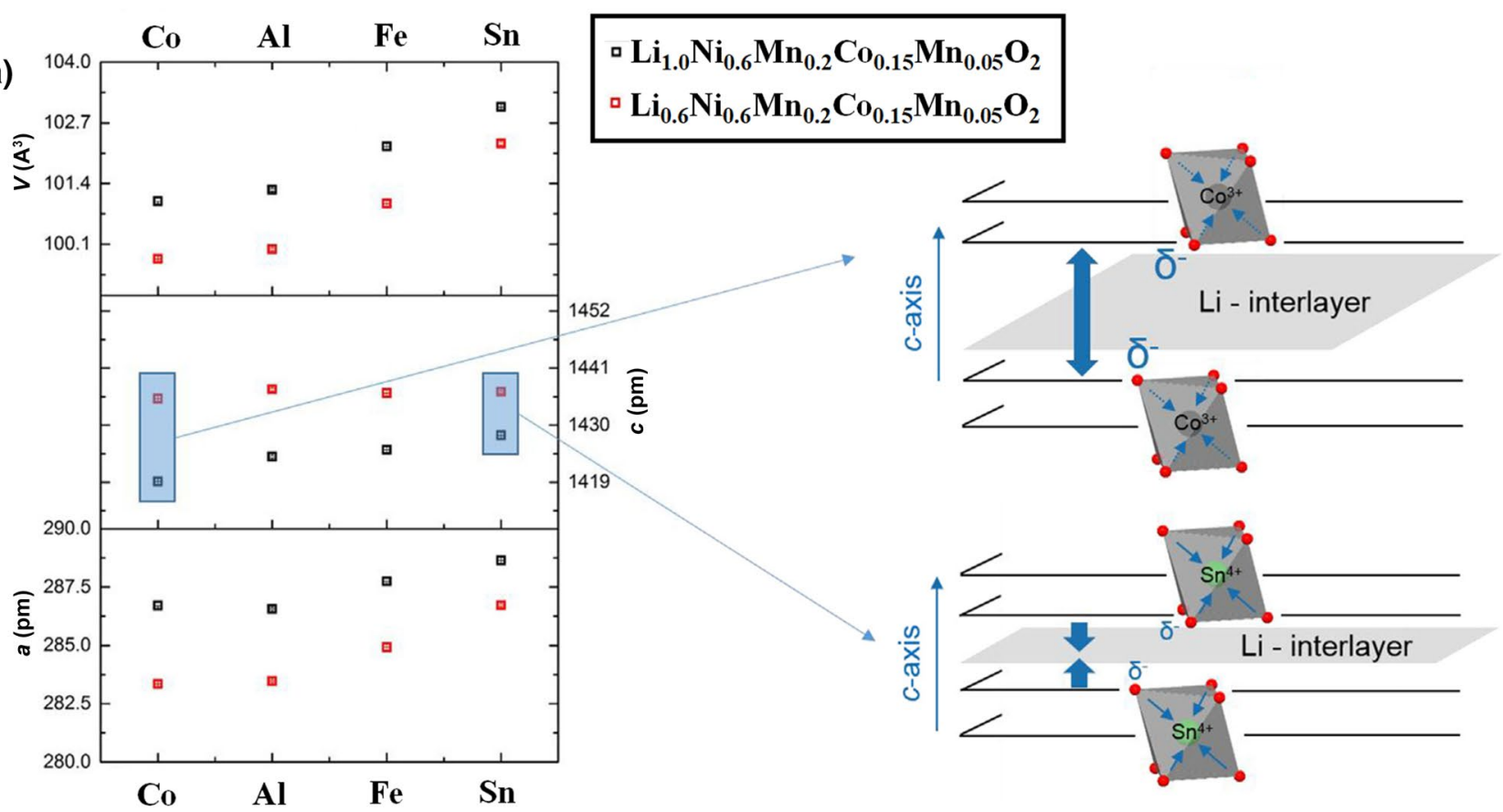

(b) Bare Li-rich
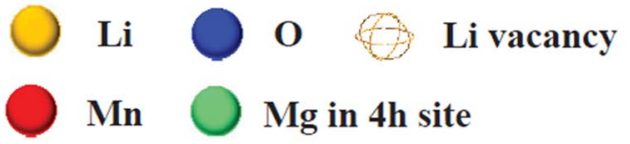

\section{Li vacancy}

Layered structure

Delithiated state

$\mathrm{Mg}$ in $4 \mathrm{~h}$ site

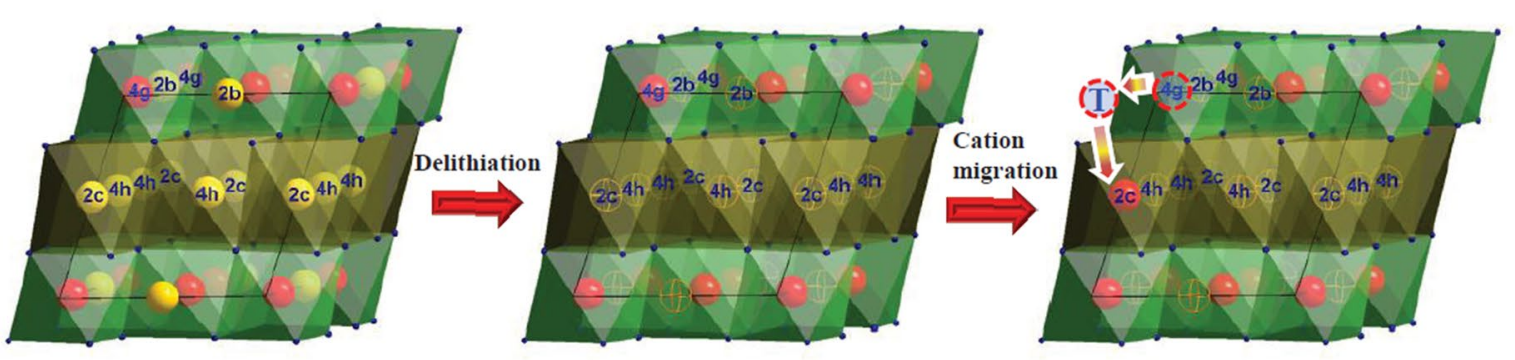

(c) Pillar effect

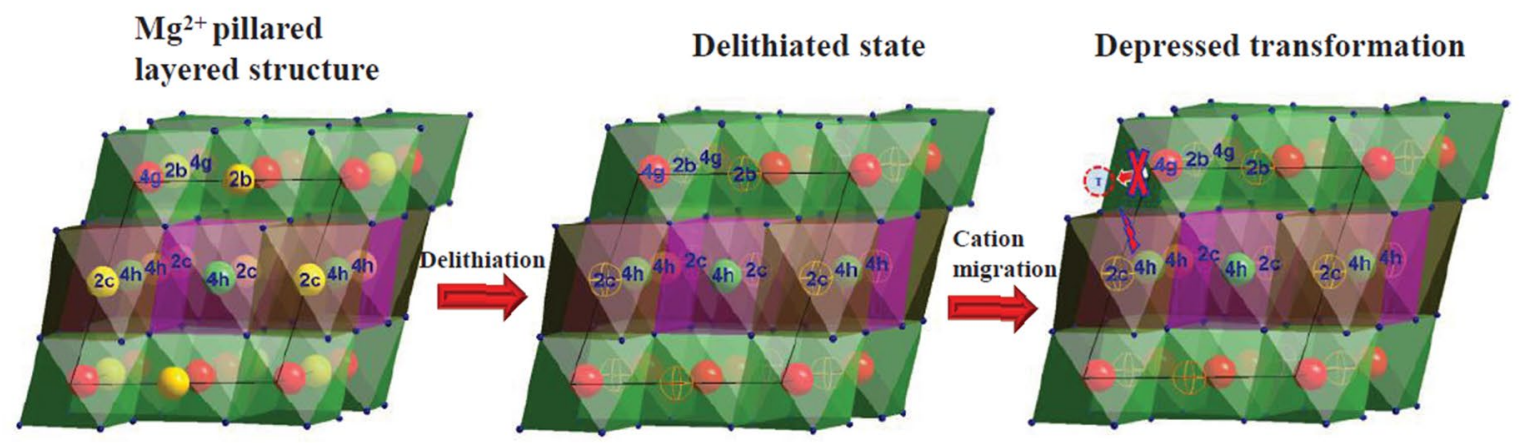

Fig. 11 a Lattice parameter trends of Co and Sn-doped NMC-622 cathode materials in fully lithiated (black squares) and 60\% delithiated (red squares) states (left) along with corresponding schematics of Li-interlayer movement along the $c$-axis due to doping effects (right) (Reprinted with permission from Ref. [153]. Copyright (C) 2018, Elsevier B.V. All rights reserved.) and structural evolution in bare and $\mathrm{Mg}^{2+}$ pillared Li-rich cathode materials. b Mn migration in bare Li-rich materials from the TM slab to the Li slab through the adjacent tetrahedral site. c Prohibition of $\mathrm{Mn}$ migration in $\mathrm{Mg}^{2+}$-doped layered oxide by electrostatic repulsion between $\mathrm{Mg}^{2+}$ and TM ions (Reprinted with permission from Ref. [125]. Copyright (C) 2015 WILEY-VCH Verlag GmbH \& Co. KGaA, Weinheim) 
[183] and an ionically conductive $\mathrm{Li}_{2} \mathrm{ZrO}_{3}$ coating layer on NMC71515 can form large islands of the coating material, protect the core and facilitate Li movement [184]. In addition, $\mathrm{Li}_{2} \mathrm{SiO}_{3}$ is also a promising coating material because it is a fast ionic conductor that can provide two pathways for $\mathrm{Li}^{+}$movement [(010) and (001) planes] [185]. Furthermore, a recent study using LPO infusion to coat NMC particles has gained much attention due to the creation of solid-solid interfaces in the gap between primary particles to replace liquid-solid interfaces, thus reinforcing the microstructure by shielding off liquid electrolytes and eliminating side reactions within secondary particles (Fig. 12b) [97]. Researchers have also suggested that other types of cathode materials with more cycling stability can be used as coating materials such as LFP [186].

Li-Free Coating Li-free coatings on the outer surface of NMC cathodes have been extensively investigated due to a unique advantage over doping in which the valence of transition metal ions remains unaffected and so does the theoretical capacity. Here, materials used for Li-free coating include transition metal phosphates [187], metal oxides [99, $188,189]$, fluorides [143, 190], silicon oxide [91, 100] and organic coating layers $[138,191]$ in which the general concept is to prevent cathode surfaces containing highly reactive $\mathrm{Ni}^{4+}$ from contacting the electrolyte and therefore to reduce side reactions. Here, coating layer thicknesses are usually between 5 and $40 \mathrm{~nm}$ and similar to doping, XRD measurements usually do not show new characteristic peaks and instead, existing peak widths/positions may change slightly. In addition, the metal ions in coating layers tend to diffuse into the cathode lattice and can change lattice parameters [192]. To meet the basic demands of coating materials, high conductivity (coatings tend to possess higher resistances and are even insulating, however) and firm adherence to NMC cathodes are preferred [138]. And to optimize cycling stability, the weight ratios of coating precursors need to be carefully estimated because excessive coating can block Li transport pathways and result in large polarization and low Li-ion diffusivity. This careful estimation of coating precursor weight ratios can also improve the uniformity and dispersity of precursor particles at the micrometer scale [141, 188].

Among various metal oxide coatings studied, $\mathrm{Al}_{2} \mathrm{O}_{3}$ has received the most attention due to multiple beneficial features (Fig. 12c) [12]. For example, Chen et al. have found that coating layers of $\mathrm{Al}_{2} \mathrm{O}_{3}$ and nano-TiO ${ }_{2}$ can suppress cation mixing $\left(\mathrm{Li}^{+}\right.$and $\left.\mathrm{Ni}^{2+}\right)$ as indicated by the ratio of $I_{003}-I_{104}$ in XRD $[99,188]$ and that $\mathrm{Al}_{2} \mathrm{O}_{3}$ layers can reduce self-redox reactions by introducing new energy levels to prevent the reduction of $\mathrm{Ni}$ ions by $\mathrm{O}^{2-}$. In addition, researchers have also found that $\mathrm{Al}_{2} \mathrm{O}_{3}$ surface coatings can maintain stabler CEI structures $[188,193]$ and that the atomic layer deposition (usually used to enhance coating uniformity through the precise control of coating thicknesses to several nanometers or even thinner) of $\mathrm{Al}_{2} \mathrm{O}_{3}$ on NMC532 [101, 130] can suppress parasitic reactions and phase transitions in which one study by Dahn group suggested that performance stabilizations were due to the protection of cathode surfaces to surface-oxidized species rather than the prevention of electrolyte oxidation [91]. Furthermore, researchers have also reported that the crystallization of amorphous $\mathrm{TiO}_{2}$ applied on NMC811 surfaces can result in $\mathrm{Li}_{2} \mathrm{TiO}_{3}$, which can further inhibit phase transformation from $\mathrm{H} 2$ to $\mathrm{H} 3$ [96]. The use of metal oxide layers has also been reported to be able to function as mediators of HF attacks due to the protection they can provide to NMC cores from corrosion [194].

The application of Li-free coatings can also lead to issues in Ni-rich NMC-based cathodes. For example, Park et al. have reported that excessive $\mathrm{Li}$ on cathode surfaces as caused by the coating of metal phosphate [187] can cause gas evolution due to its possible transformation into lithium carbonate and hydroxide as well as further side reactions with electrolytes [61]. However, researchers have also reported that the use of phosphate can lead to the formation of lithium phosphate [195] and lithium transition metal phosphate, both of which can maintain cell performance. Alternatively, $\mathrm{FePO}_{4}$ coatings have been shown to be resistive to cathode dissolution in electrolytes [192] and $\mathrm{V}_{2} \mathrm{O}_{5}$ coatings [189] applied through a wet coating method by using $\mathrm{NH}_{4} \mathrm{VO}_{3}$ were found to be capable of removing excessive Li. Moreover, the introduction of acids or metal oxides can allow for excessive Li on the surface of cathodic particles to transform into $\mathrm{Li}_{x} \mathrm{M}_{y} \mathrm{O}_{z}$ coatings at certain temperatures [196]. For example, researchers suggested that the use of excessive surface $\mathrm{Li}$ on NMC811 to form a protective layer consisting of $\mathrm{Li}^{+}$-conductive $\mathrm{Li}_{x} \mathrm{AlO}_{2}$ and superconductive $\mathrm{Li}_{x} \mathrm{Ti}_{2} \mathrm{O}_{4}$ [197] was a cost-saving and efficient method to resolve the issue of excessive $\mathrm{Li}$ and improve conductivity.

Organic coating layers possess a unique advantage of being stretchy, which allows for the absorption of internal microstrains and the mitigation of primary particle cracking [191]. And recently, a novel coating method using the transesterification of organophosphates has been reported [198] in which surface coatings were achieved through the replacement of $\mathrm{M}-\mathrm{OH}$ bonds of NMC622 with $\mathrm{M}-\mathrm{O}-\mathrm{P}$ bonds. Here, this novel coating differs from others because it can be achieved through the chemical deactivation of surface groups. Researchers have also reported that like doped fluorine, fluoride coatings can also be used to prevent HF attacks [190]. For example, $\mathrm{YF}_{3}$-coated NMC111 can exhibit enhanced electron transfer due to smaller surface potentials and reduced oxidation of electrolytes due to smaller work functions [143]. Despite these promising results, the number of studies into metal fluoride coatings on Ni-rich NMCbased cathodes is limited. Alternatively, sulfated $\mathrm{ZrO}_{2}$ as a 


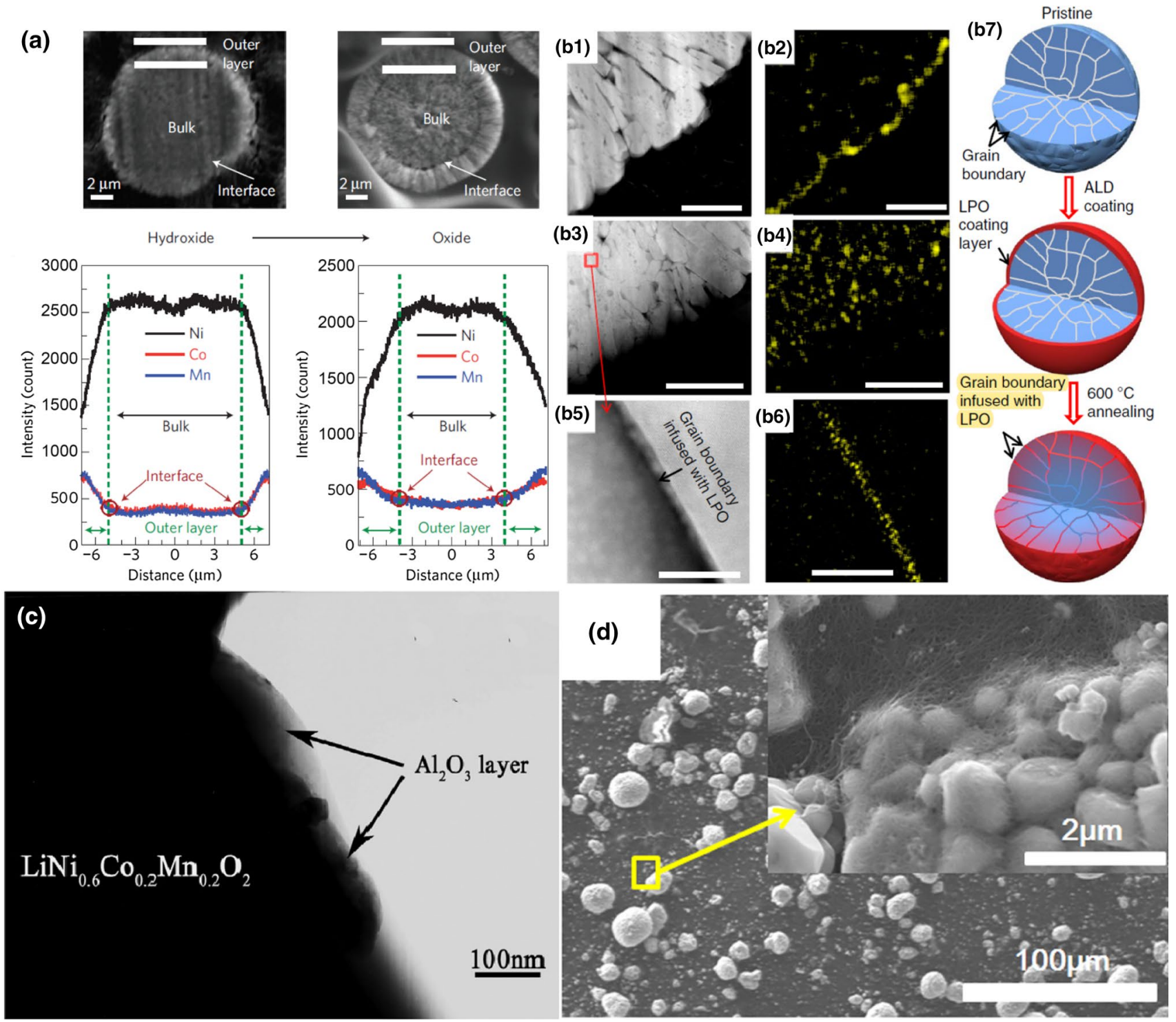

Fig. 12 a SEM and EPMA results of precursor hydroxide (left) and final lithiated oxide $\mathrm{Li}\left(\mathrm{Ni}_{0.64} \mathrm{Co}_{0.18} \mathrm{Mn}_{0.18}\right) \mathrm{O}_{2}$ (right) (Reprinted with permission from Ref. [126]. Copyright (C) 2009, Springer Nature). b STEM-HAADF images, EDS maps and schematic of an LPO-infused Ni-rich NMC layered cathode (Reprinted with permission from Ref. [97]. Copyright (C 2018, Springer Nature). c TEM image of $1.0 \mathrm{wt} \%$

coating material has shown particular promise [193]. This is because different from regular/ultrathin $\mathrm{ZrO}_{2}$ coatings [199], sulfated $\mathrm{ZrO}_{2}$ coatings can incorporate sulfate groups into coating layers and functionalize coatings by forming $-\mathrm{SO}_{3}{ }^{-}$- to stabilize CEIs on cathode surfaces, indicating that these coatings to a large extent are modifiable and functional groups can be added to gain additional functionalities. Researchers have also reported that graphene oxide-coated NMC532 does not possess a carbon matrix but a thin layer covering primary particles, allowing for the reduction of
$\mathrm{Al}_{2} \mathrm{O}_{3}$-coated $\mathrm{LiNi}_{0.6} \mathrm{Co}_{0.2} \mathrm{Mn}_{0.2} \mathrm{O}_{2}$ powder (Reprinted with permission from Ref. [188]. Copyright (C) 2014, Elsevier B.V. All rights reserved.). d SEM image of an NMC 532 cathode obtained through filtration with 5\% CNTs (Reprinted with permission from Ref. [202]. Copyright $@ 2014$, American Chemical Society)

surface impurities due to the coating separating the core from the atmosphere [200].

Carbon Matrixes A novel method to enhance the performance of Ni-rich NMC-based cathodes is to build carbon matrixes containing active material particles. Examples of this method include studies involving graphene nanosheets for NMC811, ${ }^{141}$ carbon nanotube conductive networks for NMC532 (Fig. 12d) [201, 202], and interwoven carbon fibers for NMC622 [203]. Here, the matrixes chosen are usually highly conductive carbon materials that can enhance charge 
transfer due to 3D connections. In addition, these matrixes can prevent side reactions and stabilize particle structures by fully covering primary cathode particles with a conductive matrix. Furthermore, carbon matrixes can enhance flexibility and strengthen adhesion between primary particles. Numerous unconventional and cutting-edge studies have also emerged in recent years involving the reshaping of aggregated NMC primary particles through the use of carbon matrixes. For example, multi-shelled alginate hollow fibers were used to template NMC primary particles, which allowed for the accommodation of $\mathrm{Ni}, \mathrm{Mn}$ and $\mathrm{Co}$ atoms within an organic fiber matrix that possessed pinholes to ensure $\mathrm{Li}^{+}$exchange [204].

\subsubsection{Advanced Preparation Methods}

Aside from materials for NMC development, preparation methods are also being investigated due to similar influences on the cycling/thermal stability of Ni-rich NMC materials, commonly allowing for the reduction of cation mixing. For example, Du et al. [154] have reported that NMC532 sintered in oxygen can exhibit lower degrees of cation disordering, less oxygen defects and higher discharge capacities. These researchers also reported that if $\mathrm{Ni}^{2+}$ was partially replaced by $\mathrm{Li}^{+}$, the remaining $\mathrm{Ni}$ existed as $\mathrm{Ni}^{3+}$, leading to capacity loss [154]. In addition, researchers have also reported that the atomization co-precipitation method can be used to obtain homogeneous spherical shaped primary NMC particles by forming an aerosol of precursors with an ultrasonic nebulizer [205] and that a similar effect can be achieved by using a self-combustion method, which produces massive heat flow to accelerate synthesis and therefore improve the uniformity of NMC particles [206]. Furthermore, nanoscale surface treatments utilizing Co and Li precursors combined with high-temperature sintering have been used to transform NMC622 surfaces into a Co-rich area with a NiO rocksalt phase that can act as a pillar layer to prevent inter-slab collapse [129]. Moreover, a hydrothermal procedure following the regular co-precipitation synthesis of NMC (70 15 15) can reportedly accelerate $\mathrm{Li}^{+}$entering and exiting $\mathrm{Li}$ slabs by making use of PVP to reduce crystal growth along the (001) plane and favor crystal growth along the (010) plane, which is an unimpeded pathway [207]. Dahn et al. [208] have also used a washing and reheating method to synthesize single crystal NMC622 in which superior performances as compared with multi-crystal NMC622 can be achieved if a remedial electrolyte additive was added. Carbonate coprecipitation and impregnation methods can also reportedly be combined to synthesize porous NMC622 microspheres that can effectively precipitate $\mathrm{Ni}^{2+}$ and shorten $\mathrm{Li}$ diffusion pathways [209].

\subsubsection{Synergy of Multiple Mitigation Methods}

Recently, many studies have focused on the synergy of two or more mitigation methods to achieve better overall Ni-rich NMC-based cathode performances in which the simplest examples involve multiple dopants or coatings. For example, $\mathrm{Al}$ and $\mathrm{Fe}$ can be co-doped into NMC622 [131] to combine the polarization effects of Fe with the lower chemical potential attributed to Al. As for multiple coatings, this can be achieved with the help of organic coating layers, which can supplement the insufficiencies of single-type coatings. For example, polypyrrole is a flexible and conductive polymer that is typically used in this type of modification in which researchers have reported a dual-conductive coating layer of polypyrrole on NMC811 primary particle surfaces that can convert excessive $\mathrm{Li}$ into $\mathrm{Li}_{3} \mathrm{PO}_{4}$ [191]. In another study, researchers coated a Zr-doped NMC532 with polypyrrole to form a network that prevented HF attacks [157].

Apart from coatings and dopants, a newly developed trend is to combine surface modifications with gradient layers, which can prevent phase transitions of NMC811 and NCA particles [210]. In addition, the cathodic doping of $\mathrm{Al}$ into NMC (61 27 12) with FCG has been reported to be able to consolidate and reduce grain boundaries and improve mechanical properties [211]. Moreover, researchers have combined gradient layers (the core) with Mn-rich surface coatings on NMC532 and reported that the valences of $\mathrm{Ni}$ and Co can be kept at lower states than regular NMC532 particles. Similarly, NMC811 with an exterior concentration gradient layer was uniformly coated with $\mathrm{Al}_{2} \mathrm{O}_{3}$ through freeze-drying and displayed better capacity retention as compared with untreated samples [212]. Furthermore, LiPON as a conductive material used to coat anodes can also reportedly be applied to NMC811 with a surface gradient layer to maintain rate capability and improve capacity retention [213].

\subsubsection{Summary}

Despite novel synthesis methods for NMC particles (which usually require more demanding conditions and extra procedures), modifications are usually applied to different parts of Ni-rich NMC primary particles to protect Ni-rich NMC cores. Among these, dopants and coatings are the most extensively studied methods. Here, dopants can affect surface elemental compositions and lower the Ni content, which is reactive and can generate spinel phases during cycling. In addition, dopants can expand/contract $\mathrm{LiNi}_{x} \mathrm{Mn}_{y} \mathrm{Co}_{1-x-y} \mathrm{O}_{2}$ lattices and influence $\mathrm{Li}^{+}$movement through bulk particles. Furthermore, dopants possessing different valances from substituted ions can affect the valences of $\mathrm{Ni}, \mathrm{Mn}$ and $\mathrm{Co}$ and therefore increase/decrease their capacity as the capacity is achieved by the change of valence of these elements. 
Additional effects such as the repulsion of cation disorder and the prevention of HF corrosion can also be achieved through doping. As for coatings, these can impact NMC performances by separating surfaces from electrolytes and hindering side reactions in which optimal performances can be achieved through the accurate estimation of the amount of coating applied.

\subsection{Graphite Anode}

\subsubsection{Testing Protocols}

The rate of charge, as limited by the production of plated $\mathrm{Li}$, can be increased by applying the constant-current constantvoltage (CCCV) protocol and the pulse charging protocol [105] in which Li concentration gradients are alternatingly enlarged and reduced during charging with the $\mathrm{CCCV}$ protocol and concentration differences between anode surface regions and bulk electrolytes are minimized in the pulse charging protocol.

\subsubsection{Surface Coating}

Aside from testing protocols, substantial barriers involving materials being applied to graphite surfaces through different means can fully separate graphite anodes from electrolytes, leading to significant reductions in the reductive decomposition of solvents, and subsequent conversion and thickening as well as the suppression of exfoliation. For example, LiPON as a recently investigated material can be evenly coated onto graphite anodes and can protect the anode from high-temperature storage aging [214].

\subsubsection{Electrolyte Volume Adjustment}

The performance of full cells is strongly dependent on the amount of accessible active material. And because both electrodes and the separator in full cells are porous, they need to be sufficiently wetted. In addition, electrolyte volumes can also be increased to maximize the amount of accessible active material; however, higher electrolyte volumes do not directly translate into higher capacities in which researchers have reported that excessive electrolytes tend to decrease performance because higher fractions of SEIs can dissolve into increased electrolyte volumes [215]. This principle is also valid in pouch cell studies showing the lowering of impedance and increase in cycling stability [216].

\subsection{SEI}

\subsubsection{Electrolyte Additive}

LIBs need to be safely transported and operated. Here, the addition of relatively small amounts of electrolyte additives can improve overall cell safety without the introduction of any detrimental products. For example, vinylene carbonate (VC) is one of the most extensively utilized electrolyte additives because it can improve compatibility between SEIs and graphite anodes by forming a thin film to separate electrolytes from graphite anodes and enhance the performance of ionic liquid-based electrolytes [128]. Researchers have also hypothesized that VC can reduce SEI thicknesses by inhibiting electron transfer from graphite anodes to solvents. Despite many positive influences of VC as reported by Dahn group [107], researchers have also suggested that the highly resistive film formed with $\mathrm{VC}$ can facilitate $\mathrm{Li}$ plating [217] and that the polymerization of VC can limit LIB lifespans. Here, many additives have been tested to replace VC to resolve polymerization issues in which FEC [139], PES [218] and VEC have been used to reinforce SEIs because they possess higher LUMOs that can prevent the reductive decomposition of $\mathrm{VC}$ by sacrificing themselves (Fig. 13a, b). In addition, FEC can form an SEI that is durable to fast charging, thus eliminating Li plating on graphite anodes [219]. Researchers have also reported that the use of FEC can suppress [139] or slow down [220] SEI formation (formation of lithium alkyl carbonate) to result in a thinner SEI. The use of co-solvents can also lower the viscosity and the melting point of solvents and therefore be useful in practical cases (Fig. 13c). For example, 2\% PES with 1\% DTD and 1\% TTSPi (PES211) can enhance the cycling performance of NMC cells based on its composition [142]. Researchers have also reported that PTSI as a less investigated additive can generate better SEIs with less inorganic components in which due to the presence of $\mathrm{S}=\mathrm{O}$ groups, $\mathrm{PF}_{5}$ can be suppressed as delocalized $\mathrm{N}$ cores can act as weak base sites [112]. And more recently, 3-sulfolene (3SF) as a film-forming agent was used to reduce electrolyte reduction [221]. Additives that stabilize SEI can be divided into two subgroups including SEI formers and SEI modifiers [222] and phenyl carbonate, regarded as a "modifier" additive, can outperform VC by maintaining low impedance and gas production in $\mathrm{NMC111/graphite} \mathrm{pouch} \mathrm{cells} \mathrm{and} \mathrm{there-}$ fore can be used to stabilize cells [222]. In addition, phenyl carbonate can remain stable until $4.2 \mathrm{~V}$ and possess good compatibility with $2 \%$ vinylene carbonate (VC). And since electrolyte additives can be multi-functional because certain types of additives can react with electrodes to produce gas if cells are overcharged to unsafe voltages, which results in pressurized internal environments that can deactivate cells [222], the ability to reduce gas production makes phenyl 


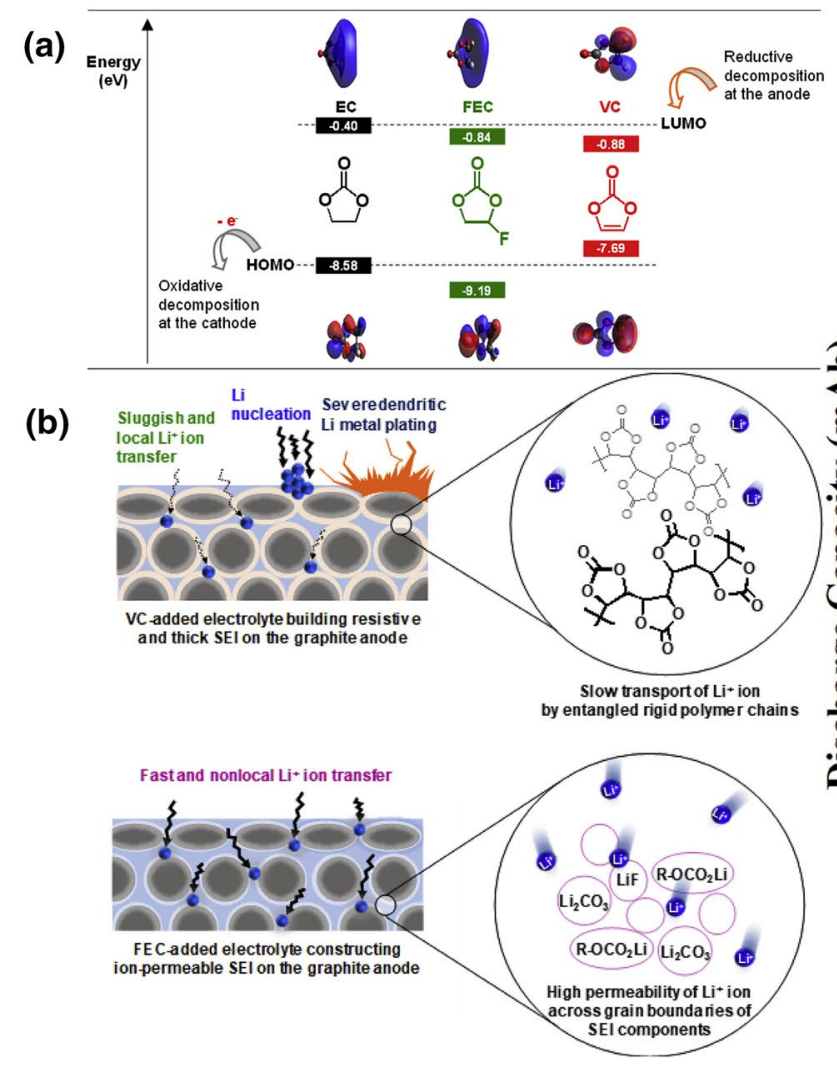

Fig. 13 a HOMO and LUMO energy levels of EC, FEC and VC. b Schematic showing the effects of VC- and FEC-derived SEIs on the fast charging capability of graphite anodes (Reprinted with permission from Ref. [219]. Copyright (C) 2018, Elsevier B.V. All rights reserved.). c Up: capacity versus cycle number for NMC111/graphite pouch cells (unclamped) containing select additives or additive

carbonate a promising type of electrolyte additives. Furthermore, PBF and PPF as electrolyte additives have also been reported to be able to positively enhance SEIs [36].

\subsubsection{Lithium Salt}

A simple method to enhance the quality and durability of anodes and SEIs is to raise the concentration of $\mathrm{Li}$ salts to above $3 \mathrm{M}$ [223], which can significantly reduce polarization that can lead to negative effects such as dendrite growth and slow charging. In addition, the resulting solvation of $\mathrm{Li}$-ions possesses a disparate structure from regular Li-ions in which the planar shape of the solvated $\mathrm{Li}$-ions benefits from $\mathrm{Li}$ intercalation and can mitigate graphite exfoliation with smaller spaces being occupied during operation [223]. Advanced Li salts have also been widely investigated to obtain better performances with promising results; however, few have been commercialized. In addition, a new group of Li salts (Fig. 14) have been reported to significantly enhance the performance

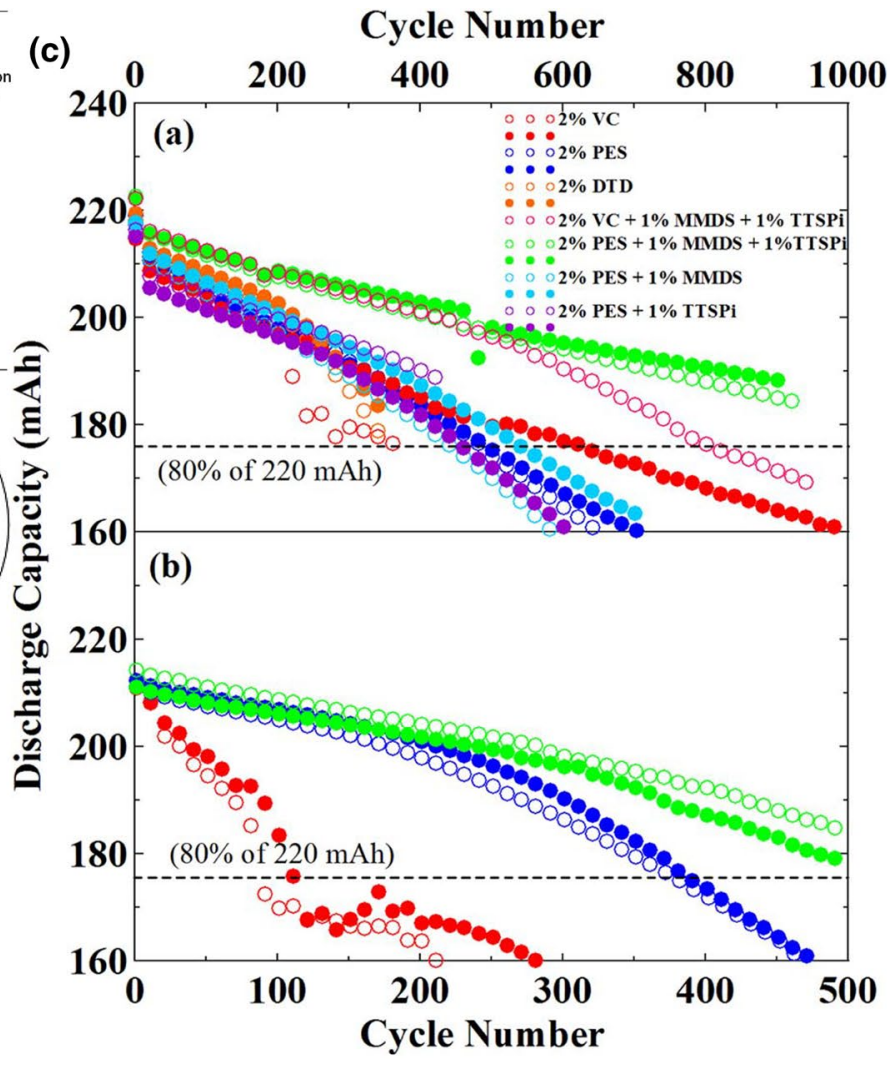

blends. Cycling was conducted between 2.8 and $4.2 \mathrm{~V}$ at $55{ }^{\circ} \mathrm{C}$ at $80 \mathrm{~mA}$. Bottom: capacity versus cycle number for NMC442/graphite pouch cells (unclamped) containing select additives or additive blends. Cycling was conducted between 3.0 and $4.4 \mathrm{~V}$ at $45{ }^{\circ} \mathrm{C}$ at $100 \mathrm{~mA}$. (Reprinted with permission from Ref. [142]. Copyright (C) The Author(s) 2015. Published by ECS)

of SEIs with capping agents such as oxalate in which the capping agents can reductively decompose electrolytes and prevent $\mathrm{LiF}$ from aggregating into large particles, thus producing $\mathrm{LiF}$ nanoparticles $5 \mathrm{~nm}$ in diameter uniformly in SEIs [224]. Furthermore, the reduction in LiF aggregation and the formation of nanostructured $\mathrm{LiF}$ can form uniform regions for $\mathrm{Li}^{+}$diffusion and reduce lithium plating (Fig. 15). Researchers have also reported that LiTFSi can outperform conventional $\mathrm{LiPF}_{6}$ salts due to its resistance to trace amounts of water and therefore minimize the production of harmful species [225].

\subsubsection{Solvent}

The polarity and the viscosity of solvents also need to be considered in the selection of appropriate solvents for $\mathrm{Li}$ intercalation/deintercalation in which solvents with lower viscosity can facilitate $\mathrm{Li}^{+}$transportation and decrease impedance, whereas the polarity of a solvent can determine the degree of solvation of $\mathrm{Li}^{+}$inside [225]. Here, ethyl methyl carbonate and dimethyl carbonate are usually 

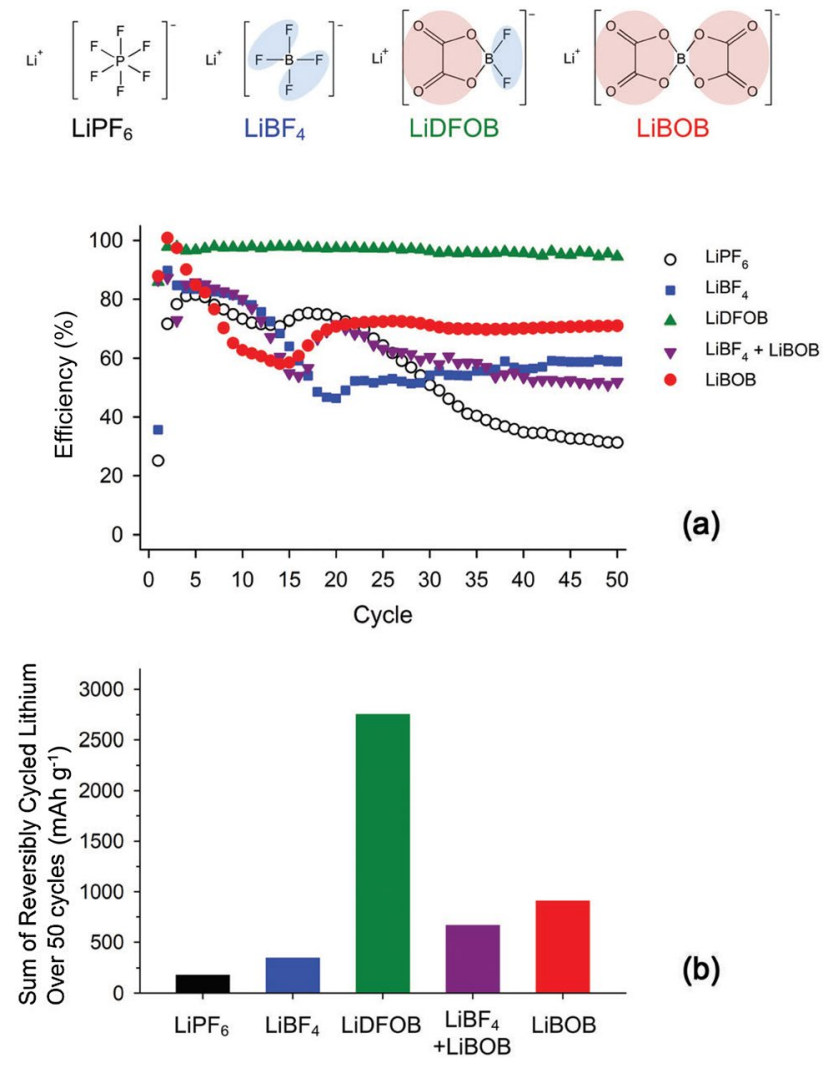

(b)

Fig. 14 Comparison of a Coulombic efficiency versus cycle number and $\mathbf{b}$ the total sum of reversibly cycled Li over 50 cycles obtained from $\mathrm{LiFePO}_{4} / \mathrm{Cu}$ cells (Reprinted with permission from Ref. [224]. Copyright (C) 2018, The Royal Society of Chemistry)

considered [219]. In addition, ionic liquids as substituents of conventional solvents can form thicker SEIs with highcapacity retentions at $90{ }^{\circ} \mathrm{C}[226]$.

\section{Summary and Prospective}

LIBs using Ni-rich NMC-based cathodes such as NMC811 can produce high specific capacities (200-220 $\mathrm{mAh} \mathrm{g}^{-1}$ ) and promising energy densities $\left(\sim 800 \mathrm{Wh} \mathrm{kg}^{-1}\right)$ in comparison with conventional $\mathrm{LiCoO}_{2}\left(\sim 570 \mathrm{Wh} \mathrm{kg}^{-1}\right)$ and $\mathrm{LiMn}_{2} \mathrm{O}_{4}$ spinel $\left(\sim 440 \mathrm{Wh} \mathrm{kg}^{-1}\right)$ materials. Because of this, these materials have received extensive attention from researchers. However, due to low portions of manganese as structural stabilizers, large amounts of $\mathrm{Ni}^{4+}$ on cathode surface layers/regions can trigger side reactions and $\mathrm{Ni}^{2+}$ can cause cation mixing. As a result, enhanced massspecific capacity comes at the expense of rate capability and structural stability in these Ni-rich cathode materials, leading to severe capacity fading. In addition, other factors such as active material dissolution, oxygen release and the intergranular cracking of primary particles also contribute toward cathode degradation. Alternatively, graphite anodes can function collaboratively with NMC-based cathodes to provide promising performances at cell levels. However, the aging of graphite anodes due to the formation of dendrites as caused by the massive plating of $\mathrm{Li}^{+}$onto graphite surfaces remains the main reason for increased impedance. Furthermore, side reactions involving electrolyte reduction (SEI formation) on graphite anodes can cause Li loss after initial charging, and the thickening and decomposition of SEIs in subsequent cycles can cause aging behaviors.

To gain a deeper understanding of degradation mechanisms of Ni-rich NMC/graphite LIBs, emerging testing protocols and characterization methods have emerged in which currently, research on LIB degradation is focused on the elucidation of the degree of capacity fading in certain mechanisms so as to distinguish major factors and allow for the design of specific remedies. And as a result of this research, mitigation strategies, functioning individually or synergistically, have been proposed to resolve long-term cyclability issues, most of which have proven to be promising. Among these, dopants, gradient layers, coatings (both Li-free and Li-contained), carbon matrixes and advanced synthesis procedures have become mainstream methods to enhance the performance of Ni-rich NMC-based cathodes. In addition, coatings, advanced protocols and the use of new electrolyte components can be applied to ameliorate anodic performances (SEIs and graphite). And with these mitigation strategies, the morphology, element composition and reactivity of electrodes can be improved.

Although differences in the performance of various $\mathrm{Ni}$-rich NMC-based cathodes have been discovered, these remain unexplained and the future of degradation mechanism investigations needs to rely on more advanced physical techniques such as X-ray tomography, operando neutron diffraction and online electrochemical mass spectroscopy, all of which can provide more comprehensive information in operando and be less destructive to cells. And for the deeper understanding of mitigation strategies for Ni-rich NMC/graphite LIBs, trade-offs in modification techniques and controversies need to be taken into considerations. Here, several prospective research directions for $\mathrm{Ni}$-rich $\mathrm{NMC} /$ graphite LIBs are proposed:

1. Future experiments should focus more on the quantitative interpretation of different aging behaviors in NMCbased cathodes with or without mitigation methods as well as the understanding of correlations between different degradation mechanisms.

2. Efforts should be made toward profiling the performance of LIBs under harsher conditions (stressors) that more closely represent practical operational conditions. 

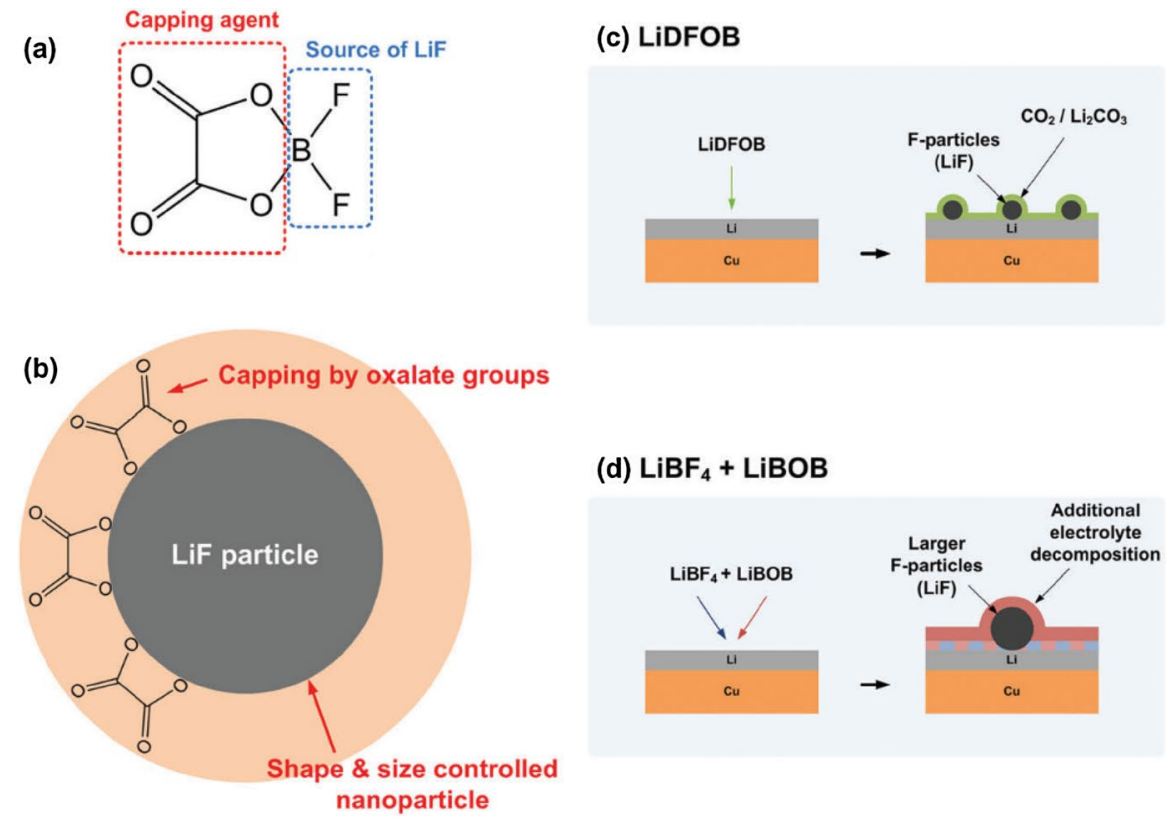

(d) $\mathrm{LiBF}_{4}+\mathrm{LiBOB}$

(e) LiDFOB
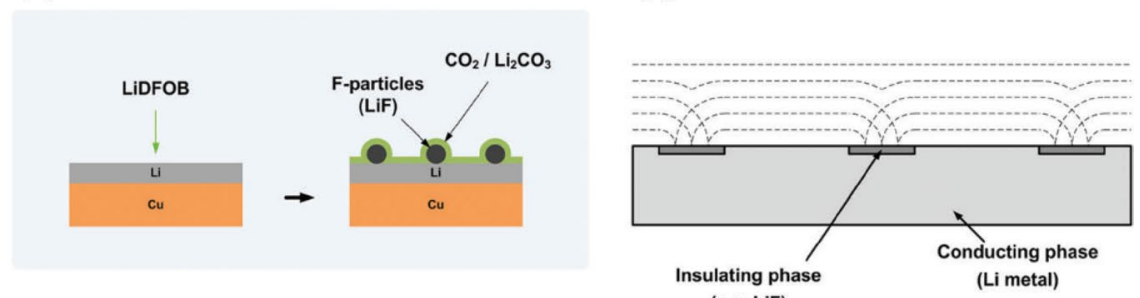

(e.g. LiF)

(f) $\mathrm{LiBF}_{4}+\mathrm{LiBOB}$

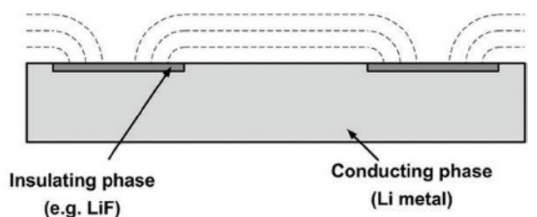

Fig. 15 a, b Proposed mechanisms of LiDFOB acting as a capping agent for $\mathrm{LiF}$ nanoparticle generation; $\mathbf{c}, \mathbf{d}$ models of SEIs from $\mathbf{c}$ LiDFOB and $\mathbf{d} \mathrm{LiBF}_{4}+\mathrm{LiBOB}$ electrolytes; and e, f schematics of diffusion fields at Li plated from each electrolyte. Each Li plate pos-

3. Studies should be conducted to investigate and optimize the synergistic effects of multiple mitigation methods on Ni-rich NMC-based cathodes that can outperform the effects of single mitigation methods and enhance capacity retention to higher levels.

4. Inexpensive and nondestructive characterization tools need to be developed to decrease research costs and prevent cell destruction, especially in the inline detection of cells. In terms of EIS that is time-consuming, fast impedance needs to be developed to accelerate measurement processes.

5. Time-dependent EIS in combination with differential specific capacity measurements should be used as a characterization tool to analyze surface phases/structures versus impedance growth.

Acknowledgements We wish to thank the Energy Storage Program of the National Research Council Canada (NRC) for its financial support as well as the support from the Energy, Mining and Environment Research Center of the NRC, Vancouver. Open discussions with team members Shawn Brueckner, Ken Tsay, Svetlana Niketic and Khalid Fatih and assistance from Tamara McLaughlin on literature searches are also highly appreciated.

\section{Compliance with Ethical Standards}

Conflict of interest The authors declare no conflicts of interest. sesses active and inactive areas on its surface (Reprinted with permission from Ref. [224]. Copyright @ 2018, The Royal Society of Chemistry)

Open Access This article is distributed under the terms of the Creative Commons Attribution 4.0 International License (http://creativeco mmons.org/licenses/by/4.0/), which permits unrestricted use, distribution, and reproduction in any medium, provided you give appropriate credit to the original author(s) and the source, provide a link to the Creative Commons license, and indicate if changes were made.

\section{References}

1. Iturrondobeitia, A., Aguesse, F., Genies, S., et al.: Post-mortem analysis of calendar-aged $16 \mathrm{Ah} \mathrm{NMC/graphite} \mathrm{pouch} \mathrm{cells} \mathrm{for}$ EV application. J. Phys. Chem. C 121, 21865-21876 (2017). https://doi.org/10.1021/acs.jpcc.7b05416

2. Julien, C.M., Mauger, A., Zaghib, K., et al.: Comparative issues of cathode materials for Li-ion batteries. Inorganics 2, 132-154 (2014). https://doi.org/10.3390/inorganics2020132

3. Ahmed, S., Nelson, P.A., Gallagher, K.G., et al.: Cost and energy demand of producing nickel manganese cobalt cathode material for lithium ion batteries. J. Power Sources 342, 733-740 (2017). https://doi.org/10.1016/j.jpowsour.2016.12.069

4. Wentker, M., Greenwood, M., Leker, J.: A bottom-up approach to lithium-ion battery cost modeling with a focus on cathode active materials. Energies 12, 504 (2019). https://doi.org/10.3390/ en12030504

5. Zheng, J.M., Yan, P.F., Zhang, J.D., et al.: Suppressed oxygen extraction and degradation of $\mathrm{LiNi}_{x} \mathrm{Mn}_{y} \mathrm{Co}_{z} \mathrm{O}_{2}$ cathodes at high charge cut-off voltages. Nano Res. 10, 4221-4231 (2017). https ://doi.org/10.1007/s12274-017-1761-6

6. Xia, Y., Zheng, J.M., Wang, C.M., et al.: Designing principle for $\mathrm{Ni}$-rich cathode materials with high energy density for practical applications. Nano Energy 49, 434-452 (2018). https://doi. org/10.1016/j.nanoen.2018.04.062 
7. Li, J., Downie, L.E., Ma, L., et al.: Study of the failure mechanisms of $\mathrm{LiNi}_{0.8} \mathrm{Mn}_{0.1} \mathrm{Co}_{0.1} \mathrm{O}_{2}$ Cathode material for lithium ion batteries. J. Electrochem. Soc. 162, A1401-A1408 (2015). https ://doi.org/10.1149/2.1011507jes

8. Zhang, N., Li, J., Li, H.Y., et al.: Structural, electrochemical, and thermal properties of nickel-rich $\mathrm{LiNi}_{x} \mathrm{Mn}_{y} \mathrm{Co}_{z} \mathrm{O}_{2}$ materials. Chem. Mater. 30, 8852-8860 (2018). https://doi.org/10.1021/acs. chemmater.8b03827

9. Li, J., Liu, H.S., Xia, J., et al.: The impact of electrolyte additives and upper cut-off voltage on the formation of a rocksalt surface layer in $\mathrm{LiNi}_{0.8} \mathrm{Mn}_{0.1} \mathrm{Co}_{0.1} \mathrm{O}_{2}$ electrodes. J. Electrochem. Soc. 164, A655-A665 (2017). https://doi.org/10.1149/2.0651704jes

10. Hwang, S., Kim, S.M., Bak, S.M., et al.: Investigating the reversibility of structural modifications of $\mathrm{Li}_{x} \mathrm{Ni}_{y} \mathrm{Mn}_{z} \mathrm{Co}_{1-y-z} \mathrm{O}_{2}$ cathode materials during initial charge/discharge, at multiple length scales. Chem. Mater. 27, 6044-6052 (2015). https://doi. org/10.1021/acs.chemmater.5b02457

11. Ma, L., Young, S., Ellis, L.D., et al.: Impact of a titaniumbased surface coating applied to $\mathrm{Li}\left[\mathrm{Ni}_{0.5} \mathrm{Mn}_{0.3} \mathrm{Co}_{0.2}\right] \mathrm{O}_{2}$ on lithium-ion cell performance. ACS Appl. Energy Mater. 1, 7052-7064 (2018). https://doi.org/10.1021/acsaem.8b01472

12. Arumugam, R.S., Ma, L., Li, J., et al.: Special synergy between electrolyte additives and positive electrode surface coating to enhance the performance of $\mathrm{Li}\left[\mathrm{Ni}_{06} \mathrm{Mn}_{0.2} \mathrm{Co}_{0.2}\right] \mathrm{O}_{2} /$ graphite cells. J. Electrochem. Soc. 163, A2531-A2538 (2016). https ://doi.org/10.1149/2.0171613jes

13. Schipper, F., Erickson, E.M., Erk, C., et al.: Review: recent advances and remaining challenges for lithium ion battery cathodes. J. Electrochem. Soc. 164, A6220-A6228 (2017). https://doi.org/10.1149/2.0351701jes

14. Manthiram, A.: An outlook on lithium ion battery technology. ACS Cent. Sci. 3, 1063-1069 (2017). https://doi.org/10.1021/ acscentsci.7b00288

15. Chen, Z.H., Qin, Y., Amine, K., et al.: Role of surface coating on cathode materials for lithium-ion batteries. J. Mater. Chem. 20, 7606 (2010). https://doi.org/10.1039/c0jm00154f

16. Xia, J., Nie, M.Y., Ma, L., et al.: Variation of coulombic efficiency versus upper cutoff potential of Li-ion cells tested with aggressive protocols. J. Power Sources 306, 233-240 (2016). https://doi.org/10.1016/j.jpowsour.2015.12.013

17. Abarbanel, D.W., Nelson, K.J., Dahn, J.R.: Exploring impedance growth in high voltage NMC/graphite Li-ion cells using a transmission line model. J. Electrochem. Soc. 163, A522-A529 (2016). https://doi.org/10.1149/2.0901603jes

18. Barré, A., Deguilhem, B., Grolleau, S., et al.: A review on lithium-ion battery ageing mechanisms and estimations for automotive applications. J. Power Sources 241, 680-689 (2013). https://doi.org/10.1016/j.jpowsour.2013.05.040

19. Dong, T., Peng, P., Jiang, F.M.: Numerical modeling and analysis of the thermal behavior of NCM lithium-ion batteries subjected to very high $\mathrm{C}$-rate discharge/charge operations. Int. J. Heat Mass Transf. 117, 261-272 (2018). https://doi.org/10.1016/j.ijheatmass transfer.2017.10.024

20. Li, J., Shunmugasundaram, R., Doig, R., et al.: In situ X-ray diffraction study of layered $\mathrm{Li}-\mathrm{Ni}-\mathrm{Mn}-\mathrm{Co}$ oxides: effect of particle size and structural stability of core-shell materials. Chem. Mater. 28, 162-171 (2016). https://doi.org/10.1021/acs.chemm ater. $5 \mathrm{~b} 03500$

21. Gabrisch, H., Yi, T.H., Yazami, R.: Transmission electron microscope studies of $\mathrm{LiNi}_{1 / 3} \mathrm{Mn}_{1 / 3} \mathrm{Co}_{1 / 3} \mathrm{O}_{2}$ before and after long-term aging at $70^{\circ} \mathrm{C}$. Electrochem. Solid State Lett. 11, A119 (2008). https://doi.org/10.1149/1.2919713

22. Weber, R., Fell, C.R., Dahn, J.R., et al.: Operando X-ray diffraction study of polycrystalline and single-crystal $\mathrm{Li}_{\mathrm{x}} \mathrm{Ni}_{0.5} \mathrm{Mn}_{0.3} \mathrm{Co}_{0.2} \mathrm{O}_{2}$. J. Electrochem. Soc. 164, A2992-A2999 (2017). https://doi.org/10.1149/2.0441713jes
23. Strehle, B., Kleiner, K., Jung, R., et al.: The role of oxygen release from $\mathrm{Li}$ - and $\mathrm{Mn}$-rich layered oxides during the first cycles investigated by on-line electrochemical mass spectrometry. J. Electrochem. Soc. 164, A400-A406 (2017). https://doi. org/10.1149/2.1001702jes

24. Jung, R., Metzger, M., Maglia, F., et al.: Chemical versus electrochemical electrolyte oxidation on NMC111, NMC622, NMC811, LNMO, and conductive carbon. J. Phys. Chem. Lett. 8, 4820 4825 (2017). https://doi.org/10.1021/acs.jpclett.7b01927

25. Jung, R., Metzger, M., Maglia, F., et al.: Oxygen release and its effect on the cycling stability of $\mathrm{LiNi}_{x} \mathrm{Mn}_{y} \mathrm{Co}_{z} \mathrm{O}_{2}(\mathrm{NMC})$ cathode materials for Li-ion batteries. J. Electrochem. Soc. 164, A1361A1377 (2017). https://doi.org/10.1149/2.0021707jes

26. Buchberger, I., Seidlmayer, S., Pokharel, A., et al.: Aging analysis of graphite/ $\mathrm{LiNi}_{1 / 3} \mathrm{Mn}_{1 / 3} \mathrm{Co}_{1 / 3} \mathrm{O}_{2}$ cells using XRD, PGAA, and AC impedance. J. Electrochem. Soc. 162, A2737-A2746 (2015). https://doi.org/10.1149/2.0721514jes

27. Lim, J.M., Hwang, T., Kim, D., et al.: Intrinsic origins of crack generation in $\mathrm{Ni}$-rich $\mathrm{LiNi}_{0.8} \mathrm{Co}_{0.1} \mathrm{Mn}_{0.1} \mathrm{O}_{2}$ layered oxide cathode material. Sci. Rep. 7, 39669 (2017). https://doi.org/10.1038/srep3 9669

28. Liu, W., Oh, P., Liu, X.E., et al.: Nickel-rich layered lithium transition-metal oxide for high-energy lithium-ion batteries. Angew. Chem. Int. Ed. 54, 4440-4457 (2015). https://doi.org/10.1002/ anie. 201409262

29. Myung, S.T., Maglia, F., Park, K.J., et al.: Nickel-rich layered cathode materials for automotive lithium-ion batteries: achievements and perspectives. ACS Energy Lett. 2, 196-223 (2017). https://doi.org/10.1021/acsenergylett.6b00594

30. Hou, P.Y., Yin, J.M., Ding, M., et al.: Surface/interfacial structure and chemistry of high-energy nickel-rich layered oxide cathodes: advances and perspectives. Small 13, 1701802 (2017). https:// doi.org/10.1002/smll.201701802

31. Vetter, J., Novak, P., Wagner, M.R., et al.: Ageing mechanisms in lithium-ion batteries. J. Power Sources 147, 269-281 (2005). https://doi.org/10.1016/j.jpowsour.2005.01.006

32. Ochida, M., Domi, Y., Doi, T., et al.: Influence of manganese dissolution on the degradation of surface films on edge plane graphite negative-electrodes in lithium-ion batteries. J. Electrochem. Soc. 159, A961-A966 (2012). https://doi.org/10.1149/2.03120 $7 \mathrm{jes}$

33. Jiang, L.H., Wang, Q.S., Sun, J.H.: Electrochemical performance and thermal stability analysis of $\mathrm{LiNiCoMnO}_{2}$ cathode based on a composite safety electrolyte. J. Hazard. Mater. 351, 260-269 (2018). https://doi.org/10.1016/j.jhazmat.2018.03.015

34. Nelson, K.J., Abarbanel, D.W., Xia, J., et al.: Effects of upper cutoff potential on $\mathrm{LaPO}_{4}$-coated and uncoated $\mathrm{Li}\left[\mathrm{Ni}_{0.42} \mathrm{Mn}_{0.42} \mathrm{Co}_{0.16}\right] \mathrm{O}_{2}$ /graphite pouch cells. J. Electrochem. Soc. 163, A272-A280 (2016). https://doi.org/10.1149/2.06916 02jes

35. Jung, R., Morasch, R., Karayaylali, P., et al.: Effect of ambient storage on the degradation of Ni-rich positive electrode materials (NMC811) for Li-ion batteries. J. Electrochem. Soc. 165, A132-A141 (2018). https://doi.org/10.1149/2.0401802jes

36. Hall, D.S., Nie, M.Y., Ellis, L.D., et al.: Surface-electrolyte interphase formation in lithium-ion cells containing pyridine adduct additives. J. Electrochem. Soc. 163, A773-A780 (2016). https:// doi.org/10.1149/2.1091605jes

37. Ellis, L.D., Allen, J.P., Hill, I.G., et al.: High-precision coulometry studies of the impact of temperature and time on SEI formation in Li-ion cells. J. Electrochem. Soc. 165, A1529-A1536 (2018)

38. Solchenbach, S., Hong, G., Freiberg, A.T.S., et al.: Electrolyte and SEI decomposition reactions of transition metal ions investigated by on-line electrochemical mass spectrometry. 
J. Electrochem. Soc. 165, A3304-A3312 (2018). https://doi. org/10.1149/2.0511814jes

39. Wang, A.P., Kadam, S., Li, H., et al.: Review on modeling of the anode solid electrolyte interphase (SEI) for lithium-ion batteries. Npj Comput. Mater. 4, 15 (2018). https://doi.org/10.1038/s4152 4-018-0064-0

40. Wang, S.Y., Yan, M.Y., Li, Y., et al.: Separating electronic and ionic conductivity in mix-conducting layered lithium transitionmetal oxides. J. Power Sources 393, 75-82 (2018). https://doi. org/10.1016/j.jpowsour.2018.05.005

41. Goodenough, J.B., Park, K.S.: The Li-ion rechargeable battery: a perspective. J. Am. Chem. Soc. 135, 1167-1176 (2013). https ://doi.org/10.1021/ja3091438

42. Bak, S.M., Hu, E.Y., Zhou, Y.N., et al.: Structural changes and thermal stability of charged $\mathrm{LiNi}_{x} \mathrm{Mn}_{y} \mathrm{Co}_{z} \mathrm{O}_{2}$ cathode materials studied by combined in situ time-resolved XRD and mass spectroscopy. ACS Appl. Mater. Interfaces 6, 22594-22601 (2014). https://doi.org/10.1021/am506712c

43. Ghanty, C., Markovsky, B., Erickson, E.M., et al.: $\mathrm{Li}^{+}$-ion extraction/insertion of Ni-rich $\mathrm{Li}_{1+x}\left(\mathrm{Ni}_{y} \mathrm{Co}_{z} \mathrm{Mn}_{z}\right)_{w} \mathrm{O}_{2}(0.005<x<0.03$; $y: z=8: 1, w \approx 1)$ electrodes: in situ XRD and Raman spectroscopy study. ChemElectroChem 2, 1479-1486 (2015). https://doi. org/10.1002/celc. 201500398

44. Wang, X.L., An, K., Cai, L., et al.: Visualizing the chemistry and structure dynamics in lithium-ion batteries by in situ neutron diffraction. Sci. Rep. 2, 747 (2012)

45. Yang, J., Xia, Y.Y.: Suppressing the phase transition of the layered Ni-rich oxide cathode during high-voltage cycling by introducing low-content $\mathrm{Li}_{2} \mathrm{MnO}_{3}$. ACS Appl. Mater. Interfaces 8 , 1297-1308 (2016). https://doi.org/10.1021/acsami.5b09938

46. Laubach, S., Laubach, S., Schmidt, P., et al.: Changes in the crystal and electronic structure of $\mathrm{LiCoO}_{2}$ and $\mathrm{LiNiO}_{2}$ upon $\mathrm{Li}$ intercalation and de-intercalation. Phys. Chem. Chem. Phys. 11, 3278-3289 (2009)

47. Yabuuchi, N., Makimura, Y., Ohzuku, T.: Solid-state chemistry and electrochemistry of $\mathrm{LiCo}_{1 / 3} \mathrm{Ni}_{1 / 3} \mathrm{Mn}_{1 / 3} \mathrm{O}_{2}$ for advanced lithium-ion batteries. J. Electrochem. Soc. 154, A314-A321 (2007). https://doi.org/10.1149/1.2455585

48. Cui, S., Wei, Y., Liu, T., et al.: Optimized temperature effect of Li-ion diffusion with layer distance in $\mathrm{Li}\left(\mathrm{Ni}_{x} \mathrm{Mn}_{y} \mathrm{Co}_{z}\right) \mathrm{O}_{2}$ cathode materials for high performance Li-ion battery. Adv. Energy Mater. 6, 1501309 (2016)

49. Markus, I.M., Lin, F., Kam, K.C., et al.: Computational and experimental investigation of $\mathrm{Ti}$ substitution in $\mathrm{Li}_{1}\left(\mathrm{Ni}_{x} \mathrm{Mn}_{x} \mathrm{Co}_{1-2 x-y} \mathrm{Ti}_{y}\right) \mathrm{O}_{2}$ for lithium ion batteries. J. Phys. Chem. Lett. 5, 3649-3655 (2014). https://doi.org/10.1021/jz501 7526

50. Yang, J., Hou, M.Y., Haller, S., et al.: Improving the cycling performance of the layered Ni-rich oxide cathode by introducing low-content $\mathrm{Li}_{2} \mathrm{MnO}_{3}$. Electrochim. Acta 189, 101-110 (2016). https://doi.org/10.1016/j.electacta.2015.12.080

51. Chebiam, R.V., Prado, F., Manthiram, A.: Structural instability of delithiated $\mathrm{Li}_{1-x} \mathrm{Ni}_{1-y} \mathrm{Co}_{y} \mathrm{O}_{2}$ cathodes. J. Electrochem. Soc. 148, A49 (2001). https://doi.org/10.1149/1.1339029

52. Hua, W.B., Zhang, J.B., Zheng, Z., et al.: Na-doped Ni-rich $\mathrm{LiNi}_{0.5} \mathrm{Co}_{0.2} \mathrm{Mn}_{0.3} \mathrm{O}_{2}$ cathode material with both high rate capability and high tap density for lithium ion batteries. Dalton Trans. 43, 14824-14832 (2014). https://doi.org/10.1039/c4dt01611d

53. Chen, M.M., Zhao, E.Y., Chen, D.F., et al.: Decreasing Li/Ni disorder and improving the electrochemical performances of Ni-rich $\mathrm{LiNi}_{0.8} \mathrm{Co}_{0.1} \mathrm{Mn}_{0.1} \mathrm{O}_{2}$ by Ca doping. Inorg. Chem. 56, 8355-8362 (2017). https://doi.org/10.1021/acs.inorgchem.7b01035

54. Ding, Y., Mu, D.B., Wu, B.R., et al.: Recent progresses on nickelrich layered oxide positive electrode materials used in lithiumion batteries for electric vehicles. Appl. Energy 195, 586-599 (2017). https://doi.org/10.1016/j.apenergy.2017.03.074
55. Huang, R., Ikuhara, Y.: STEM characterization for lithium-ion battery cathode materials. Curr. Opin. Solid State Mater. Sci. 16, 31-38 (2012). https://doi.org/10.1016/j.cossms.2011.08.002

56. Jung, S.K., Gwon, H., Hong, J., et al.: Understanding the degradation mechanisms of $\mathrm{LiNi}_{0.5} \mathrm{Co}_{0.2} \mathrm{Mn}_{03} \mathrm{O}_{2}$ cathode material in lithium ion batteries. Adv. Energy Mater. 4, 1300787 (2014). https://doi.org/10.1002/aenm.201300787

57. Robert, R., Villevieille, C., Novák, P.: Enhancement of the high potential specific charge in layered electrode materials for lithium-ion batteries. J. Mater. Chem. A 2, 8589-8598 (2014)

58. Gabrisch, H., Yazami, R.: Electron diffraction studies of $\mathrm{LiNi}_{1 / 3} \mathrm{Mn}_{1 / 3} \mathrm{Co}_{1 / 3} \mathrm{O}_{2}$ after charge-discharge cycling. Electrochem. Solid State Lett. 13, A88-A90 (2010)

59. Ravdel, B., Abraham, K.M., Gitzendanner, R., et al.: Thermal stability of lithium-ion battery electrolytes. J. Power Sources 119-121, 805-810 (2003). https://doi.org/10.1016/s0378 $-7753(03) 00257-\mathrm{x}$

60. Konishi, H., Yoshikawa, M., Hirano, T.: The effect of thermal stability for high-Ni-content layer-structured cathode materials, $\mathrm{LiNi}_{0.8} \mathrm{Mn}_{0.1-x} \mathrm{Co}_{0.1} \mathrm{Mo}_{x} \mathrm{O}_{2}(x=0,0.02,0.04)$. J. Power Sources 244, 23-28 (2013). https://doi.org/10.1016/j.jpows our.2013.05.004

61. Xiong, X.H., Wang, Z.X., Yue, P., et al.: Washing effects on electrochemical performance and storage characteristics of $\mathrm{LiNi}_{0.8} \mathrm{Co}_{0.1} \mathrm{Mn}_{0.1} \mathrm{O}_{2}$ as cathode material for lithium-ion batteries. J. Power Sources 222, 318-325 (2013). https://doi.org/10.1016/j. jpowsour.2012.08.029

62. Wang, D., Li, X.H., Wang, Z.X., et al.: Improved high voltage electrochemical performance of $\mathrm{Li}_{2} \mathrm{ZrO}_{3}$-coated $\mathrm{LiNi}_{0.5} \mathrm{Co}_{0.2} \mathrm{Mn}_{0.3} \mathrm{O}_{2}$ cathode material. J. Alloys Compd. 647, 612-619 (2015). https://doi.org/10.1016/j.jallcom.2015.06.071

63. Lin, F., Markus, I.M., Nordlund, D., et al.: Surface reconstruction and chemical evolution of stoichiometric layered cathode materials for lithium-ion batteries. Nat. Commun. 5, 3529 (2014). https ://doi.org/10.1038/ncomms4529

64. Ruan, Y.L., Song, X.Y., Fu, Y.B., et al.: Structural evolution and capacity degradation mechanism of $\mathrm{LiNi}_{0.6} \mathrm{Mn}_{0.2} \mathrm{Co}_{0.2} \mathrm{O}_{2}$ cathode materials. J. Power Sources 400, 539-548 (2018). https://doi. org/10.1016/j.jpowsour.2018.08.056

65. Xu, J., Lin, F., Doeff, M.M., et al.: A review of Ni-based layered oxides for rechargeable Li-ion batteries. J. Mater. Chem. A 5, 874-901 (2017). https://doi.org/10.1039/c6ta07991a

66. Hwang, S., Chang, W., Kim, S.M., et al.: Investigation of changes in the surface structure of $\mathrm{Li}_{x} \mathrm{Ni}_{0.8} \mathrm{Co}_{0.15} \mathrm{Al}_{0.05} \mathrm{O}_{2}$ cathode materials induced by the initial charge. Chem. Mater. 26, 1084-1092 (2014). https://doi.org/10.1021/cm403332s

67. Yang, J., Xia, Y.Y.: Enhancement on the cycling stability of the layered Ni-rich oxide cathode by in situ fabricating nano-thickness cation-mixing layers. J. Electrochem. Soc. 163, A2665A2672 (2016). https://doi.org/10.1149/2.0841613jes

68. Ryu, H.H., Park, K.J., Yoon, C.S., et al.: Capacity fading of $\mathrm{Ni}$-rich $\mathrm{Li}\left[\mathrm{Ni}_{x} \mathrm{Co}_{y} \mathrm{Mn}_{1-x-y}\right] \mathrm{O}_{2}(0.6 \leqslant x \leqslant 0.95)$ cathodes for high-energy-density lithium-ion batteries: bulk or surface degradation? Chem. Mater. 30, 1155-1163 (2018). https://doi. org/10.1021/acs.chemmater.7b05269

69. Zheng, S.Y., Hong, C.Y., Guan, X.Y., et al.: Correlation between long range and local structural changes in Ni-rich layered materials during charge and discharge process. J. Power Sources 412, 336-343 (2019). https://doi.org/10.1016/j.jpowsour.2018.11.053

70. Fu, C.C., Li, G.S., Luo, D., et al.: Nickel-rich layered microspheres cathodes: lithium/nickel disordering and electrochemical performance. ACS Appl. Mater. Interfaces 6, 15822-15831 (2014). https://doi.org/10.1021/am5030726

71. Chebiam, R.V., Kannan, A.M., Prado, F., et al.: Comparison of the chemical stability of the high energy density cathodes of 
lithium-ion batteries. Electrochem. Commun. 3, 624-627 (2001). https://doi.org/10.1016/s1388-2481(01)00232-6

72. Chen, Z.Q., Wang, J., Huang, J.X., et al.: The high-temperature and high-humidity storage behaviors and electrochemical degradation mechanism of $\mathrm{LiNi}_{0.6} \mathrm{Co}_{0.2} \mathrm{Mn}_{0.2} \mathrm{O}_{2}$ cathode material for lithium ion batteries. J. Power Sources 363, 168-176 (2017). https://doi.org/10.1016/j.jpowsour.2017.07.087

73. Shkrob, I.A., Gilbert, J.A., Phillips, P.J., et al.: Chemical weathering of layered $\mathrm{Ni}$-rich oxide electrode materials: evidence for cation exchange. J. Electrochem. Soc. 164, A1489-A1498 (2017). https://doi.org/10.1149/2.0861707jes

74. Zheng, H.H., Sun, Q.N., Liu, G., et al.: Correlation between dissolution behavior and electrochemical cycling performance for $\mathrm{LiNi}_{1 / 3} \mathrm{Co}_{1 / 3} \mathrm{Mn}_{1 / 3} \mathrm{O}_{2}$-based cells. J. Power Sources 207, 134-140 (2012). https://doi.org/10.1016/j.jpowsour.2012.01.122

75. Gallus, D.R., Schmitz, R., Wagner, R., et al.: The influence of different conducting salts on the metal dissolution and capacity fading of NCM cathode material. Electrochim. Acta 134, 393-398 (2014). https://doi.org/10.1016/j.electacta.2014.04.091

76. Wandt, J., Freiberg, A., Thomas, R., et al.: Transition metal dissolution and deposition in $\mathrm{Li}$-ion batteries investigated by operando X-ray absorption spectroscopy. J. Mater. Chem. A 4, 18300-18305 (2016). https://doi.org/10.1039/c6ta08865a

77. Xiao, X.C., Liu, Z.Y., Baggetto, L., et al.: Unraveling manganese dissolution/deposition mechanisms on the negative electrode in lithium ion batteries. Phys. Chem. Chem. Phys. 16, 10398 (2014). https://doi.org/10.1039/c4cp00833b

78. Joshi, T., Eom, K., Yushin, G., et al.: Effects of dissolved transition metals on the electrochemical performance and SEI growth in lithium-ion batteries. J. Electrochem. Soc. 161, A1915-A1921 (2014). https://doi.org/10.1149/2.0861412jes

79. Zhan, C., Lu, J., Jeremy Kropf, A., et al.: Mn(II) deposition on anodes and its effects on capacity fade in spinel lithium manganate-carbon systems. Nat. Commun. 4, 2437 (2013)

80. Xia, Y.Y.: An investigation of lithium ion insertion into spinel structure Li-Mn-O compounds. J. Electrochem. Soc. 143, 825833 (1996). https://doi.org/10.1149/1.1836544

81. Jiao, F., Bao, J.L., Hill, A., et al.: Synthesis of ordered mesoporous $\mathrm{Li}-\mathrm{Mn}-\mathrm{O}$ spinel as a positive electrode for rechargeable lithium batteries. Angew. Chem. Int. Ed. 47, 9711-9716 (2008). https://doi.org/10.1002/anie.200803431

82. Venkatraman, S., Shin, Y., Manthiram, A.: Phase relationships and structural and chemical stabilities of charged $\mathrm{Li}_{1-x} \mathrm{CoO}_{2-\delta}$ and $\mathrm{Li}_{1-x} \mathrm{Ni}_{0.85} \mathrm{Co}_{0.15} \mathrm{O}_{2-\delta}$ cathodes. Electrochem. Solid State Lett. 6, A9-A12 (2003). https://doi.org/10.1149/1.1525430

83. Andersson, A.M., Abraham, D.P., Haasch, R., et al.: Surface characterization of electrodes from high power lithium-ion batteries. J. Electrochem. Soc. 149, A1358-A1369 (2002). https:// doi.org/10.1149/1.1505636

84. Berkes, B.B., Schiele, A., Sommer, H., et al.: On the gassing behavior of lithium-ion batteries with NCM523 cathodes. J. Solid State Electrochem. 20, 2961-2967 (2016). https://doi. org/10.1007/s10008-016-3362-9

85. Xiong, D.J., Ellis, L.D., Li, J., et al.: Measuring oxygen release from delithiated $\mathrm{LiNi}_{x} \mathrm{Mn}_{y} \mathrm{Co}_{1-x-y} \mathrm{O}_{2}$ and its effects on the performance of high voltage Li-ion cells. J. Electrochem. Soc. 164, A3025-A3037 (2017)

86. Wandt, J., Freiberg, A.T.S., Ogrodnik, A., et al.: Singlet oxygen evolution from layered transition metal oxide cathode materials and its implications for lithium-ion batteries. Mater. Today 21, 825-833 (2018). https://doi.org/10.1016/j.mattod.2018.03.037

87. Metzger, M., Strehle, B., Solchenbach, S., et al.: Origin of $\mathrm{H}_{2}$ Evolution in LIBs: $\mathrm{H}_{2} \mathrm{O}$ reduction vs. electrolyte oxidation. J. Electrochem. Soc. 163, A798-A809 (2016). https://doi. org/10.1149/2.1151605jes
88. Jung, R., Strobl, P., Maglia, F., et al.: Temperature dependence of oxygen release from $\mathrm{LiNi}_{0.6} \mathrm{Mn}_{0.2} \mathrm{Co}_{0.2} \mathrm{O}_{2}$ (NMC622) cathode materials for Li-ion batteries. J. Electrochem. Soc. 165, A2869A2879 (2018)

89. Hatsukade, T., Schiele, A., Hartmann, P., et al.: Origin of carbon dioxide evolved during cycling of nickel-rich layered NCM cathodes. ACS Appl. Mater. Interfaces 10, 38892-38899 (2018)

90. Streich, D., Erk, C., Guéguen, A., et al.: Operando monitoring of early Ni-mediated surface reconstruction in layered lithiated Ni-Co-Mn oxides. J. Phys. Chem. C 121, 13481-13486 (2017). https://doi.org/10.1021/acs.jpcc.7b02303

91. Xiong, D.J., Hynes, T., Ellis, L.D., et al.: Effects of surface coating on gas evolution and impedance growth at $\mathrm{LiNi}_{x} \mathrm{Mn}_{y} \mathrm{Co}_{1-x-y} \mathrm{O}_{2}$ Positive electrodes in Li-ion cells. J. Electrochem. Soc. 164, A3174-A3181 (2017). https://doi. org/10.1149/2.0991713jes

92. Lin, F., Nordlund, D., Li, Y.Y., et al.: Metal segregation in hierarchically structured cathode materials for high-energy lithium batteries. Nat. Energy 1, 15004 (2016). https://doi.org/10.1038/ nenergy.2015.4

93. Choi, J., Manthiram, A.: Investigation of the irreversible capacity loss in the layered $\mathrm{LiNi}_{1 / 3} \mathrm{Mn}_{1 / 3} \mathrm{Co}_{1 / 3} \mathrm{O}_{2}$ cathodes. Electrochem. Solid State Lett. 8, C102-C105 (2005). https://doi. org/10.1149/1.1943567

94. Kang, S.H., Abraham, D.P., Yoon, W.S., et al.: First-cycle irreversibility of layered $\mathrm{Li}-\mathrm{Ni}-\mathrm{Co}-\mathrm{Mn}$ oxide cathode in $\mathrm{Li}$-ion batteries. Electrochim. Acta 54, 684-689 (2008). https://doi. org/10.1016/j.electacta.2008.07.007

95. Burns, J.C., Kassam, A., Sinha, N.N., et al.: Predicting and extending the lifetime of Li-ion batteries. J. Electrochem. Soc. 160, A1451-A1456 (2013)

96. Meng, K., Wang, Z.X., Guo, H.J., et al.: Improving the cycling performance of $\mathrm{LiNi}_{0.8} \mathrm{Co}_{0.1} \mathrm{Mn}_{0.1} \mathrm{O}_{2}$ by surface coating with $\mathrm{Li}_{2} \mathrm{TiO}_{3}$. Electrochim. Acta 211, 822-831 (2016). https://doi. org/10.1016/j.electacta.2016.06.110

97. Yan, P., Zheng, J., Liu, J., et al.: Tailoring grain boundary structures and chemistry of Ni-rich layered cathodes for enhanced cycle stability of lithium-ion batteries. Nat. Energy 3, 600-605 (2018)

98. Dahn, H.M., Smith, A.J., Burns, J.C., et al.: User-friendly differential voltage analysis freeware for the analysis of degradation mechanisms in Li-ion batteries. J. Electrochem. Soc. 159, A1405-A1409 (2012)

99. Chen, Y., Zhang, Y., Chen, B., et al.: An approach to application for $\mathrm{LiNi}_{0.6} \mathrm{Co}_{0.2} \mathrm{Mn}_{0.2} \mathrm{O}_{2}$ cathode material at high cutoff voltage by $\mathrm{TiO}_{2}$ coating. J. Power Sources 256, 20-27 (2014)

100. Cho, W., Kim, S.M., Song, J.H., et al.: Improved electrochemical and thermal properties of nickel rich $\mathrm{LiNi}_{0.6} \mathrm{Co}_{0.2} \mathrm{Mn}_{0.2} \mathrm{O}_{2}$ cathode materials by $\mathrm{SiO}_{2}$ coating. J. Power Sources 282, 45-50 (2015). https://doi.org/10.1016/j.jpowsour.2014.12.128

101. Shi, Y., Zhang, M.H., Qian, D.N., et al.: Ultrathin $\mathrm{Al}_{2} \mathrm{O}_{3}$ coatings for improved cycling performance and thermal stability of $\mathrm{LiNi}_{0.5} \mathrm{Co}_{0.2} \mathrm{Mn}_{0.3} \mathrm{O}_{2}$ cathode material. Electrochim. Acta 203, 154-161 (2016). https://doi.org/10.1016/j.elect acta.2016.03.185

102. Habte, B.T., Jiang, F.M.: Effect of microstructure morphology on Li-ion battery graphite anode performance: electrochemical impedance spectroscopy modeling and analysis. Solid State Ion. 314, 81-91 (2018). https://doi.org/10.1016/j.ssi.2017.11.024

103. Schweidler, S., de Biasi, L., Schiele, A., et al.: Volume changes of graphite anodes revisited: a combined Operando X-ray diffraction and in situ pressure analysis study. J. Phys. Chem. C 122, 8829-8835 (2018)

104. Leng, Y., Ge, S., Marple, D., et al.: Electrochemical cycle-life characterization of high energy lithium-ion cells with thick 
$\mathrm{Li}\left(\mathrm{Ni}_{0.6} \mathrm{Mn}_{0.2} \mathrm{Co}_{0.2}\right) \mathrm{O}_{2}$ and graphite electrodes. J. Electrochem. Soc. 164, A1037-A1049 (2017)

105. Hasan, M.F., Chen, C.F., Shaffer, C.E., et al.: Analysis of the implications of rapid charging on lithium-ion battery performance. J. Electrochem. Soc. 162, A1382-A1395 (2015)

106. Wandt, J., Jakes, P., Granwehr, J., et al.: Quantitative and timeresolved detection of lithium plating on graphite anodes in lithium ion batteries. Mater. Today 21, 231-240 (2018)

107. Liu, Q.Q., Ma, L., Du, C.Y., et al.: Effects of the $\mathrm{LiPO}_{2} \mathrm{~F}_{2}$ additive on unwanted lithium plating in lithium-ion cells. Electrochim. Acta 263, 237-248 (2018)

108. Ushirogata, K., Sodeyama, K., Futera, Z., et al.: Near-shore aggregation mechanism of electrolyte decomposition products to explain solid electrolyte interphase formation. J. Electrochem. Soc. 162, A2670-A2678 (2015)

109. Nie, M.Y., Lucht, B.L.: Role of lithium salt on solid electrolyte interface (SEI) formation and structure in lithium ion batteries. J. Electrochem. Soc. 161, A1001-A1006 (2014). https://doi. org/10.1149/2.054406jes

110. Vissers, D.R., Chen, Z.H., Shao, Y.Y., et al.: Role of manganese deposition on graphite in the capacity fading of lithium ion batteries. ACS Appl. Mater. Interfaces 8, 14244-14251 (2016). https ://doi.org/10.1021/acsami.6b02061

111. Esbenshade, J.L., Gewirth, A.A.: Effect of $\mathrm{Mn}$ and $\mathrm{Cu}$ addition on lithiation and SEI formation on model anode electrodes. J. Electrochem. Soc. 161, A513-A518 (2014). https://doi. org/10.1149/2.009404jes

112. Wang, R.H., Li, X.H., Wang, Z.X., et al.: Electrochemical analysis graphite/electrolyte interface in lithium-ion batteries: p-Toluenesulfonyl isocyanate as electrolyte additive. Nano Energy 34, 131-140 (2017). https://doi.org/10.1016/j.nanoen.2017.02.037

113. Kim, J., Lee, J.G., Kim, H.S., et al.: Thermal degradation of solid electrolyte interphase (SEI) layers by phosphorus pentafluoride (PF5) attack. J. Electrochem. Soc. 164, A2418-A2425 (2017)

114. Bernhard, R., Metzger, M., Gasteiger, H.A.: Gas evolution at graphite anodes depending on electrolyte water content and SEI quality studied by on-line electrochemical mass spectrometry. J. Electrochem. Soc. 162, A1984-A1989 (2015). https://doi. org/10.1149/2.0191510jes

115. Stevens, D.A., Ying, R.Y., Fathi, R., et al.: Using high precision coulometry measurements to compare the degradation mechanisms of NMC/LMO and NMC-only automotive scale pouch cells. J. Electrochem. Soc. 161, A1364-A1370 (2014). https:// doi.org/10.1149/2.0971409jes

116. Smith, A.J., Burns, J.C., Zhao, X.M., et al.: Publisher's note: a high precision coulometry study of the SEI growth in Li/graphite cells. J. Electrochem. Soc. 158, S23 (2011). [J. Electrochem. Soc., 158, A447 (2011)]

117. Gilbert, J.A., Bareño, J., Spila, T., et al.: Cycling behavior of NCM523/graphite lithium-ion cells in the 3-4.4 V range: diagnostic studies of full cells and harvested electrodes. J. Electrochem. Soc. 164, A6054-A6065 (2017). https://doi. org/10.1149/2.0081701jes

118. Wu, S.H., Lee, P.H.: Storage fading of a commercial 18650 cell comprised with NMC/LMO cathode and graphite anode. J. Power Sources 349, 27-36 (2017). https://doi.org/10.1016/j. jpowsour.2017.03.002

119. Kato, H., Kobayashi, Y., Miyashiro, H.: Differential voltage curve analysis of a lithium-ion battery during discharge. J. Power Sources 398, 49-54 (2018). https://doi.org/10.1016/j.jpows our.2018.07.043

120. Pop, V., Bergveld, H.J., Op het Veld, J.H.G., et al.: Modeling battery behavior for accurate state-of-charge indication. J. Electrochem. Soc. 153, A2013-A2022 (2006). https://doi. org/10.1149/1.2335951
121. Li, D.J., Li, H., Danilov, D., et al.: Temperature-dependent cycling performance and ageing mechanisms of $\mathrm{C}_{6}$ l $\mathrm{LiNi}_{1 / 3} \mathrm{Mn}_{1 / 3} \mathrm{Co}_{1 / 3} \mathrm{O}_{2}$ batteries. J. Power Sources 396, 444-452 (2018). https://doi.org/10.1016/j.jpowsour.2018.06.035

122. Aryal, S., Timofeeva, E.V., Segre, C.U.: Structural studies of capacity activation and reduced voltage fading in Li-rich, Mn$\mathrm{Ni}-\mathrm{Fe}$ composite oxide cathode. J. Electrochem. Soc. 165, A71A78 (2018). https://doi.org/10.1149/2.0031802jes

123. Liang, L.W., Hu, G.R., Jiang, F., et al.: Electrochemical behaviours of $\mathrm{SiO}_{2}$-coated $\mathrm{LiNi}_{0.8} \mathrm{Co}_{0.1} \mathrm{Mn}_{0.1} \mathrm{O}_{2}$ cathode materials by a novel modification method. J. Alloys Compd. 657, 570-581 (2016). https://doi.org/10.1016/j.jallcom.2015.10.177

124. Song, B.H., Li, W.D., Yan, P.F., et al.: A facile cathode design combining Ni-rich layered oxides with Li-rich layered oxides for lithium-ion batteries. J. Power Sources 325, 620-629 (2016). https://doi.org/10.1016/j.jpowsour.2016.06.056

125. Liu, W., Oh, P., Liu, X.E., et al.: Countering voltage decay and capacity fading of lithium-rich cathode material at $60{ }^{\circ} \mathrm{C}$ by hybrid surface protection layers. Adv. Energy Mater. 5, 1500274 (2015). https://doi.org/10.1002/aenm.201500274

126. Sun, Y.K., Myung, S.T., Park, B.C., et al.: High-energy cathode material for long-life and safe lithium batteries. Nat. Mater. 8, 320-324 (2009). https://doi.org/10.1038/nmat2418

127. Noh, H.J., Chen, Z.H., Yoon, C.S., et al.: Cathode material with nanorod structure: an application for advanced high-energy and safe lithium batteries. Chem. Mater. 25, 2109-2115 (2013). https ://doi.org/10.1021/cm4006772

128. Morales-Ugarte, J.E., Bolimowska, E., Rouault, H., et al.: EIS and XPS investigation on SEI layer formation during first discharge on graphite electrode with a vinylene carbonate doped imidazolium based ionic liquid electrolyte. J. Phys. Chem. C 122, 18223-18230 (2018)

129. Kim, H., Kim, M.G., Jeong, H.Y., et al.: A new coating method for alleviating surface degradation of $\mathrm{LiNi}_{0.6} \mathrm{Co}_{0.2} \mathrm{Mn}_{0.2} \mathrm{O}_{2}$ cathode material: nanoscale surface treatment of primary particles. Nano Lett. 15, 2111-2119 (2015). https://doi.org/10.1021/acs. nanolett.5b00045

130. Su, Y.T., Cui, S.H., Zhuo, Z.Q., et al.: Enhancing the high-voltage cycling performance of $\mathrm{LiNi}_{0.5} \mathrm{Mn}_{0.3} \mathrm{Co}_{0.2} \mathrm{O}_{2}$ by retarding its interfacial reaction with an electrolyte by atomic-layer-deposited $\mathrm{Al}_{2} \mathrm{O}_{3}$. ACS Appl. Mater. Interfaces 7, 25105-25112 (2015). https://doi.org/10.1021/acsami.5b05500

131. El Mofid, W., Ivanov, S., Konkin, A., et al.: A high performance layered transition metal oxide cathode material obtained by simultaneous aluminum and iron cationic substitution. J. Power Sources 268, 414-422 (2014). https://doi.org/10.1016/j.jpows our.2014.06.048

132. Evertz, M., Kasnatscheew, J., Winter, M., et al.: Investigation of various layered lithium ion battery cathode materials by plasmaand X-ray-based element analytical techniques. Anal. Bioanal. Chem. 411, 277-285 (2019). https://doi.org/10.1007/s0021 6-018-1441-8

133. Ran, Q.W., Zhao, H.Y., Wang, Q., et al.: Dual functions of gradient phosphate polyanion doping on improving the electrochemical performance of $\mathrm{Ni}$-rich $\mathrm{LiNi}_{06} \mathrm{Co}_{0.2} \mathrm{Mn}_{0.2} \mathrm{O}_{2}$ cathode at high cut-off voltage and high temperature. Electrochim. Acta 299, 971-978 (2019). https://doi.org/10.1016/j.electacta.2019.01.082

134. Hu, K.H., Qi, X.Y., Lu, C.F., et al.: Enhanced electrochemical performance of $\mathrm{LiNi}_{0.8} \mathrm{Co}_{0.1} \mathrm{Mn}_{0.1} \mathrm{O}_{2}$ cathode materials via $\mathrm{Li}_{4} \mathrm{P}_{2} \mathrm{O}_{7}$ surface modification for Li-ion batteries. Ceram. Int. 44, 14209-14216 (2018). https://doi.org/10.1016/j.ceram int.2018.05.024

135. Han, E.S., Du, X.J., Yang, P.J., et al.: The effects of copper and titanium co-substitution on $\mathrm{LiNi}_{0.6} \mathrm{Co}_{0.15} \mathrm{Mn}_{0.25} \mathrm{O}_{2}$ for lithium ion batteries. Ionics 24, 393-401 (2018). https://doi.org/10.1007/ s11581-017-2226-3 
136. Laszczynski, N., Solchenbach, S., Gasteiger, H.A., et al.: Understanding electrolyte decomposition of graphite/NCM811 cells at elevated operating voltage. J. Electrochem. Soc. 166, A1853A1859 (2019). https://doi.org/10.1149/2.0571910jes

137. Thompson, L.M., Stone, W., Eldesoky, A., et al.: Quantifying changes to the electrolyte and negative electrode in aged NMC532/graphite lithium-ion cells. J. Electrochem. Soc. 165, A2732-A2740 (2018). https://doi.org/10.1149/2.0721811jes

138. Xiong, X.H., Ding, D., Wang, Z.X., et al.: Surface modification of $\mathrm{LiNi}_{0.8} \mathrm{Co}_{0.1} \mathrm{Mn}_{0.1} \mathrm{O}_{2}$ with conducting polypyrrole. $\mathrm{J}$. Solid State Electrochem. 18, 2619-2624 (2014). https://doi. org/10.1007/s10008-014-2519-7

139. Nie, M.Y., Demeaux, J., Young, B.T., et al.: Effect of vinylene carbonate and fluoroethylene carbonate on SEI formation on graphitic anodes in Li-ion batteries. J. Electrochem. Soc. 162, A7008-A7014 (2015). https://doi.org/10.1149/2.0021513jes

140. Noh, H.J., Ju, J.W., Sun, Y.K.: Comparison of nanorod-structured $\mathrm{Li}\left[\mathrm{Ni}_{0.54} \mathrm{Co}_{0.16} \mathrm{Mn}_{0.30}\right] \mathrm{O}_{2}$ with conventional cathode materials for Li-ion batteries. ChemSusChem 7, 245-252 (2014). https://doi. org/10.1002/cssc. 201300379

141. Jan, S.S., Nurgul, S., Shi, X.Q., et al.: Improvement of electrochemical performance of $\mathrm{LiNi}_{0.8} \mathrm{Co}_{0.1} \mathrm{Mn}_{0.1} \mathrm{O}_{2}$ cathode material by graphene nanosheets modification. Electrochim. Acta 149, 86-93 (2014). https://doi.org/10.1016/j.electacta.2014.10.093

142. Ma, L., Xia, J., Dahn, J.R.: Ternary electrolyte additive mixtures for Li-ion cells that promote long lifetime and less reactivity with charged electrodes at elevated temperatures. J. Electrochem. Soc. 162, A1170-A1174 (2015). https://doi.org/10.1149/2.0181507jes

143. Chen, L.C., Yang, Y.M., Wang, Z.S., et al.: Enhanced electrochemical performances and thermal stability of $\mathrm{LiNi}_{1 / 3} \mathrm{Co}_{1 / 3} \mathrm{Mn}_{1 / 3} \mathrm{O}_{2}$ by surface modification with $\mathrm{YF}_{3}$. J. Alloys Compd. 711, 462-472 (2017). https://doi.org/10.1016/j.jallc om.2017.03.130

144. Cho, Y., Lee, S., Lee, Y., et al.: Spinel-layered core-shell cathode materials for Li-ion batteries. Adv. Energy Mater. 1, 821-828 (2011). https://doi.org/10.1002/aenm.201100239

145. Dolotko, O., Senyshyn, A., Mühlbauer, M.J., et al.: Understanding structural changes in NMC Li-ion cells by in situ neutron diffraction. J. Power Sources 255, 197-203 (2014). https://doi. org/10.1016/j.jpowsour.2014.01.010

146. Wang, S., Chen, S., Gao, W., Liu, L., Zhang, S.: A new additive 3-isocyanatopropyltriethoxysilane to improve electrochemical performance of Li/NCM622 half-cell at high voltage. J. Power Sources 423, 90-97 (2019)

147. Zhu, C.Y., Liu, J., Yu, X., et al.: 4-bromoanisole (4BA) as additive for overcharge protection of lithium-ion batteries. Int. J. Electrochem. Sci. 14, 4571-4579 (2019). https://doi. org/10.20964/2019.05.17

148. Cao, Z.Y., Hashinokuchi, M., Doi, T., et al.: Improved cycle performance of $\mathrm{LiNi}_{0.8} \mathrm{Co}_{0.1} \mathrm{Mn}_{0.1} \mathrm{O}_{2}$ positive electrode material in highly concentrated $\mathrm{LiBF}_{4} / \mathrm{DMC}$. J. Electrochem. Soc. 166, A82-A88 (2019). https://doi.org/10.1149/2.0291902jes

149. Wang, C.Y., Yu, L., Fan, W.Z., et al.: Enhanced high-voltage cyclability of $\mathrm{LiNi}_{0.5} \mathrm{Co}_{0.2} \mathrm{Mn}_{0.3} \mathrm{O}_{2}{ }^{-}$based pouch cells via lithium difluorophosphate introducing as electrolyte additive. J. Alloys Compd. 755, 1-9 (2018). https://doi.org/10.1016/j.jallc om.2018.05.005

150. Liu, L.L., Wang, S.L., Zhang, Z.Y., et al.: Fluoroethylene carbonate as an electrolyte additive for improving interfacial stability of high-voltage $\mathrm{LiNi}_{0.6} \mathrm{Co}_{0.2} \mathrm{Mn}_{0.2} \mathrm{O}_{2}$ cathode. Ionics 25, 1035-1043 (2019). https://doi.org/10.1007/s11581-018-2641-0

151. Wang, L.N., Liu, S.Q., Zhao, K.M., et al.: Improving the rate performance and stability of $\mathrm{LiNi}_{0.6} \mathrm{Co}_{0.2} \mathrm{Mn}_{0.2} \mathrm{O}_{2}$ in high voltage lithium-ion battery by using fluoroethylene carbonate as electrolyte additive. Ionics 24, 3337-3346 (2018). https://doi. org/10.1007/s11581-018-2534-2
152. Zhang, S.S., Fan, X.L., Wang, C.S.: Enhanced electrochemical performance of Ni-rich layered cathode materials by using $\mathrm{LiPF}_{6}$ as a cathode additive. ChemElectroChem 6, 1536-1541 (2019). https://doi.org/10.1002/celc.201801858

153. Eilers-Rethwisch, M., Winter, M., Schappacher, F.M.: Synthesis, electrochemical investigation and structural analysis of doped $\mathrm{Li}\left[\mathrm{Ni}_{0.6} \mathrm{Mn}_{0.2} \mathrm{Co}_{0.2-x} \mathrm{M}_{x}\right] \mathrm{O}_{2}(x=0,0.05 ; \mathrm{M}=\mathrm{Al}, \mathrm{Fe}, \mathrm{Sn})$ cathode materials. J. Power Sources 387, 101-107 (2018). https://doi. org/10.1016/j.jpowsour.2018.02.080

154. Du, Q.X., Tang, Z.F., Ma, X.H., et al.: Improving the electrochemical properties of high-energy cathode material $\mathrm{LiNi}_{0.5} \mathrm{Co}_{0.2} \mathrm{Mn}_{0.3} \mathrm{O}_{2}$ by $\mathrm{Zr}$ doping and sintering in oxygen. Solid State Ion. 279, 11-17 (2015). https://doi.org/10.1016/j. ssi.2015.07.006

155. Wu, Y.P., Rahm, E., Holze, R.: Effects of heteroatoms on electrochemical performance of electrode materials for lithium ion batteries. Electrochim. Acta 47, 3491-3507 (2002). https://doi. org/10.1016/s0013-4686(02)00317-1

156. Hildebrand, S., Friesen, A., Haetge, J., et al.: Delayed thermal runaway investigation on commercial 2.6 Ah NCM-LCO based 18650 lithium ion cells with accelerating rate calorimetry. ECS Trans. 74, 85-94 (2016). https://doi.org/10.1149/07401.0085ecst

157. Wang, D., Li, X.H., Wang, Z.X., et al.: Co-modification of $\mathrm{LiNi}_{0.5} \mathrm{Co}_{0.2} \mathrm{Mn}_{0.3} \mathrm{O}_{2}$ cathode materials with zirconium substitution and surface polypyrrole coating: towards superior high voltage electrochemical performances for lithium ion batteries. Electrochim. Acta 196, 101-109 (2016). https://doi.org/10.1016/j. electacta.2016.02.156

158. Kang, K., Ceder, G.: Factors that affect Li mobility in layered lithium transition metal oxides. Phys. Rev. B 74, 094105 (2006)

159. Li, G.Y., Zhang, Z.J., Wang, R.N., et al.: Effect of trace Al surface doping on the structure, surface chemistry and low temperature performance of $\mathrm{LiNi}_{0.5} \mathrm{Co}_{0.2} \mathrm{Mn}_{0.3} \mathrm{O}_{2}$ cathode. Electrochim. Acta 212, 399-407 (2016). https://doi.org/10.1016/j.elect acta.2016.07.033

160. Du, H., Zheng, Y.Y., Dou, Z.J., et al.: Zn-doped $\mathrm{LiNi}_{1 / 3} \mathrm{Co}_{1 / 3} \mathrm{Mn}_{1 / 3} \mathrm{O}_{2}$ Composite as cathode material for lithium ion battery: preparation, characterization, and electrochemical properties. J. Nanomater. 2015, 1-5 (2015). https://doi. org/10.1155/2015/867618

161. Li, L.J., Li, X.H., Wang, Z.X., et al.: Synthesis, structural and electrochemical properties of $\mathrm{LiNi}_{0.79} \mathrm{Co}_{0.1} \mathrm{Mn}_{0.1} \mathrm{Cr}_{0.01} \mathrm{O}_{2}$ via fast co-precipitation. J. Alloys Compd. 507, 172-177 (2010). https:// doi.org/10.1016/j.jallcom.2010.07.148

162. Schipper, F., Dixit, M., Kovacheva, D., et al.: Stabilizing nickelrich layered cathode materials by a high-charge cation doping strategy: zirconium-doped $\mathrm{LiNi}_{0.6} \mathrm{Co}_{0.2} \mathrm{Mn}_{0.2} \mathrm{O}_{2}$. J. Mater. Chem. A 4, 16073-16084 (2016). https://doi.org/10.1039/c6ta06740a

163. Huang, Z.J., Wang, Z.X., Zheng, X.B., et al.: Effect of Mg doping on the structural and electrochemical performance of $\mathrm{LiNi}_{0.6} \mathrm{Co}_{0.2} \mathrm{Mn}_{0.2} \mathrm{O}_{2}$ cathode materials. Electrochim. Acta 182, 795-802 (2015). https://doi.org/10.1016/j.electacta.2015.09.151

164. Huang, Z.J., Wang, Z.X., Jing, Q., et al.: Investigation on the effect of $\mathrm{Na}$ doping on structure and Li-ion kinetics of layered $\mathrm{LiNi}_{0.6} \mathrm{Co}_{0.2} \mathrm{Mn}_{0.2} \mathrm{O}_{2}$ cathode material. Electrochim. Acta 192, 120-126 (2016). https://doi.org/10.1016/j.elect acta.2016.01.139

165. Zhao, R.R., Yang, Z.L., Liang, J.X., et al.: Understanding the role of Na-doping on Ni-rich layered oxide $\mathrm{LiNi}_{0.5} \mathrm{Co}_{0.2} \mathrm{Mn}_{0.3} \mathrm{O}_{2}$. $\mathrm{J}$. Alloys Compd. 689, 318-325 (2016). https://doi.org/10.1016/j. jallcom.2016.07.230

166. Kang, K., Meng, Y.S., Breger, J., et al.: Electrodes with high power and high capacity for rechargeable lithium batteries. ChemInform (2006). https://doi.org/10.1002/chin.200620021

167. Cho, Y., Oh, P., Cho, J.: A new type of protective surface layer for high-capacity Ni-based cathode materials: nanoscaled surface 
pillaring layer. Nano Lett. 13, 1145-1152 (2013). https://doi. org/10.1021/nl304558t

168. Yue, P., Wang, Z.X., Guo, H.J., et al.: A low temperature fluorine substitution on the electrochemical performance of layered $\mathrm{LiNi}_{0.8} \mathrm{Co}_{0.1} \mathrm{Mn}_{0.1} \mathrm{O}_{2-2} \mathrm{~F}_{z}$ cathode materials. Electrochim. Acta 92, 1-8 (2013). https://doi.org/10.1016/j.electacta.2013.01.018

169. Shin, H.S., Park, S.H., Yoon, C.S., et al.: Effect of fluorine on the electrochemical properties of layered $\mathrm{Li}\left[\mathrm{Ni}_{0.43} \mathrm{Co}_{0.22} \mathrm{Mn}_{0.35}\right]$ $\mathrm{O}_{2}$ cathode materials via a carbonate process. Electrochem. Solid State Lett. 8, A559-A563 (2005). https://doi. org/10.1149/1.2039954

170. Kim, G.H., Kim, M.H., Myung, S.T., et al.: Effect of fluorine on $\mathrm{Li}\left[\mathrm{Ni}_{1 / 3} \mathrm{Co}_{1 / 3} \mathrm{Mn}_{1 / 3}\right] \mathrm{O}_{2-z} \mathrm{~F}_{z}$ as lithium intercalation material. J. Power Sources 146, 602-605 (2005). https://doi.org/10.1016/j. jpowsour.2005.03.045

171. Li, G.Y., Huang, Z.L., Zuo, Z.C., et al.: Understanding the trace Ti surface doping on promoting the low temperature performance of $\mathrm{LiNi}_{1 / 3} \mathrm{Co}_{1 / 3} \mathrm{Mn}_{1 / 3} \mathrm{O}_{2}$ cathode. J. Power Sources 281, 69-76 (2015). https://doi.org/10.1016/j.jpowsour.2015.01.173

172. Zhu, H.L., Li, Q.F., Gong, X.L., et al.: Enhanced high voltage performance of chlorine/bromine Co-doped lithium nickel manganese cobalt oxide. Crystals 8, 425 (2018). https://doi. org/10.3390/cryst8110425

173. Park, K.J., Lim, B.B., Choi, M.H., et al.: A high-capacity $\mathrm{Li}\left[\mathrm{Ni}_{0.8} \mathrm{Co}_{0.06} \mathrm{Mn}_{0.14}\right] \mathrm{O}_{2}$ positive electrode with a dual concentration gradient for next-generation lithium-ion batteries. J. Mater. Chem. A 3, 22183-22190 (2015). https://doi.org/10.1039/c5ta0 $5657 \mathrm{~h}$

174. Sun, Y.K., Chen, Z.H., Noh, H.J., et al.: Nanostructured highenergy cathode materials for advanced lithium batteries. Nat. Mater. 11, 942-947 (2012). https://doi.org/10.1038/nmat3435

175. Hou, P.Y., Zhang, L.Q., Gao, X.P.: A high-energy, full concentration-gradient cathode material with excellent cycle and thermal stability for lithium ion batteries. J. Mater. Chem. A 2, 17130 17138 (2014). https://doi.org/10.1039/c4ta03158j

176. Song, D.W., Hou, P.Y., Wang, X.Q., et al.: Understanding the origin of enhanced performances in core-shell and concentration-gradient layered oxide cathode materials. ACS Appl. Mater. Interfaces 7, 12864-12872 (2015). https://doi.org/10.1021/acsam i. $5 \mathrm{~b} 02373$

177. Li, Y., Xu, R., Ren, Y., et al.: Synthesis of full concentration gradient cathode studied by high energy X-ray diffraction. Nano Energy 19, 522-531 (2016). https://doi.org/10.1016/j.nanoe n.2015.07.019

178. Noh, H.J., Myung, S.T., Lee, Y.J., et al.: High-energy layered oxide cathodes with thin shells for improved surface stability. Chem. Mater. 26, 5973-5979 (2014). https://doi.org/10.1021/ $\mathrm{cm} 502774 \mathrm{u}$

179. Lim, B.B., Yoon, S.J., Park, K.J., et al.: Advanced concentration gradient cathode material with two-slope for high-energy and safe lithium batteries. Adv. Funct. Mater. 25, 4673-4680 (2015). https://doi.org/10.1002/adfm.201501430

180. Oh, P., Oh, S.M., Li, W.D., et al.: High-performance heterostructured cathodes for lithium-ion batteries with a Ni-rich layered oxide core and a Li-rich layered oxide shell. Adv. Sci. 3, 1600184 (2016). https://doi.org/10.1002/advs.201600184

181. Shi, H., Wang, X.Q., Hou, P.Y., et al.: Core-shell structured Li $\left[\left(\mathrm{Ni}_{0.8} \mathrm{Co}_{0.1} \mathrm{Mn}_{0.1}\right)_{0.7}\left(\mathrm{Ni}_{0.45} \mathrm{Co}_{0.1} \mathrm{Mn}_{0.45}\right)_{0.3}\right] \mathrm{O}_{2}$ cathode material for high-energy lithium ion batteries. J. Alloys Compd. 587, 710-716 (2014). https://doi.org/10.1016/j.jallcom.2013.10.226

182. Oh, P., Song, B.H., Li, W.D., et al.: Overcoming the chemical instability on exposure to air of $\mathrm{Ni}$-rich layered oxide cathodes by coating with spinel $\mathrm{LiMn}_{1.9} \mathrm{Al}_{0.1} \mathrm{O}_{4}$. J. Mater. Chem. A 4, 5839-5841 (2016). https://doi.org/10.1039/c6ta01061j

183. Wang, Z.Y., Huang, S.S., Chen, B.J., et al.: Infiltrative coating of $\mathrm{LiNi}_{0.5} \mathrm{Co}_{0.2} \mathrm{Mn}_{0.3} \mathrm{O}_{2}$ microspheres with layer-structured $\mathrm{LiTiO}_{2}$ : towards superior cycling performances for Li-ion batteries. J. Mater. Chem. A 2, 19983-19987 (2014). https://doi.org/10.1039/ c4ta04196h

184. Song, B.H., Li, W.D., Oh, S.M., et al.: Long-life nickel-rich layered oxide cathodes with a uniform $\mathrm{Li}_{2} \mathrm{ZrO}_{3}$ surface coating for lithium-ion batteries. ACS Appl. Mater. Interfaces 9, 9718-9725 (2017). https://doi.org/10.1021/acsami.7b00070

185. Wang, L., Mu, D.B., Wu, B.R., et al.: Enhanced electrochemical performance of lithium metasilicate-coated $\mathrm{LiNi}_{0.6} \mathrm{Co}_{0.2} \mathrm{Mn}_{0.2} \mathrm{O}_{2}$ $\mathrm{Ni}$-rich cathode for Li-ion batteries at high cutoff voltage. Electrochim. Acta 222, 806-813 (2016). https://doi.org/10.1016/j. electacta.2016.11.041

186. Wu, Z.Z., Ji, S.P., Liu, T.C., et al.: Aligned $\mathrm{Li}^{+}$tunnels in coreshell $\mathrm{Li}\left(\mathrm{Ni}_{x} \mathrm{Mn}_{y} \mathrm{Co}_{z}\right) \mathrm{O}_{2} @ \mathrm{LiFePO}_{4}$ enhances its high voltage cycling stability as Li-ion battery cathode. Nano Lett. 16, 63576363 (2016). https://doi.org/10.1021/acs.nanolett.6b02742

187. Park, K., Park, J.H., Choi, B., et al.: Metal phosphate-coated Ni-rich layered oxide positive electrode materials for Li-ion batteries: improved electrochemical performance and decreased $\mathrm{Li}$ residuals content. Electrochim. Acta 257, 217-223 (2017). https ://doi.org/10.1016/j.electacta.2017.10.101

188. Chen, Y.P., Zhang, Y., Wang, F., et al.: Improve the structure and electrochemical performance of $\mathrm{LiNi}_{0.6} \mathrm{Co}_{0.2} \mathrm{Mn}_{0.2} \mathrm{O}_{2}$ cathode material by nano- $\mathrm{Al}_{2} \mathrm{O}_{3}$ ultrasonic coating. J. Alloys Compd. 611, 135-141 (2014). https://doi.org/10.1016/j.jallcom.2014.05.068

189. Xiong, X.H., Wang, Z.X., Guo, H.J., et al.: Enhanced electrochemical properties of lithium-reactive $\mathrm{V}_{2} \mathrm{O}_{5}$ coated on the $\mathrm{LiNi}_{0.8} \mathrm{Co}_{0.1} \mathrm{Mn}_{0.1} \mathrm{O}_{2}$ cathode material for lithium ion batteries at $60^{\circ} \mathrm{C}$. J. Mater. Chem. A 1, 1284-1288 (2013). https://doi. org/10.1039/c2ta00678b

190. Shi, S.J., Tu, J.P., Mai, Y.J., et al.: Structure and electrochemical performance of $\mathrm{CaF}_{2}$ coated $\mathrm{LiMn}_{1 / 3} \mathrm{Ni}_{1 / 3} \mathrm{Co}_{1 / 3} \mathrm{O}_{2}$ cathode material for Li-ion batteries. Electrochim. Acta 83, 105-112 (2012). https://doi.org/10.1016/j.electacta.2012.08.029

191. Chen, S., He, T., Su, Y.F., et al.: Ni-rich $\mathrm{LiNi}_{0.8} \mathrm{Co}_{0.1} \mathrm{Mn}_{0.1} \mathrm{O}_{2}$ oxide coated by dual-conductive layers as high performance cathode material for lithium-ion batteries. ACS Appl. Mater. Interfaces 9, 29732-29743 (2017). https://doi.org/10.1021/acsam i. $7 \mathrm{~b} 08006$

192. Bai, Y.S., Wang, X.Y., Yang, S.Y., et al.: The effects of $\mathrm{FePO}_{4}$-coating on high-voltage cycling stability and rate capability of $\mathrm{Li}\left[\mathrm{Ni}_{0.5} \mathrm{Co}_{0.2} \mathrm{Mn}_{0.3}\right] \mathrm{O}_{2}$. J. Alloys Compd. 541, 125-131 (2012). https://doi.org/10.1016/j.jallcom.2012.06.101

193. Woo, S.G., Han, J.H., Kim, K.J., et al.: Surface modification by sulfated zirconia on high-capacity nickel-based cathode materials for Li-ion batteries. Electrochim. Acta 153, 115-121 (2015). https://doi.org/10.1016/j.electacta.2014.12.001

194. Chen, Z.H., Dahn, J.R.: Studies of $\mathrm{LiCoO}_{2}$ coated with metal oxides. Electrochem. Solid State Lett. 6, A221-A224 (2003). https://doi.org/10.1149/1.1611731

195. Jo, C.H., Cho, D.H., Noh, H.J., et al.: An effective method to reduce residual lithium compounds on Ni-rich $\mathrm{Li}\left[\mathrm{Ni}_{0.6} \mathrm{Co}_{0.2} \mathrm{Mn}_{0.2}\right] \mathrm{O}_{2}$ active material using a phosphoric acid derived $\mathrm{Li}_{3} \mathrm{PO}_{4}$ nanolayer. Nano Res. 8, 1464-1479 (2015). https://doi.org/10.1007/s12274-014-0631-8

196. Liu, S.J., Wu, H., Huang, L., et al.: Synthesis of $\mathrm{Li}_{2} \mathrm{Si}_{2} \mathrm{O}_{5}$-coated $\mathrm{LiNi}_{0.6} \mathrm{Co}_{0.2} \mathrm{Mn}_{0.2} \mathrm{O}_{2}$ cathode materials with enhanced high-voltage electrochemical properties for lithiumion batteries. J. Alloys Compd. 674, 447-454 (2016). https:// doi.org/10.1016/j.jallcom.2016.03.060

197. Li, L.J., Xu, M., Yao, Q., et al.: Alleviating surface degradation of nickel-rich layered oxide cathode material by encapsulating with nanoscale $\mathrm{Li}$-ions/electrons superionic conductors hybrid membrane for advanced Li-ion batteries. ACS Appl. Mater. Interfaces 8, 30879-30889 (2016). https://doi.org/10.1021/ acsami.6b09197 
198. Neudeck, S., Walther, F., Bergfeldt, T., et al.: Molecular surface modification of NCM622 cathode material using organophosphates for improved Li-ion battery full-cells. ACS Appl. Mater. Interfaces 10, 20487-20498 (2018). https://doi.org/10.1021/ acsami.8b04405

199. Kong, J.Z., Wang, S.S., Tai, G.A., et al.: Enhanced electrochemical performance of $\mathrm{LiNi}_{0.5} \mathrm{Co}_{0.2} \mathrm{Mn}_{0.3} \mathrm{O}_{2}$ cathode material by ultrathin $\mathrm{ZrO}_{2}$ coating. J. Alloys Compd. 657, 593-600 (2016). https://doi.org/10.1016/j.jallcom.2015.10.187

200. Luo, W.B., Zheng, B.L., He, J.: Enhanced electrochemical performance of $\mathrm{LiNi}_{0.5} \mathrm{Co}_{0.2} \mathrm{Mn}_{0.3} \mathrm{O}_{2}$ cathode material after surface modification with graphene oxide. J. Alloys Compd. 705, 405-412 (2017). https://doi.org/10.1016/j.jallcom.2017.02.114

201. Du, Z.J., Li, J.L., Wood, M., et al.: Three-dimensional conductive network formed by carbon nanotubes in aqueous processed NMC electrode. Electrochim. Acta 270, 54-61 (2018). https:// doi.org/10.1016/j.electacta.2018.03.063

202. Wu, Z.Z., Han, X.G., Zheng, J.X., et al.: Depolarized and fully active cathode based on $\mathrm{Li}\left(\mathrm{Ni}_{0.5} \mathrm{Co}_{0.2} \mathrm{Mn}_{0.3}\right) \mathrm{O}_{2}$ embedded in carbon nanotube network for advanced batteries. Nano Lett. 14, 4700-4706 (2014). https://doi.org/10.1021/n15018139

203. Kang, J., Pham, H.Q., Kang, D.H., et al.: Improved rate capability of highly loaded carbon fiber-interwoven $\mathrm{LiNi}_{0.6} \mathrm{Co}_{0.2} \mathrm{Mn}_{0.2} \mathrm{O}_{2}$ cathode material for high-power Li-ion batteries. J. Alloys Compd. 657, 464-471 (2016). https://doi. org/10.1016/j.jallcom.2015.10.127

204. Zou, Y.H., Yang, X.F., Lv, C., et al.: Multishelled Ni-rich $\mathrm{Li}\left(\mathrm{Ni}_{x} \mathrm{Co}_{y} \mathrm{Mn}_{z}\right) \mathrm{O}_{2}$ Hollow fibers with low cation mixing as high-performance cathode materials for Li-ion batteries. Adv. Sci. 4, 1600262 (2017). https://doi.org/10.1002/advs.20160 0262

205. Zheng, X.B., Li, X.H., Zhang, B., et al.: Enhanced electrochemical performance of $\mathrm{LiNi}_{0.8} \mathrm{Co}_{0.1} \mathrm{Mn}_{0.1} \mathrm{O}_{2}$ cathode materials obtained by atomization co-precipitation method. Ceram. Int. 42, 644-649 (2016). https://doi.org/10.1016/j.ceramint.2015.08.159

206. Ahn, W., Lim, S.N., Jung, K.N., et al.: Combustion-synthesized $\mathrm{LiNi}_{0.6} \mathrm{Mn}_{0.2} \mathrm{Co}_{0.2} \mathrm{O}_{2}$ as cathode material for lithium ion batteries. J. Alloys Compd. 609, 143-149 (2014). https://doi.org/10.1016/j. jallcom.2014.03.123

207. Tian, J., Su, Y.F., Wu, F., et al.: High-rate and cycling-stable nickel-rich cathode materials with enhanced $\mathrm{Li}^{+}$diffusion pathway. ACS Appl. Mater. Interfaces 8, 582-587 (2016). https://doi. org/10.1021/acsami.5b09641

208. Li, H.Y., Li, J., Ma, X.W., et al.: Synthesis of single crystal $\mathrm{LiNi}_{0.6} \mathrm{Mn}_{0.2} \mathrm{Co}_{0.2} \mathrm{O}_{2}$ with enhanced electrochemical performance for lithium ion batteries. J. Electrochem. Soc. 165, A1038A1045 (2018). https://doi.org/10.1149/2.0951805jes

209. Zheng, Z., Guo, X.D., Chou, S.L., et al.: Uniform Ni-rich $\mathrm{LiNi}_{0.6} \mathrm{Co}_{0.2} \mathrm{Mn}_{0.2} \mathrm{O}_{2}$ porous microspheres: facile designed synthesis and their improved electrochemical performance. Electrochim. Acta 191, 401-410 (2016). https://doi.org/10.1016/j.elect acta.2016.01.092

210. Mohanty, D., Dahlberg, K., King, D.M., et al.: Modification of Ni-rich FCG NMC and NCA cathodes by atomic layer deposition: preventing surface phase transitions for high-voltage lithium-ion batteries. Sci. Rep. 6, 26532 (2016). https://doi. org/10.1038/srep26532

211. Kim, U.H., Lee, E.J., Yoon, C.S., et al.: Compositionally graded cathode material with long-term cycling stability for electric vehicles application. Adv. Energy Mater. (2017). https://doi. org/10.1002/aenm.201700254

212. Wang, J.P., Du, C.Y., Yan, C.Q., et al.: $\mathrm{Al}_{2} \mathrm{O}_{3}$ coated concentration-gradient $\mathrm{Li}\left[\mathrm{Ni}_{0.73} \mathrm{Co}_{0.12} \mathrm{Mn}_{0.15}\right] \mathrm{O}_{2}$ cathode material by freeze drying for long-life lithium ion batteries. Electrochim.
Acta 174, 1185-1191 (2015). https://doi.org/10.1016/j.elect acta.2015.06.112

213. Wang, J.P., Du, C.Y., Xu, X., et al.: Lithium phosphorus oxynitride coated concentration gradient $\mathrm{Li}\left[\mathrm{Ni}_{0.73} \mathrm{Co}_{0.12} \mathrm{Mn}_{0.15}\right] \mathrm{O}_{2}$ cathode material with enhanced electrochemical properties. Electrochim. Acta 192, 340-345 (2016). https://doi.org/10.1016/j. electacta.2016.01.176

214. Liu, Y., Xie, K., Pan, Y., et al.: LiPON as a protective layer on graphite anode to extend the storage life of Li-ion battery at elevated temperature. Ionics 24, 723-734 (2018). https://doi. org/10.1007/s11581-017-2250-3

215. Long, B.R., Rinaldo, S.G., Gallagher, K.G., et al.: Enabling high-energy, high-voltage lithium-ion cells: standardization of coin-cell assembly, electrochemical testing, and evaluation of full cells. J. Electrochem. Soc. 163, A2999-A3009 (2016). https ://doi.org/10.1149/2.0691614jes

216. An, S.J., Li, J.L., Mohanty, D., et al.: Correlation of electrolyte volume and electrochemical performance in lithium-ion pouch cells with graphite anodes and NMC532 cathodes. J. Electrochem. Soc. 164, A1195-A1202 (2017). https://doi. org/10.1149/2.1131706jes

217. Smart, M.C., Ratnakumar, B.V.: Effects of electrolyte composition on lithium plating in lithium-ion cells. J. Electrochem. Soc. 158, A379 (2011). https://doi.org/10.1149/1.3544439

218. Genieser, R., Ferrari, S., Loveridge, M., et al.: Lithium ion batteries (NMC/graphite) cycling at $80^{\circ} \mathrm{C}$ : different electrolytes and related degradation mechanism. J. Power Sources 373, 172-183 (2018). https://doi.org/10.1016/j.jpowsour.2017.11.014

219. Son, H.B., Jeong, M.Y., Han, J.G., et al.: Effect of reductive cyclic carbonate additives and linear carbonate co-solvents on fast chargeability of $\mathrm{LiNi}_{0.6} \mathrm{Co}_{0.2} \mathrm{Mn}_{0.2} \mathrm{O}_{2}$ /graphite cells. J. Power Sources 400, 147-156 (2018). https://doi.org/10.1016/j.jpows our.2018.08.022

220. Liu, D.Q., Qian, K., He, Y.B., et al.: Positive film-forming effect of fluoroethylene carbonate (FEC) on high-voltage cycling with three-electrode $\mathrm{LiCoO}_{2}$ /graphite pouch cell. Electrochim. Acta 269, 378-387 (2018). https://doi.org/10.1016/j.elect acta.2018.02.151

221. Wang, K., Xing, L.D., Zhi, H.Z., et al.: High stability graphite/ electrolyte interface created by a novel electrolyte additive: a theoretical and experimental study. Electrochim. Acta 262, 226-232 (2018). https://doi.org/10.1016/j.electacta.2018.01.018

222. Petibon, R., Rotermund, L.M., Dahn, J.R.: Evaluation of phenyl carbonates as electrolyte additives in lithium-ion batteries. J. Power Sources 287, 184-195 (2015). https://doi.org/10.1016/j. jpowsour.2015.04.012

223. Shi, P.C., Lin, M., Zheng, H., et al.: Effect of propylene carbonate- $\mathrm{Li}^{+}$solvation structures on graphite exfoliation and its application in Li-ion batteries. Electrochim. Acta 247, 12-18 (2017). https://doi.org/10.1016/j.electacta.2017.06.174

224. Jurng, S., Brown, Z.L., Kim, J., et al.: Effect of electrolyte on the nanostructure of the solid electrolyte interphase (SEI) and performance of lithium metal anodes. Energy Environ. Sci. 11, 2600-2608 (2018). https://doi.org/10.1039/c8ee00364e

225. Farhat, D., Maibach, J., Eriksson, H., et al.: Towards highvoltage Li-ion batteries: reversible cycling of graphite anodes and $\mathrm{Li}$-ion batteries in adiponitrile-based electrolytes. Electrochim. Acta 281, 299-311 (2018). https://doi.org/10.1016/j.elect acta.2018.05.133

226. Rodrigues, M.T.F., Sayed, F.N., Gullapalli, H., et al.: High-temperature solid electrolyte interphases (SEI) in graphite electrodes. J. Power Sources 381, 107-115 (2018). https://doi.org/10.1016/j. jpowsour.2018.01.070 


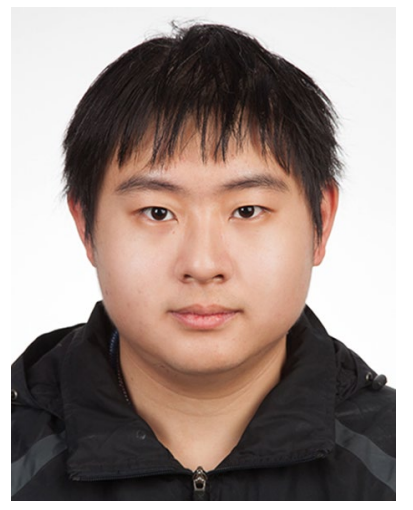

Tianyu Li received his Bachelor of Science (B.Sc.) degree in Materials Science at Nanjing University. He is currently working toward a $\mathrm{Ph} . \mathrm{D}$. degree in chemistry at the University of Victoria, specializing in the microfluidic devices for online detection of alcohol electrooxidation with Raman spectroscopy. $\mathrm{He}$ worked as a co-op student researcher at National Research Council Canada.

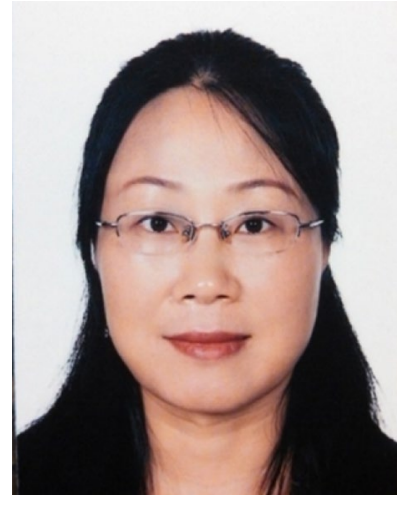

Dr. Xiao-Zi Yuan is a Research Officer at the Energy, Mines and Environment (EME) Research Centre of the National Research Council Canada (NRC). Dr. Yuan received her B.S. and M.Sc. in Corrosion and Protection from Nanjing University of Technology in 1991 and 1994, respectively, and her Ph.D. in Material Science from Shanghai Jiaotong University in 2003. Beginning in 2004, she carried out a 3-year postdoctoral research program supported by Natural Sciences and Engineering Research Council (NSERC). Since 2007, Dr. Yuan has been working with NRC. Her research interests include PEM fuel cells, Li-ion batteries, $\mathrm{Zn} / \mathrm{Li}$ air batteries, and other types of electrochemical devices and energy storage systems. Her research areas range from cell design, electrode material and structure to cell testing, diagnosis and durability. In 2014 and 2016, Dr. Yuan was listed as a Highly Cited Researcher by Thomson Reuters under the Engineering Section and World's Most Influential Scientific Minds.

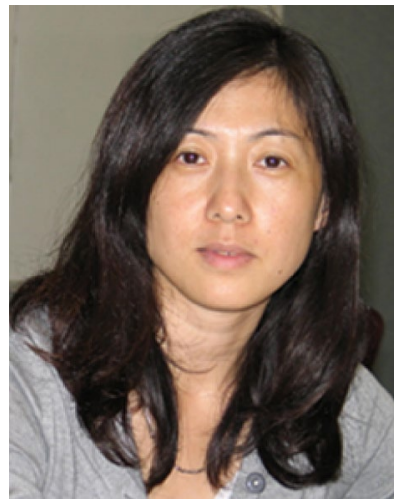

Lei Zhang is currently a Senior Research Officer at Energy, Mining and Environment (EME) of National Research Council Canada (NRC), a Fellow of the Royal Society of Chemistry (FRSC) and a member of the NSERC Industrial R\&D Fellowships College of Reviewers. Lei received her first Master's degree in Materials Chemistry (1993) from Wuhan University and her second Master's degree in Physical Chemistry (2000) from Simon Fraser University, Canada. Lei's main research interests include advanced materials and electrochemical energy technologies in the area of PEM fuel cell electrocatalysis, supercapacitors, metal-air batteries and Li-ion batteries. She has co-authored more than 200 publications ( $>16300$ citations)

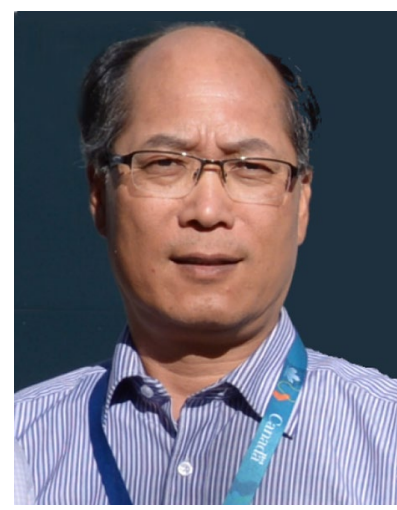

Datong Song obtained his Ph.D. in Computational Mechanics from Jilin University in 1994. Currently, he is a senior research officer at Energy, Mining and Environment Research Centre, National Research Council (NRC) of Canada. He has more than 20-year experience in mechanical engineering, fuel cell modeling and optimization, and energy storage modeling and analysis. Prior to joining NRC, he was a professor in the Department of Mechanics, Jilin University, Jilin, China. His research interests cover mechanical dynamics, vibration and stress analysis, modeling simulation for fuel cells and batteries.

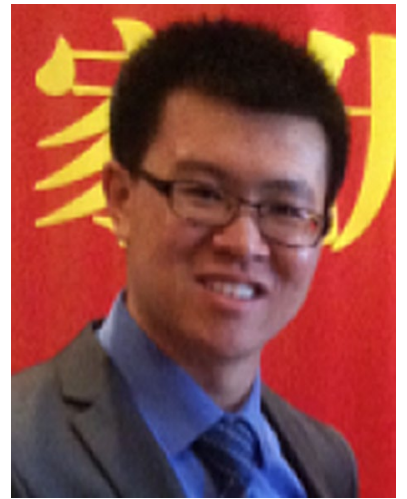

Kaiyuan Shi is currently an Assistant Research Officer at Energy, Mining and Environment Research Centre, National Research Council Canada. Prior to this, he worked as a Postdoctoral Scholar in the Department of Chemical Engineering at California Institute of Technology (Caltech) after securing his Ph.D. degree from McMaster University. His research is mainly focused on developing advanced materials for electrochemical energy storage, including supercapacitors, Li-ion capacitors, fuel cells and Li-ion batteries. Besides, he has conducted substantive research on capacitive deionization, steels and cast irons, surface cladding and fatigue analysis of metals.

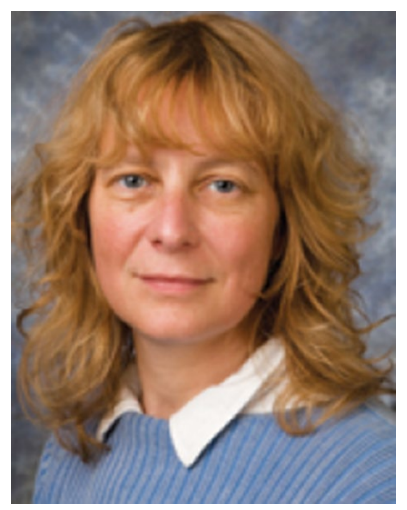

Christina Bock is a Senior Research Officer at the Energy, Mining and Environment Research Centre, of the National Research Council Canada in Ottawa. She is the leader of the Energy Storage Materials and Formulation Team and also the program technical leader of NRC's Energy Storage for Grid Security and Modernization Program. She has over 25 years of experience in electrochemistry and materials research for energy storage, energy conversion and the environment. 